\title{
Cognitive Effects of MDMA in Laboratory Animals: A Systematic Review Focusing on Dose
}

\author{
Madeline M. Pantoni and Stephan G. Anagnostaras \\ Molecular Cognition Laboratory, Department of Psychology (M.M.P., S.G.A.) and \\ Program in Neurosciences (S.G.A.), University of California San Diego, \\ La Jolla, California
}

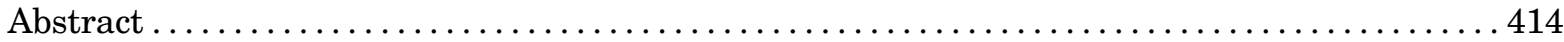

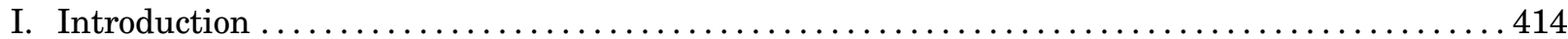

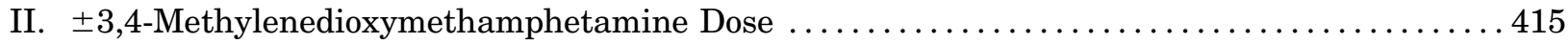

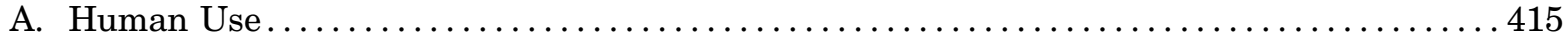

B. Animal to Human Scaling.......................................... 417

III. Neurotoxicity in Animals and Humans ...................................... 418

IV. Cognitive Effects in Humans . . . . . . . . . . . . . . . . . . . . . . . . . . . . . . . . . . . . . 419

V. Cognitive Effects in Animals_-Systematic Review .............................. 419

A. Attention ................................................... 420

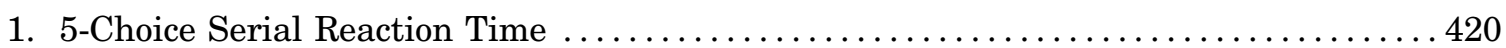

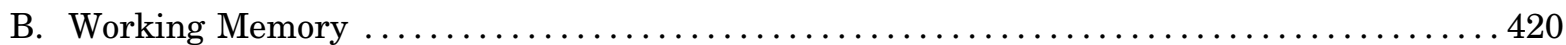

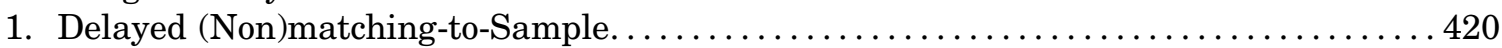

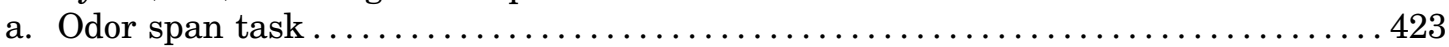

2. Spontaneous and Delayed Alternation ................................ 423

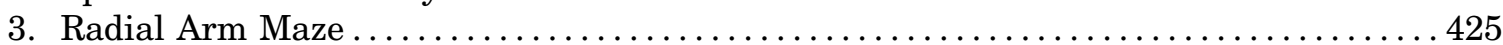

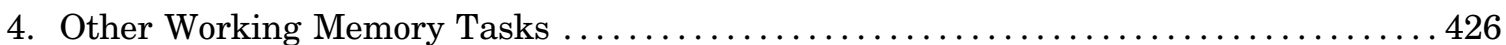

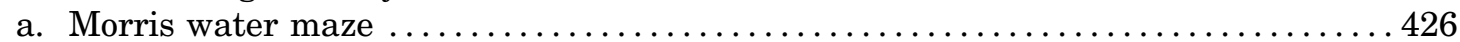

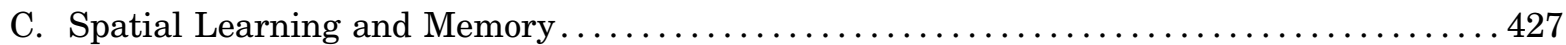

1. Morris Water Maze ........................................... 427

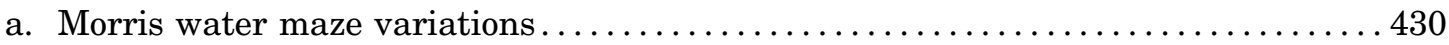

2. Radial Arm Maze ............................................... 431

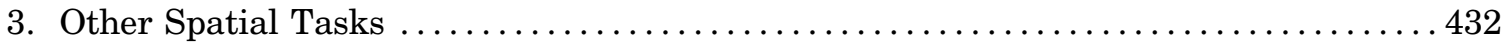

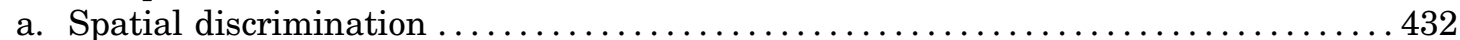

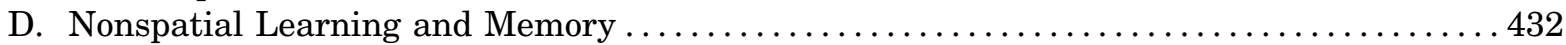

1. Novel Object Recognition........................................ 432

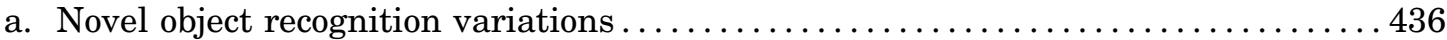

2. Other Nonspatial Tasks....................................... 437

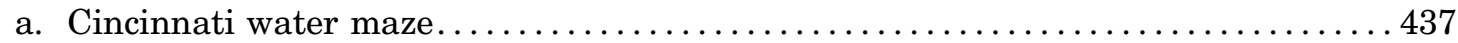

E. Fear-Motivated Learning and Memory............................... 437

1. Passive Avoidance ............................................. 437

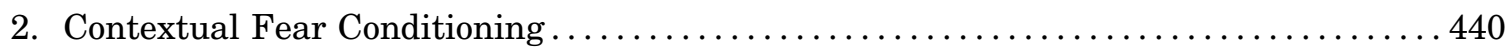

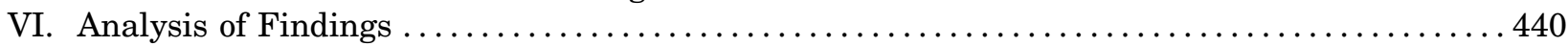

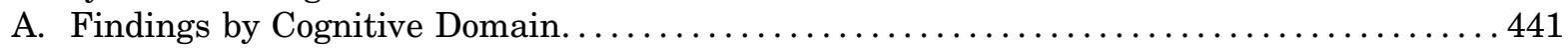

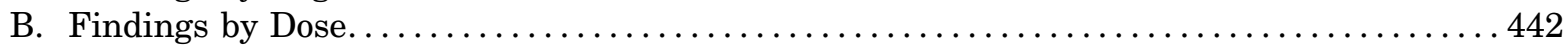

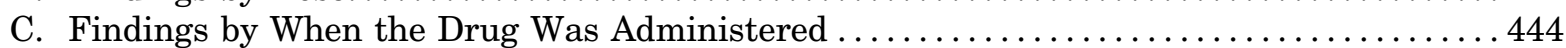

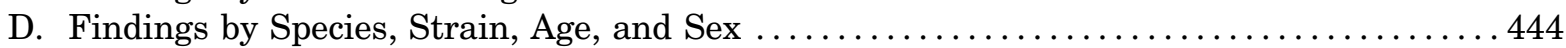

VII. High Doses and Neurotoxicology of Drugs of Abuse . . . . . . . . . . . . . . . . . . . . . . . . . . . . . . 445

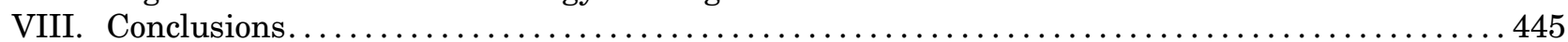

Address correspondence to: Madeline M. Pantoni, Department of Psychology, University of California San Diego, 9500 Gilman Drive MC 0109, La Jolla, CA 92093-0109. E-mail: maddie.pantoni@gmail.com

This work was supported in part by the National Institutes of Health National Institute on Drug Abuse [Grant DA020041 (to S.G.A.)]. https://doi.org/10.1124/pr.118.017087. 


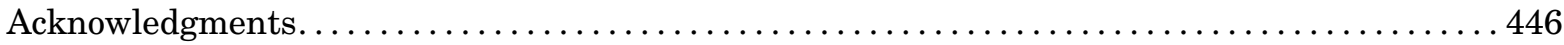

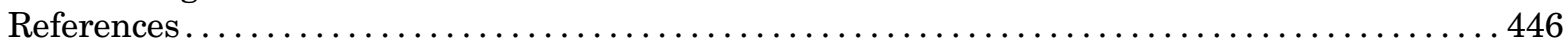

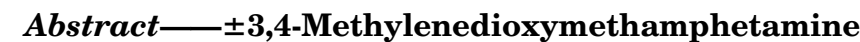
(MDMA) is a synthetic, psychoactive drug that is primarily used recreationally but also may have some therapeutic value. At low doses, MDMA produces feelings of relaxation, empathy, emotional closeness, and euphoria. Higher doses can produce unpleasant psychostimulantand hallucinogen-like adverse effects and therefore are usually not taken intentionally. There is considerable evidence that MDMA produces neurotoxicity and cognitive deficits at high doses; however, these findings may not generalize to typical recreational or therapeutic use of low-dose MDMA. Here, we systematically review 25 years of research on the cognitive effects of MDMA in animals, with a critical focus on dose. We found no evidence that doses of less than $3 \mathrm{mg} / \mathrm{kg}$ MDMA-the dose range that users typically take-produce cognitive

\section{Introduction}

"Solely the dose determines that a thing is not a poison." - Paracelsus

\pm 3,4-Methylenedioxymethamphetamine (MDMA, known as Ecstasy or Molly; Fig. 1) is a synthetic, psychoactive drug that is usually described as having mixed psychostimulant- and hallucinogen-like effects (i.e., effects like amphetamine and lysergic acid diethylamide) (Green et al., 2003). As with other phenethylamine and cathinone stimulant-psychedelics, MDMA primarily increases the neurotransmission of serotonin (5-HT) in the brain, specifically by reversing the 5-HT reuptake transporter (SERT) and causing the calcium-independent release of 5-HT (Rudnick and Wall, 1992; Wichems et al., 1995). MDMA also reverses the dopamine and norepinephrine transporters but to a lesser degree than SERT (Battaglia et al., 1988). These changes in brain chemistry produce desirable effects of relaxation, euphoria, arousal, and increased sociability as well as potential adverse effects such as nausea, headache, hallucinations, agitation, and palpitations. As dose is increased, MDMA produces more adverse effects and fewer desirable effects (Baylen and Rosenberg, 2006; Brunt et al., 2012), and therefore it is unlikely that MDMA is used intentionally at atypically high doses. As such, at the doses people typically take (i.e., 75-125 mg, see section II.A), MDMA primarily produces effects unlike classic psychostimulants or hallucinogens (Nichols, 1986). MDMA is usually described by its proponents as an "empathogen-entactogen"-a drug that increases empathy and closeness, both emotional and physical. It is these latter effects that are of significant therapeutic deficits in animals. Doses of $3 \mathrm{mg} / \mathrm{kg}$ or greater, which were administered most often and frequently ranged from 5 to 20 times greater than an average dose, also did not produce cognitive deficits in a slight majority of experiments. Overall, the preclinical evidence of MDMA-induced cognitive deficits is weak and, if anything, may be the result of unrealistically high dosing. While factors associated with recreational use such as polydrug use, adulterants, hyperthermia, and hyponatremia can increase the potential for neurotoxicity, the short-term, infrequent, therapeutic use of ultra low-dose MDMA is unlikely to pose significant cognitive risks. Future studies must examine any adverse cognitive effects of MDMA using clinically relevant doses to reliably assess its potential as a psychotherapeutic.

interest and are not shared with psychostimulants or hallucinogens. However, considerable evidence that MDMA is neurotoxic at high doses (see section III) has given considerable pause to this therapeutic interest.

Although MDMA is frequently described as the prototypical "designer drug," MDMA was synthesized and patented by Merck in 1912 as an unimportant precursor in a new chemical pathway (Freudenmann et al., 2006). The compound was shelved until Alexander Shulgin "rediscovered" MDMA in the 1970s. Shulgin produced the first reports on the psychoactive effects of MDMA and promoted its use as an adjunct to psychotherapy (Shulgin and Nichols, 1978). It was not until the early 1980s that MDMA began to be used recreationally, often at nightclubs, dance parties, and raves (Weir, 2000). The growing popularity of MDMA, in addition to new research findings on its adverse effects, led the U.S. Drug Enforcement Administration to classify MDMA as a Schedule I drug in 1985 for having "high abuse potential and no medical value" (Lawn, 1985, 1988; Shulgin, 1986). Despite its illegality, the recreational use of MDMA steadily increased through the 1990s with the rise of the underground rave scene (Schwartz and Miller, 1997) and plateaued in the early 2000s (Schulenberg et al., 2018). Any current increase in MDMA use may be related to the emergence of electronic dance music into mainstream culture (Fraser, 2012). Recently, scientific interest in the potential therapeutic value of MDMA has re-emerged as the result of findings that MDMA-assisted psychotherapy may be effective for treatment-resistant post-traumatic stress disorder (Bouso et al., 2008; Mithoefer et al., 2011, 2013, 2016; Oehen et al., 2013). 


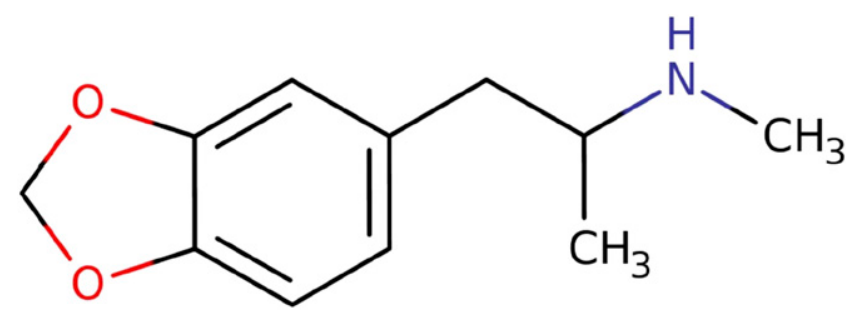

Fig. 1. Chemical structure of $\pm 3,4$-methylenedioxymethamphetamine (MDMA) (https://chem.nlm.nih.gov/chemidplus/name/mdma\%20hcl, Open Source).

The United States "Monitoring the Future" national survey indicates that the lifetime prevalence of MDMA use among young adults (19-28 years of age) has remained relatively stable since 2000 (about 13\%) and is significantly higher than in the 1990s (about 5\%) (Schulenberg et al., 2018). Most MDMA users consume the drug relatively infrequently and only for a few years in their early twenties (Green et al., 2003; Kuypers et al., 2016). The 2016 U.S. National Survey on Drug Use and Health revealed that about one-third of lifetime MDMA users aged 18-25 years had used the drug in the past year, while less than $8 \%$ of lifetime MDMA users aged 26 years and older had used the drug within the past year (Center for Behavioral Health Statistics and Quality, 2016). Despite the low exposure, the long-term effects of MDMA use in young adulthood are a significant concern and one that is especially relevant to the current young adult population.

As both recreational and therapeutic interest in MDMA has increased over the past 40 years, so have concerns regarding the possible harmful effects of MDMA. There is evidence from both human and animal research that MDMA produces neurotoxicity and cognitive deficits. This evidence, however, is controversial and may have resulted from experiments with methodology that fail to generalize to typical MDMA users. The validity of MDMA toxicological findings rests particularly with respect to self-reported drug use and other confounding variables in human studies, the doses administered in animal studies, and the ability to generalize findings from animals to humans. Dose is a determinant of toxicity for virtually any substance, as even water and oxygen produce adverse effects and can lead to death at high doses. The question of critical importance then is: do the doses typical users actually take actually produce cognitive deficits and/or neurotoxicity? This question becomes even more acute when one considers that therapeutic dosing may be even lower than recreational dosing, meaning that MDMA could have therapeutic value at doses far below those for which any evidence of toxicity exists.

Others have extensively reviewed findings on the cognitive and neurotoxic effects of MDMA in humans as well as the neurotoxic effects of MDMA in animals (e.g., Baumann et al., 2007; Zakzanis et al., 2007; Mueller et al., 2016). In this paper, we summarize these review articles and discuss some potential methodological issues. Our aim is to provide the first ever full systematic review of findings on the cognitive effects of MDMA in animals. We review these studies with a critical focus on dose.

\section{II. $\pm 3,4$-Methylenedioxymethamphetamine Dose}

\section{A. Human Use}

MDMA is almost exclusively administered as a racemic mixture, although there is evidence that its two enantiomers have different pharmacological and behavioral effects (Fantegrossi, 2008; Pitts et al., 2018). MDMA is commonly sold as a tablet (i.e., "Ecstasy"; Fig. 2) or as crystalline powder (loose or in a capsule, i.e., "Molly"; Fig. 3) and is usually ingested orally; however, crushed tablets or crystalline powder can also be taken sublingually, buccally, or intranasally (Eisner, 1989). Because pure MDMA cannot be made into a pressed tablet by itself, Ecstasy tablets contain other substances, including excipients such as cellulose and often other active agents such as stimulants or other MDMA-like substances. "Molly" is often perceived by the purchasers to be pure MDMA, but is also frequently contaminated with other cheaper or more accessible substances (Palamar, 2017). Based on EcstasyData.org, an independent laboratory testing service for street MDMA, only $43.7 \%$ of the 4063 samples tested between 1996 and 2017 contained only MDMA. The remaining samples contained either MDMA with additional substance(s) (18\%) or no MDMA (39\%) (Fig. 4). Therefore, only $62 \%$ of street MDMA truly contained any MDMA, and 57\% of street MDMA consisted partially or entirely of other substances (often a cocktail of substances). The most common substances mixed with or sold as MDMA included stimulants (55\%; e.g., caffeine, methamphetamine, trifluoromethylphenylpiperazine, benzylpiperazine, pseudoephedrine), MDMA-like substances

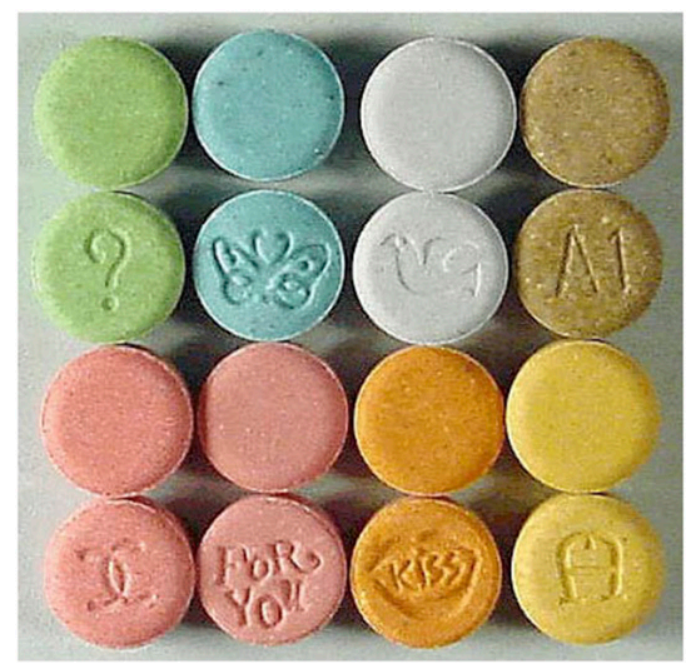

Fig. 2. MDMA in the form of "Ecstasy" tablets (http://www.usdoj.gov/dea/ programs/forensicsci/microgram/mg0103/mg0103.html, Open Source). 


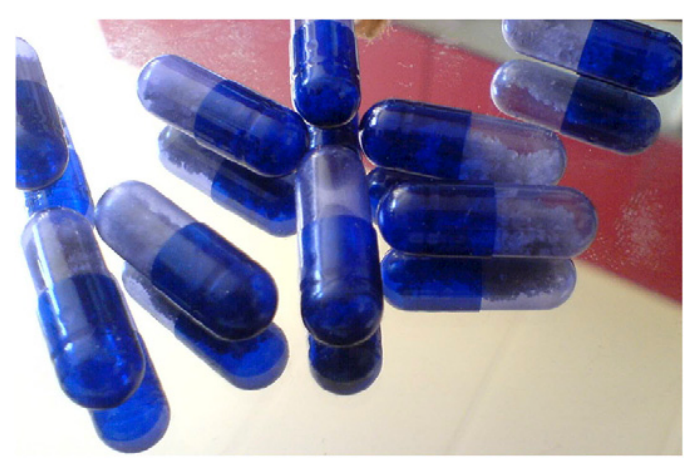

Fig. 3. MDMA crystalline powder in capsule form, commonly referred to as "Molly" (https://commons.wikimedia.org/w/index.php?curid=1884576, Open Source).

(20\%; e.g., methylenedioxyamphetamine, methylenedioxyethylamphetamine, methylone), and/or dissociatives (11\%; e.g., dextromethorphan, ketamine) (https:// www.ecstasydata.org/stats.php). ${ }^{1}$ It is important to note that the samples from EcstasyData.org are voluntarily submitted and are not a random sampling of available street MDMA. Nevertheless, given that the available data shows that more than half of street MDMA is adulterated and almost half of street MDMA does not contain any MDMA, MDMA users have most likely consumed these other psychoactive substance(s) in addition to and/or instead of MDMA.

MDMA users most commonly take doses of about $75-125 \mathrm{mg}$, or about 1 to $2 \mathrm{mg} / \mathrm{kg}$, while doses higher than $200 \mathrm{mg}$ are usually unintentional because they can produce unpleasant adverse effects, including hyperthermia and paranoia (https://erowid.org/chemicals/ mdma/mdma_dose.shtml; Hayner and McKinney, 1986; Green et al., 2003; Gouzoulis-Mayfrank and Daumann, 2006; Morgan, 2000; Ricaurte et al., 2000). Consistent with this, Brunt et al. (2012) revealed that doses of 81-100 mg MDMA are associated with the highest probability of experiencing desirable subjective effects, while doses greater than $160 \mathrm{mg}$ MDMA lead to more adverse than desirable effects. Analyses of street MDMA contents indicate that tablets usually contain doses in the range of those commonly used, yet there are some variations by batch and location. Older reports have suggested that MDMA tablets contain $70-120 \mathrm{mg}$ on average (Parrott, 2004). Several more recent large-scale analyses in various countries indicated that MDMA tablets contain average doses of about $66-87 \mathrm{mg}$ (close to $1 \mathrm{mg} / \mathrm{kg}$ ) (Giraudon and Bello, 2007; Vogels et al., 2009;

\footnotetext{
${ }^{1}$ The values for this analysis were obtained from the Test Result Statistics: Summary Data on EcstasyData.org (Display as: Numbers; By date: Tested; Uncheck: EcstasyData Only). We included the laboratory testing results for all samples sold as MDMA between 1996 and 2017, which is listed as the total number of samples containing 1) MDMA Only, 2) MDMA + Something, or 3) No MDMA. Most of the samples (about three-fourths) were submitted from the United States. This analysis was conducted on 05/04/2017 and therefore includes all laboratory testing results up to that date.
}

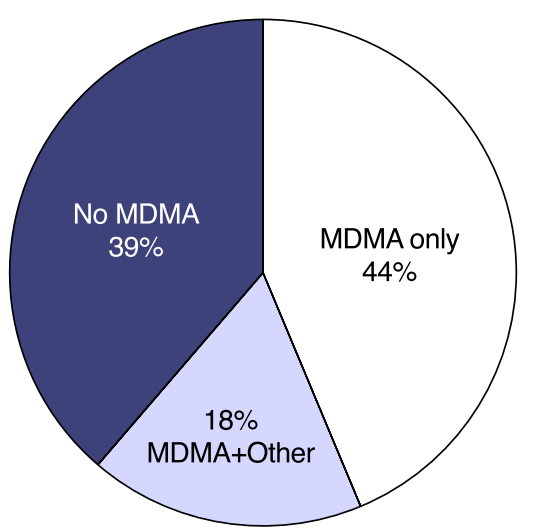

Street MDMA
(1996 to 2017)

Fig. 4. Contents of 4063 samples of street MDMA tested by EcstasyData.org and other organizations between 1996 and 2017. Samples sold as MDMA contained either MDMA only, MDMA in combination with other substances, or no MDMA at all. Less than half of street MDMA samples contained MDMA only and more than half of street MDMA samples consisted partially or entirely of other substances (original figure; data redrawn with permission from https://www.ecstasydata.org/stats.php).

Brunt et al., 2012; Vidal Giné et al., 2016). Data from the 2016 European Drug Report indicated that tablets typically contain between 68 and $95 \mathrm{mg}$ of MDMA (also close to $1 \mathrm{mg} / \mathrm{kg}$ ) (EMCDDA, 2016).

MDMA users usually take one to two tablets per occasion and generally use MDMA once per week or less because of rapid tolerance to its desirable effects (Topp et al., 1999; Morgan, 2000; Winstock et al., 2001; Riley et al., 2001; Scholey et al., 2004; Gouzoulis-Mayfrank and Daumann, 2006; Parrott et al., 2006; ter Bogt et al., 2006). Only about 9\%-17\% of MDMA users take an average of three or four tablets per occasion, and about $3 \%-10 \%$ of MDMA users take an average of more than four tablets per occasion (Scholey et al., 2004; Parrott et al., 2006; ter Bogt et al., 2006). Because each tablet is expected to have a dose of about $1 \mathrm{mg} / \mathrm{kg}$, a typical weekly dose of two tablets is about $2 \mathrm{mg} / \mathrm{kg}$, but heavier users may be taking weekly doses of $3 \mathrm{mg} / \mathrm{kg}$ or more. In our review, we focus on understanding typical recreational MDMA users rather than atypical heavy users.

The therapeutic doses of MDMA used in current clinical trials are comparable to typical recreational doses yet are administered on only a few separate occasions. In the two completed phase 2 clinical trials testing MDMA-assisted psychotherapy for treatmentresistant post-traumatic stress disorder, patients were treated with a dose of $125 \mathrm{mg}$ MDMA, plus a $62.5 \mathrm{mg}$ supplemental dose in some cases, on two or three occasions (Mithoefer et al., 2011; Oehen et al., 2013). MDMA may potentially have therapeutic value at even lower doses, and we encourage investigators to explore those doses.

In summary, relatively low doses $(<3 \mathrm{mg} / \mathrm{kg})$ are used both therapeutically and recreationally. However, it is critical to differentiate between the therapeutic use of 
pure MDMA in controlled medical settings and the recreational use of potentially impure MDMA in potentially high-risk settings. Our systematic review of preclinical MDMA research speaks to the use of pure MDMA in therapeutic settings or low-risk recreational settings.

\section{B. Animal to Human Scaling}

There has been significant controversy regarding whether the doses of MDMA administered to animals in preclinical studies accurately reflect those taken by human users. Given the average human weight of $70 \mathrm{~kg}$, a typical MDMA dose of 75-125 mg is equivalent to about 1 to $2 \mathrm{mg} / \mathrm{kg}$ MDMA. Despite this, the majority of animal studies administer doses ranging from 10 to $20 \mathrm{mg} / \mathrm{kg}$, which is equivalent to $700-1400 \mathrm{mg}$ in a $70-\mathrm{kg}$ human and is about 5-20 times larger than a typical MDMA dose.

Early MDMA researchers argued that the method of "interspecies scaling" (Mordenti and Chappell, 1989) should be used to translate MDMA doses across species (Ricaurte et al., 2000; McCann and Ricaurte, 2001). This method proposes that smaller animals require much larger doses than humans, using the equation $\mathrm{D}_{\text {human }}=$ $\mathrm{D}_{\text {animal }} \times\left(\mathrm{W}_{\text {human }} / \mathrm{W}_{\text {animal }}\right)^{0.7}$, where $\mathrm{D}$ is drug dose in milligrams, $\mathrm{W}$ is body weight in kilograms, and 0.7 is the "allometric constant" that accounts for differences in drug elimination. As a result, a dose of $98 \mathrm{mg}$ in a $70 \mathrm{~kg}$ human $(1.4 \mathrm{mg} / \mathrm{kg})$ was equated to $7 \mathrm{mg} / \mathrm{kg}$ in rats and $5 \mathrm{mg} / \mathrm{kg}$ in monkeys. Most the studies reviewed here argued that doses of $10-20 \mathrm{mg} / \mathrm{kg}$ in rodents are suitable for modeling recreational use of MDMA, as they translate to a human dose of 140-280 mg under "allometric scaling." Allometric scaling results in animal doses that are exceedingly higher than those determined by a simple conversion of dose based on body weight, and the approach is not without controversy.

We have typically argued that one-to-one dosing should be used, unless further specific knowledge (for example, metabolic or actual exposure data) justifies some specific kind of alternative scaling (Shuman et al., 2009; Wood et al., 2014; Carmack et al., 2014). Furthermore, although doses vary somewhat in veterinary medicine, across a wide variety of indications, most drugs are given roughly on the same scale as human doses converted on a straight milligrams per kilogram basis. For example, fluoxetine dosing in dogs and cats is 1 to $2 \mathrm{mg} / \mathrm{kg}$ (https:// www.reconcile.com/pdfs/prescribing-information.pdf), which is quite similar to human dosing (http://pi.lilly.com/ us/prozac.pdf).

More recently, several researchers have argued that allometric scaling is not a valid approach for MDMA research. Specifically, this method does not take principles of pharmacokinetics/pharmacodynamics into account. Green et al. (2009, 2012a) explain that factors such as bioavailability, active metabolites, plasma protein binding differences, and patterns of systematic exposure are critical influences on drug effects, and these factors can vary markedly between species and methods. Humans almost always ingest MDMA orally, whereas animals are administered MDMA intraperitoneally or subcutaneously, which may lead to significant differences in bioavailability and/or metabolism (Green et al., 2009, 2012a). In humans, there is a nonlinear relationship between dose and plasma concentration such that a twofold increase in dose (from 1 to $2 \mathrm{mg} / \mathrm{kg}$ ) results in a fourfold increase in plasma concentration, while the relationship between dose and plasma concentration in rats is approximately linear. As a result, the dose-plasma concentration curves of humans and rats are comparable at doses below $2.5 \mathrm{mg} / \mathrm{kg}$ but differ drastically at higher doses (Green et al., 2009, 2012a). Specifically, $C_{\max }$ (peak plasma concentration) of $1.6 \mathrm{mg} / \mathrm{kg}$ MDMA (orally) in humans and $2 \mathrm{mg} / \mathrm{kg}$ MDMA (intraperitoneally and subcutaneously) in rats is similar [humans (oral): $292 \pm 76 \mathrm{ng} / \mathrm{ml}$, rats (intraperitoneal): $210 \pm 108 \mathrm{ng} / \mathrm{ml}$, rats (subcutaneous): $196 \pm 50 \mathrm{ng} / \mathrm{ml}$ ). Time of drug peak, however, is much shorter in rats [0.14 \pm 0.08 hours (intraperitoneal), $0.75 \pm 0.29$ hours (subcutaneous)] than in humans [2.4 \pm 0.6 hours (oral)] (Kolbrich et al., 2008; Baumann et al., 2009). Thus, testing rats 10-45 minutes after parenteral doses of about $2 \mathrm{mg} / \mathrm{kg}$ is roughly equivalent to peak exposure in humans 2.4 hours after taking about one and a half oral tablets. The differences in time course are because MDMA is absorbed and metabolized much faster in rats than in humans and the proportion of metabolites formed differs strikingly between species (Green et al., $2009,2012 a)$. This is a major concern because the active metabolites of MDMA, rather than MDMA itself, appear to be responsible for long-term neurotoxicity. For instance, methylenedioxyamphetamine, an active and neurotoxic metabolite of MDMA, accounts for 23\%-34\% of MDMA metabolism in rats but only about $10 \%$ in humans (Green et al., 2012a). Nonetheless, MDMA is extensively metabolized in both animals and humans, a condition under which the allometric relationship does not hold true (Lin, 1998; Baumann et al., 2007).

For the reasons above, as well as others extensively discussed by Baumann et al. (2007) and Green et al. (2009, 2012a), allometric scaling in MDMA research is arguably flawed, and findings under this method should be interpreted with caution for using excessive dosing. Baumann et al. (2007) proposes the alternative method of "effect scaling" for extrapolating doses between species. Under this method, animal doses are determined based on the lowest dose of drug that produces a specific pharmacological response in animals and humans. Doses of about 1 to $2 \mathrm{mg} / \mathrm{kg}$ MDMA produce equivalent pharmacology effects in humans (orally) and rats (intraperitoneally, subcutaneously, or intravenously), including the in vivo release of serotonin and dopamine [humans (oral): $1.5 \mathrm{mg} / \mathrm{kg}$, rats (intraperitoneal): $2.5 \mathrm{mg} / \mathrm{kg}$, rats (subcutaneous): $1 \mathrm{mg} / \mathrm{kg}$, secretion of prolactin and 
glucocorticoids [humans (oral): 1.5 or $1.67 \mathrm{mg} / \mathrm{kg}$, rats (intraperitoneal): $1-3 \mathrm{mg} / \mathrm{kg}$ ], drug discrimination [humans (oral): $1.5 \mathrm{mg} / \mathrm{kg}$, rats (intraperitoneal): $1.5 \mathrm{mg} / \mathrm{kg}$ ], and drug reinforcement [humans (oral): 1 to $2 \mathrm{mg} / \mathrm{kg}$, rats (intravenous): $1 \mathrm{mg} / \mathrm{kg}$ ) (Baumann et al., 2007). Unlike Green et al.'s findings, Baumann et al. (2009) found that the pharmacokinetics of MDMA are not only nonlinear in monkeys and humans but also in rats. Regardless of this discrepancy, it is agreed that the pharmacokinetics of doses of about 1 to $2 \mathrm{mg} / \mathrm{kg}$ MDMA are similar across species. Because the pharmacologically relevant doses of MDMA are similar across species, there is not adequate scientific justification for using interspecies scaling to "adjust" MDMA doses (Baumann et al., 2007, 2009). This is especially true when considering toxicology, because most of the "adjustments" have been radical increases in dose, which tend to suggest a drug is more toxic than it actually is. Indeed, one might think this could impose a bias in "finding" toxic effects in drugs of abuse, in general.

Given that doses of about 1 to $2 \mathrm{mg} / \mathrm{kg}$ MDMA produce similar pharmacokinetic, pharmacological, and psychoactive effects across species and are analogous to the doses taken by human MDMA users, these low doses should be used in preclinical MDMA research in the absence of explicitly justified interspecies scaling. While low doses are unlikely to produce neurotoxicity, they may still have adverse cognitive effects (Green et al., 2012a,b). A central aim of this review is to determine if MDMA influences cognitive functioning at these doses.

\section{Neurotoxicity in Animals and Humans}

The long-term neurotoxic effects of MDMA have been studied extensively in animals and humans. Ricaurte et al. (2000), Green et al. (2003), and Lyles and Cadet (2003) were among the first to review the many findings on MDMA-induced neurotoxicity in animals. Research in rats and non-human primates demonstrated that MDMA produces significant reductions in biochemical markers of serotonergic activity that last for months to years. The most prominent reductions include decreased levels of 5-HT and 5-hydroxyindoleacetic acid (the major metabolite of 5-HT), decreased numbers of SERT, and decreased activity of tryptophan hydroxylase (the ratelimiting enzyme in 5-HT synthesis). Additional studies found through histologic methods (e.g., silver staining) that MDMA produces degeneration of 5-HT axons and terminals. These findings suggest that the long-lasting and selective serotonergic biomarker reductions produced by MDMA may reflect neurodegeneration. However, as with amphetamine neurotoxicity, there is no evidence of actual cell death.

These early studies used MDMA doses that are exceedingly large and not representative of those taken by typical users (as was done in early amphetamine neurotoxicity studies). Most rat strains (e.g., Lister Hooded, Sprague-Dawley, and Wistar) typically require several
MDMA doses of $20 \mathrm{mg} / \mathrm{kg}$ or more to exhibit serotonergic deficits (Colado et al., 1993; Aguirre et al., 1998; Shankaran and Gudelsky, 1999; Green et al., 2003). Non-human primates show higher sensitivity to MDMA-induced serotonergic deficits, as doses of about $5 \mathrm{mg} / \mathrm{kg}$ will produce deficits that are more severe than those observed in rats (Ricaurte et al., 1988; Ricaurte and McCann, 1992; Green et al., 2003). Mice are far less sensitive than rats to MDMA-induced serotonergic deficits, as doses of up to $50 \mathrm{mg} / \mathrm{kg}$ produce only slight deficits (Stone et al., 1987; Logan et al., 1988; Green et al., 2003). Although there are differences between species/strains, MDMAinduced deficits in markers of serotonergic neurons require fairly high and often sustained dosing (Green et al., 2003).

In a more recent review, Baumann et al. (2007) analyzed findings on MDMA-induced neurotoxicity in rats with respect to dose. Several studies have demonstrated that behaviorally relevant doses of MDMA (i.e., 1 to $2 \mathrm{mg} / \mathrm{kg}$; see section II.B) do not produce reductions in biochemical markers of 5-HT neurons. The doses of MDMA that do produce serotonergic deficits (i.e., 10$20 \mathrm{mg} / \mathrm{kg}$ ) are five or more times greater than behaviorally relevant doses of MDMA. Even so, these high doses are not reliably associated with 5-HT neuron degeneration. Rather, even more extreme doses of MDMA were used in the histology studies that found neurotoxic damage. For instance, massive cumulative doses of 100$600 \mathrm{mg} / \mathrm{kg}$ (i.e., up to $42,000 \mathrm{mg}$ or $600 \mathrm{MDMA}$ tablets in humans) were given to rats that exhibited increased silver-positive staining in degenerating 5 -HT neurons. Thus, MDMA-induced reductions in biochemical markers of 5-HT neurons do not necessarily reflect neurotoxic damage (see Baumann et al. for additional supporting evidence). There is insufficient evidence that the MDMA doses typically used by humans result in serotonergic neurotoxicity in animal models.

Nevertheless, evidence of possible MDMA-induced neurotoxicity in animals has raised concern for neurotoxicity in human MDMA users. Reneman et al. (2006) and Cowan (2007) provided reviews on some of the latest neuroimaging studies in human MDMA users. While there has been much debate regarding the methods used in early human studies on MDMA-induced neurotoxicity, modern neuroimaging techniques such as positron and single photon emission tomography provide updated findings on the effects of MDMA in the human brain. The most consistent finding is that MDMA users exhibit a reduction in SERT density that appears to be associated with the degree of MDMA exposure, while findings on other serotonergic deficits are largely inconsistent. It remains unclear whether the SERT reductions in MDMA users are a direct reflection of serotonergic neurodegeneration.

A concern regarding the above findings is that most studies investigated samples of heavy MDMA users, with a mean lifetime consumption ranging from 
173 to 880 MDMA tablets. Only about $13 \%-18 \%$ of MDMA users report having taken MDMA on more than 100 occasions (Scholey et al., 2004; Parrott et al., 2006), and while this research may be indicative of neurotoxicity in these heavy users, it is not indicative of the effects of MDMA in the typical user and is highly unlikely to reflect patients treated therapeutically only a few times with MDMA. Mueller et al. (2016) addressed this issue with a systematic review of neuroimaging studies in moderate MDMA users (those with lifetime use of $<50$ occasions or $<100$ tablets). The 19 studies that met inclusion criteria provided little, if any, evidence for brain alterations in moderate MDMA users.

The animal and human data together suggest that heavy use of MDMA may produce neurotoxicity, but typical (i.e., low to moderate) MDMA use may have no effect on brain structure and function. Human MDMA research, however, may have issues with experimental design, confounding variables, and methodological techniques (explained further in section IV and by GouzoulisMayfrank and Daumann, 2006). In this review, we explore the functional consequences of MDMA use, specifically the effects on cognition, as potential indicators of MDMA-induced neurotoxicity.

\section{Cognitive Effects in Humans}

Numerous review articles have evaluated findings on cognitive functioning in MDMA users. Recent metaanalyses and systematic reviews suggest that MDMA users, when compared with drug-naïve or polydrug controls, are impaired in several cognitive domains including decision-making (Betzler et al., 2017), attention (Verbaten, 2003; Zakzanis et al., 2007), executive functioning (Zakzanis et al., 2007; Murphy et al., 2009; Roberts et al., 2016), verbal and visuospatial working memory, short-term memory, and long-term memory (Verbaten, 2003; Laws and Kokkalis, 2007; Zakzanis et al., 2007; Murphy et al., 2009, 2012; Nulsen et al., 2010). Others, however, have found that MDMA users and controls show no differences in executive switching (Murphy et al., 2009), executive inhibition (Roberts et al., 2016), visual short- and long- term memory (Laws and Kokkalis, 2007), and verbal long-term memory (Kuypers et al., 2016). Like the neurotoxicity studies, many of these reviews include data from heavy MDMA users only (Verbaten, 2003; Laws and Kokkalis, 2007; Nulsen et al., 2010; Roberts et al., 2016). Some deficits have been attributed to polydrug/cannabis use rather than MDMA use specifically, such as those in decision-making, visual short-term memory, and verbal long-term memory (Verbaten, 2003; Nulsen et al., 2010; Betzler et al., 2017), although there is some evidence of the contrary regarding verbal memory (Laws and Kokkalis, 2007). Overall, the most consistent findings are that heavy MDMA users exhibit long-term deficits in attention, executive updating, verbal and visuospatial working memory, and verbal short-term memory; findings regarding other cognitive domains are fairly inconsistent.

Research on the cognitive effects of MDMA in humans face a multitude of potential methodological issues. Dose-related, double-blind, placebo-controlled paradigms are the strongest in human psychopharmacology research, but there is a lack of such prospective studies in MDMA research due to the ethical and legal barriers of administering MDMA to human volunteers (Verbaten, 2003). As a result, retrospective cross-sectional designs dominate in this field, in which a group of selfreported MDMA users are compared with a control group. In contrast to prospective designs, retrospective designs decrease the ability to control potential confounds. A potential confounding variable in the studies reviewed above is that MDMA users are typically polydrug users, either knowingly or due to the impurity of street MDMA. While some studies controlled for selfreported polydrug use, the contents of impure street MDMA is typically unbeknownst to all and therefore cannot be controlled for. Self-reported drug use also introduces uncertainty in drug use patterns, including doses, number of exposures, and duration of abstinence. Another potential issue with retrospective designs is that the observed effects could be due to pre-existing differences, such as intelligence, cognitive, psychologic, neurochemical, genetic, or personality differences in the selected control group. It is conceivable that individuals with cognitive deficits may be more likely to use MDMA, and therefore the cognitive deficits observed in MDMA users could have been a cause of MDMA use rather than a consequence, although the direction of causality has been sparsely explored and is still a matter of debate (Curran, 2000; Roberts et al., 2016; Betzler et al., 2017).

To summarize, there has been consistent evidence of some cognitive deficits in heavy MDMA users (specifically in attention, executive updating, working memory, and verbal short-term memory), but we cannot be certain that these deficits are exclusively due to MDMA use rather than the use of other drugs, pre-existing conditions, and/or other confounding variables (Curran, 2000; also discussed further in the reviews/meta-analyses cited above). It is likely that MDMA poses considerable risk at high doses, as does high-dose amphetamine. However, as with amphetamine, low-dose MDMA may have great clinical potential and should not be barred based on unfounded concerns about behavioral or neural toxicity.

\section{Cognitive Effects in Animals- Systematic Review}

Because of the methodological issues in human MDMA research, animal models may be ideal for studying the cognitive effects of MDMA, specifically with respect to the therapeutic use of pure MDMA. Here we provide the first systematic review of findings on the cognitive effects 
of MDMA in animal models. A total of 90 experiments (from 68 articles) provide such findings using a variety of tasks. We divided research findings by task into five major cognitive domains: 1) attention, 2) working memory, 3) spatial learning and memory, 4) nonspatial learning and memory, and 5) fear-motivated learning and memory. Findings on both the on-drug (acute) and post-drug (long-lasting) effects of MDMA are included. In some cases, on-drug impairments are associated with task performance impairments (e.g., impaired movement or altered state while intoxicated) rather than actual cognitive impairment. All findings are reviewed with respect to methodology, with a specific emphasis on the doses of MDMA administered. Again, we stress that most of these studies used doses that are exceedingly higher than low, behaviorally relevant doses of 1 to $2 \mathrm{mg} / \mathrm{kg}$ MDMA. The ability to generalize high-dose ( $\geq 3 \mathrm{mg} / \mathrm{kg}$ MDMA) findings to typical MDMA use, and specifically therapeutic use, is limited.

\section{A. Attention}

1. 5-Choice Serial Reaction Time. The 5-choice serial reaction time (5-CSRT) task (Robbins, 2002) is commonly used to assess attention and impulsivity in non-human primates. As to the studies reviewed here, the task is conducted in an operant chamber that contains a monitor and a single response lever. On each trial, five circles connected by lines are presented on the monitor, and the trial begins when the animal presses and holds down the response lever. After a variable delay period of $0.75-2.5$ seconds, a yellow circle is quickly presented on one of the five circles for 20,100 , or 1000 milliseconds. The animal must touch the circle that contained the yellow circle within 2 seconds for reinforcer delivery. The release latency (time to release the lever) and movement time (time to move from lever to target) are used to measure attentional performance, with longer release latencies/movement times representing poorer attention.

Taffe et al. (2001, 2002) investigated the effects of MDMA on the 5-CSRT task, and these studies are listed in Table 1. Taffe et al. (2001) trained adult male rhesus monkeys on the task for 4 weeks prior to drug treatment. Monkeys were then given two daily injections of $10 \mathrm{mg} / \mathrm{kg}$ i.m. MDMA at a 12 -hour interval for 4 consecutive days. Testing continued during the treatment week (3-5 hours after the first injection of each day, so testing occurred after the peak drug effect) and also for the following 21 weeks. During all three testing periods (pretreatment weeks, treatment week, and posttreatment weeks), MDMA-treated monkeys and saline controls did not significantly differ in release latency or movement time. However, the release latency of MDMA-treated monkeys was significantly longer during the treatment week than during the pretreatment weeks. Taffe et al. (2002) tested the same group of rhesus monkeys 13 months later, and again MDMAtreated monkeys and saline controls did not significantly differ in release latency or movement time. Together, these findings indicate that treatment with repeated doses of $10 \mathrm{mg} / \mathrm{kg}$ MDMA may produce slight attentional deficits during the treatment period but have no residual effects on attention for more than 1 year later.

\section{B. Working Memory}

1. Delayed (Non)matching-to-Sample. The delayed matching-to-sample (DMS) and delayed nonmatchingto-sample (DNMS) tasks (see Dudchenko, 2004) are widely used to study working memory in many species, including rodents, birds, and non-human primates. These tasks assess recognition memory for a visual stimulus and can be conducted using stimuli such as retractable levers, color illuminated keys, or visual stimuli displayed on a press-plate or touchscreen. Each trial has three main phases: sample presentation, delay, and choice. During the sample presentation, a single visual stimulus is presented to the animal (i.e., right or left lever, red or green key, a geometric shape on the press-plate or touchscreen). After the animal makes an observing response (i.e., a press or nose-poke) to the sample stimulus, the stimulus is removed for a delay period of a specified duration. The delay period is followed by the choice phase, when two or three visual stimuli are presented to the animal, only one of which is identical to the sample stimulus. The animal must respond (i.e., a press or nosepoke) to the sample stimulus in the DMS task or the novel stimulus in the DNMS task for accuracy, food reinforcer delivery, and initiation of the next trial.

Sessions are typically conducted daily, and a range of delay periods are tested, with each animal performing multiple trials at each delay duration. Accuracy is

TABLE 1

Studies examining the effects of MDMA on attention

\begin{tabular}{|c|c|c|c|c|c|}
\hline Article & $\operatorname{Task}^{a}$ & Subjects $^{b}$ & Doses/Frequency $^{c}$ & Timeline $^{d}$ & Effects $^{e}$ \\
\hline Taffe et al., 2001 & 5-CSRT & Monkeys (R), Adult, Male & $10 \mathrm{mg} / \mathrm{kg}$ (i.m.) × 2/day, 4 days & $\begin{array}{l}\text { Training: Predrug } \\
\text { Testing: On-Drug, Postdrug }\end{array}$ & $\downarrow$ (On-Drug), $\varnothing$ (Postdrug) \\
\hline Taffe et al., 2002 & 5-CSRT & Monkeys (R), Adult, Male & $10 \mathrm{mg} / \mathrm{kg}$ (i.m.) × 2/day, 4 days & $\begin{array}{l}\text { Training: Predrug } \\
\text { Testing: Postdrug }\end{array}$ & $\varnothing$ \\
\hline
\end{tabular}

${ }^{a}$ Studies used the 5-choice serial reaction time (5-CSRT) task.

${ }^{b}$ Species (strain), age, and sex of subjects. Strains include rhesus (R) monkeys.

"Dose, route, and frequency of MDMA administration. Treatment days/weeks are consecutive unless noted as "spaced."

${ }^{d}$ When training and testing occurred in relation to drug treatment. Pre- and post-drug training/testing were always conducted off-drug.

${ }^{e}$ Effects of drug treatment on attention: $\oslash$ No Effect, $\downarrow$ Impairment, $\uparrow$ Enhancement. 
determined at each delay by average percent correct (i.e., percent of trials that a correct response was made). Under normal working memory function, accuracy will decrease as the duration of the delay period increases. A working memory deficit is usually indicated by normal accuracy under no delay or ultra-short delays but a significant decrease in accuracy relative to normal at longer delays. A significant decrease in accuracy relative to normal across all delays [i.e., no/ultra-short delay(s) and long delays] does not represent impaired working memory, but rather a performance impairment.

Table 2 includes the seven studies that tested the effects of MDMA on the DMS (5 studies) and DNMS (2 studies) tasks. All of these studies trained animals on the task to a criterion level before beginning on-drug testing, and some of the studies continued testing after the on-drug trials.

Harper et al. (2005) and Harper (2011) trained and tested adult male Sprague-Dawley rats on a DMS task using retractable levers and delays of $0.1,3,9$, and 18 seconds. Harper et al. (2005) gave rats $0,0.3,1,2$, or $3 \mathrm{mg} / \mathrm{kg}$ i.p. MDMA in a within-subjects design 10 minutes before on-drug test sessions. Relative to saline, doses of 0.3 and $1 \mathrm{mg} / \mathrm{kg}$ MDMA had no effect on accuracy, and doses of 2 and $3 \mathrm{mg} / \mathrm{kg}$ MDMA significantly decreased accuracy across all delays. Harper (2011) gave rats 0 or $3 \mathrm{mg} / \mathrm{kg}$ i.p. MDMA in a within-subjects design 5 min before on-drug test sessions. A dose of $3 \mathrm{mg} / \mathrm{kg}$ MDMA significantly decreased accuracy across all delays relative to saline. Together, these results indicate that while doses of 2 and $3 \mathrm{mg} / \mathrm{kg}$ MDMA impair performance on the task, doses of $0.3,1,2$, and $3 \mathrm{mg} / \mathrm{kg}$ MDMA have no effect on working memory.

Frederick et al. (1995a) trained and tested adult male rhesus monkeys on a DMS task using a press-plate apparatus and delays of $2,4,8,16,32$, and 48 seconds. Monkeys were given $0,0.1,0.3$, or $1 \mathrm{mg} / \mathrm{kg}$ i.m. MDMA in a within-subjects design 30 minutes before on-drug test sessions. MDMA had no effect on overall accuracy relative to saline at any of the doses tested. In continuation of this study, Frederick et al. (1995b) tested the same rhesus monkeys on the same task under different MDMA treatments. Monkeys were given two daily injections of i.m. MDMA at an 8-hour interval for 14 consecutive days. The dose of MDMA was increased every 2 weeks, such that doses of $0,0.1,0.3,1,3,5.6,10$, and $20 \mathrm{mg} / \mathrm{kg}$ MDMA were each given for 14 consecutive days in sequential order. On-drug testing took place 30 minutes after the first injection of each day, and MDMA had no effect on overall accuracy relative to saline at any dose. Five months later, monkeys were given $0,0.3,1,1.75,3$, or $5.6 \mathrm{mg} / \mathrm{kg}$ i.m. MDMA in a within-subjects design $30 \mathrm{~min}$ before daily on-drug test sessions. Doses of $0.3,1,1.75$, and $3 \mathrm{mg} / \mathrm{kg}$ MDMA had no effect on overall accuracy relative to saline, and the effect of $5.6 \mathrm{mg} / \mathrm{kg}$ MDMA could not be determined due to performance failure. In all, these studies indicate that doses of $0.1,0.3,1,1.75,3,5.6,10$, and $20 \mathrm{mg} / \mathrm{kg}$ MDMA may have no effect on working memory.

LeSage et al. (1993) trained and tested adult White Carneau pigeons on a DMS task using color illuminated keys and delays of 0,3 , and 6 seconds. Pigeons were given $0,0.32,1,1.7,3.2,4.2$, or $5.6 \mathrm{mg} / \mathrm{kg}$ i.m. MDMA in a within-subjects design 10 minutes before on-drug test sessions. Relative to saline, doses of $0.32,1$, and $1.7 \mathrm{mg} / \mathrm{kg}$ MDMA had no effect on accuracy across all delays, doses of 3.2 and $4.2 \mathrm{mg} / \mathrm{kg}$ MDMA significantly decreased accuracy across all delays, and a dose of $5.6 \mathrm{mg} / \mathrm{kg}$ MDMA completely suppressed responding. Ten days later, pigeons were given i.m. MDMA at doses of $0 \mathrm{mg} / \mathrm{kg}$ for 2 days (baseline), followed by $3.2 \mathrm{mg} / \mathrm{kg}$ for 20 days, $4.2 \mathrm{mg} / \mathrm{kg}$ for 1 day (challenge dose), $3.2 \mathrm{mg} / \mathrm{kg}$ for 5 days, and $5.6 \mathrm{mg} / \mathrm{kg}$ for 1 day (challenge dose) (all consecutive days). The final dose of $3.2 \mathrm{mg} / \mathrm{kg}$ MDMA and the challenge doses of 4.2 and $5.6 \mathrm{mg} / \mathrm{kg}$ MDMA had no effect on accuracy relative to saline (baseline) across all delays. These findings suggest that doses of 3.2, 4.2, and $5.6 \mathrm{mg} / \mathrm{kg}$ MDMA initially impair performance on the DMS task but these impairments diminish after treatment with repeated doses of MDMA. Nevertheless, doses of $0.32,1,1.7,3.2,4.2$, and $5.6 \mathrm{mg} / \mathrm{kg}$ MDMA appear to have no effect on working memory.

Taffe et al. (2001) trained adult male rhesus monkeys on a DNMS task using touchscreen stimuli. Monkeys were first tested under delays of $0,16,32$, and 64 seconds for 4 weeks. The following week, monkeys were given two daily injections of $10 \mathrm{mg} / \mathrm{kg}$ i.m. MDMA at a 12 -hour interval for 4 consecutive days. Testing continued during the MDMA treatment week (3-5 hours after the first injection of each day, so testing occurred after the peak drug effect) and for the 21 weeks following treatment. During all three testing periods (pretreatment weeks, treatment week, and posttreatment weeks), MDMA-treated monkeys and saline controls did not significantly differ in accuracy across all four delays. The accuracy of MDMA-treated monkeys was significantly reduced during the treatment week compared with the pretreatment weeks at delays of 0 and 64 seconds, but this effect can be attributed to performance deficits rather than working memory deficits as the reductions were seen at both no delay and a long delay. In all, these findings indicate that treatment with repeated doses of $10 \mathrm{mg} / \mathrm{kg}$ MDMA may have no effect on working memory during treatment and for at least 5 months later.

Marston et al. (1999) trained and tested adult male Lister Hooded rats on a DNMS task using retractable levers and delays of $0.3,1,3,5.6,10,17.6$, and 30 seconds. Rats were given two daily injections of i.p. MDMA at a 10-hour interval for 3 consecutive days at doses of $10 \mathrm{mg} / \mathrm{kg}$ MDMA on day $1,15 \mathrm{mg} / \mathrm{kg}$ MDMA on day 2 , and $20 \mathrm{mg} / \mathrm{kg}$ MDMA on day 3 . Testing continued during MDMA treatment (45-130 min after the first injection of each day) and for the 3-16 days following treatment. MDMA suppressed responding during the 


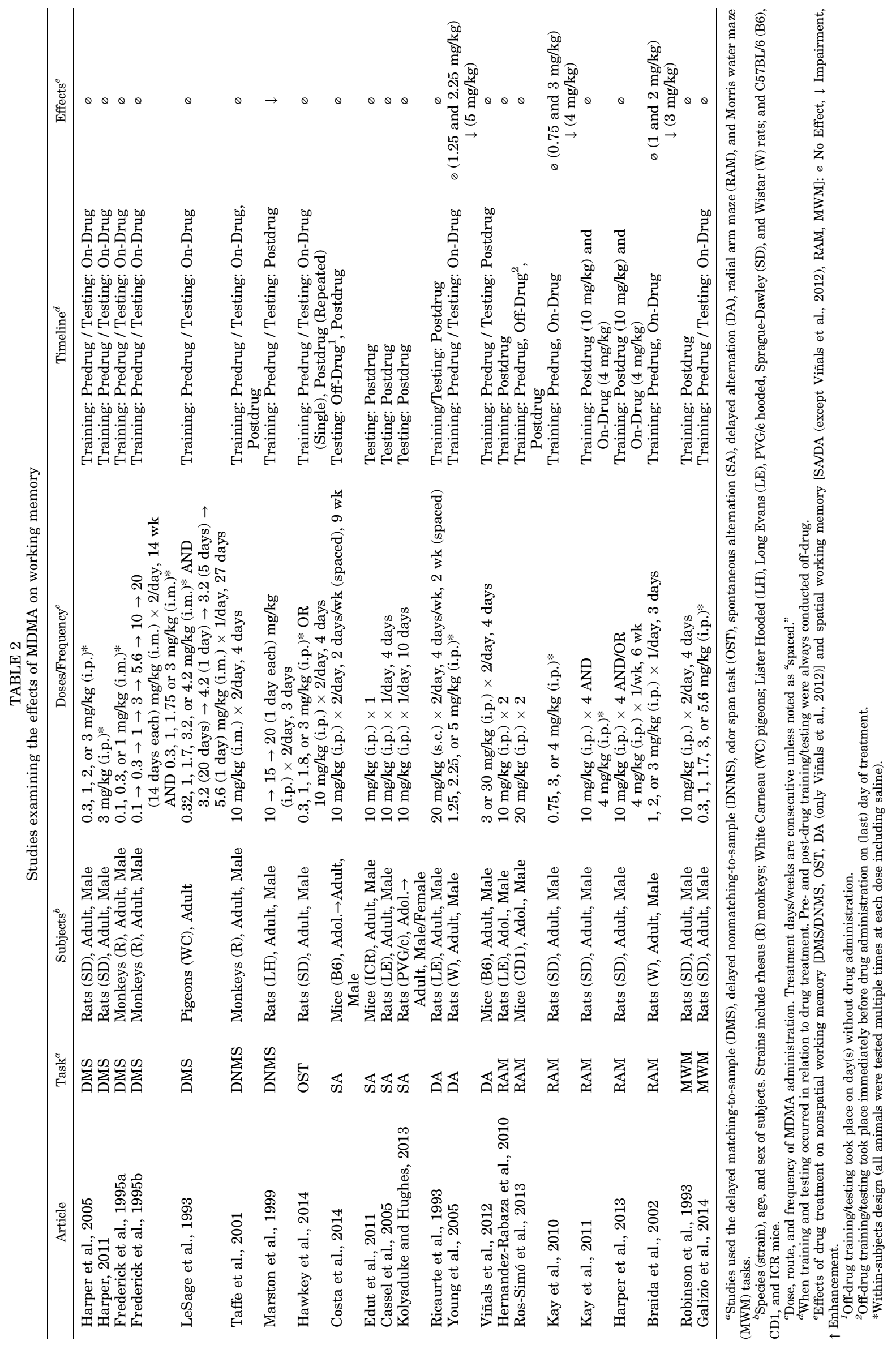


treatment days, so the results on accuracy were not reported. During the posttreatment days, the accuracy of MDMA-treated rats was significantly reduced relative to saline controls at the longer delays of 17.6 and 30 seconds (but not the shorter delays) during the last few days of testing. These results suggest that treatment with increasing doses of 10-20 mg/kg MDMA impairs working memory for up to about 2 weeks later.

a. Odor span task. Hawkey et al. (2014) conducted a variation of the DNMS task, the odor span task (OST), and this study is included in Table 2. In the OST, the stimuli are plastic cups that contain sand and a food reinforcer with different scented lids. On the first trial, a single olfactory stimulus is presented. On the second trial, the familiar olfactory stimulus is presented with a novel olfactory stimulus. On each subsequent trial, an additional olfactory stimulus is added so that the number of familiar olfactory stimuli increases with each trial, but there is always only one novel olfactory stimulus. Beyond the fifth trial, the number of stimuli does not increase, but the familiar and novel scents are still changed between trials. Simple discrimination trials are also interspersed between OST trials, which test for simple task performance but not working memory functioning. On each simple discrimination trial, the same five olfactory stimuli are presented and the single stimulus that is reinforced remains constant for all trials (while responses to the other four stimuli are never reinforced). In this study, each test session consisted of 24 OST trials and 6 simple discrimination trials. OST percent correct, simple discrimination percent correct, span (number of trials completed before an error), and longest run (longest series of correct responses) were scored for each session.

Hawkey et al. (2015) trained adult male Sprague-Dawley rats on the OST and simple discrimination tasks to a criterion level prior to testing. Rats were given $0,0.3,1$, 1.8 , or $3 \mathrm{mg} / \mathrm{kg}$ i.p. MDMA in a within-subjects design 15 minutes before on-drug test sessions. Doses of $0.3,1$, and $1.8 \mathrm{mg} / \mathrm{kg}$ MDMA had no effect on OST percent correct, simple discrimination percent correct, span, or longest run relative to saline. A dose of $3 \mathrm{mg} / \mathrm{kg}$ MDMA significantly decreased span and longest run relative to saline but had no effect on OST percent correct or simple discrimination percent correct. The reductions in span and longest run were due to a significant increase in response omissions on both simple discrimination and OST trials, rather than being due to working memory deficits. Another group of rats was given two daily injections of $10 \mathrm{mg} / \mathrm{kg}$ i.p. MDMA for 4 consecutive days and then tested off-drug 3 days later for a total of 10 sessions. MDMA-treated rats and saline controls did not significantly differ in OST percent correct, simple discrimination percent correct, span, or longest run. In all, these findings demonstrate that doses of $0.3,1,1.8$, and $3 \mathrm{mg} / \mathrm{kg}$ MDMA have no on-drug effect on working memory (although $3 \mathrm{mg} / \mathrm{kg}$ MDMA did produce performance deficits), and pretreatment with repeated doses of $10 \mathrm{mg} / \mathrm{kg}$ MDMA also have no subsequent effect on working memory.

2. Spontaneous and Delayed Alternation. The spontaneous alternation (SA) and delayed alternation (DA) tasks (see Dudchenko, 2004; Hughes, 2004) are used to assess spatial working memory in rodents, typically on a T- or Y-maze. The main difference between these two tasks is that SA responses are driven by the natural tendency for rodents to explore novel environments, and DA responses are driven by food reinforcement. In both tasks, the goal of the animal is to investigate a new arm of the T- or Y-maze rather than one that they recently visited.

There are two main versions of the SA task, continuous SA and two-trial SA. The continuous SA task is completed in one trial, during which the animal is allowed to freely explore all three arms of the maze for the entire duration (usually several minutes). Number of alternations, defined as consecutive entries into all three arms without repeated entries, is scored for each animal and converted to percent alternation (ratio of actual to possible alternations given number of arm entries). The two-trial SA task consists of a forced trial and a test trial. On the forced trial, the animal is placed at the end of the "start" arm and is only allowed to enter one other arm (the "familiar" arm), as the third arm (the "novel" arm) is blocked by a door. Normally, a delay period is placed after the forced trial and before the test trial. On the test trial, the animal is returned to the end of the "start" arm and allowed to enter either the "familiar" arm or the "novel" arm (all three arms are open). A correct response or alternation is defined as an entry into the "novel" arm on the test trial.

The DA task is quite similar to the two-trial SA task. Each session usually consists of one forced trial followed by several choice trials. The forced trial is conducted in the same manner as the SA task, except a food reinforcer is placed at the end of the "familiar" arm. On the first choice trial, the food reinforcer is placed at the end of the "novel" arm, and for all subsequent choice trials, the food reinforcer is placed at the end of the arm that was not entered on the previous trial. Only one entry is permitted per trial, and a correct response or alternation is defined as a reinforced response, an entry into the arm that was not entered on the previous trial.

Table 2 includes the seven studies that explored the effects of MDMA on the SA (four studies) and DA (three studies) tasks. Of these studies, only Costa et al. (2014) conducted the continuous SA task. In this study, male C57BL/6 mice were given two daily injections of $10 \mathrm{mg} / \mathrm{kg}$ i.p. MDMA at a 4- to 6 -hour interval on the 2 nd and 5 th days of each week for 9 weeks, which began in adolescence and extended into adulthood. Mice were tested on a Y-maze, off-drug, on the 7 th day of drug treatment weeks 1,4 , and 9 and postdrug treatment weeks 2 and 3 . The percent alternations of MDMA-treated mice and saline controls did not significantly differ at any time 
point, suggesting that treatment with repeated doses of $10 \mathrm{mg} / \mathrm{kg}$ MDMA has no effect on spatial working memory for up to 3 weeks after treatment.

Edut et al. (2011) and Cassel et al. (2005) tested rodents on the two-trial SA task at least 1 week after MDMA treatment. Edut et al. gave adult male ICR mice a single injection of $10 \mathrm{mg} / \mathrm{kg}$ i.p. MDMA and tested them 7 and 30 days later on a Y-maze. Mice were permitted to enter multiple arms during a 5-minute forced trial and a 2-minute choice trial, which were separated by a 2 -minute delay period. The preference index [(time at "novel" arm - time at "familiar" arm)/(time at "novel" arm + time at "familiar" arm)] of MDMA-treated mice and saline controls did not significantly differ at both 7 and 30 days later. Cassel et al. gave adult male Long Evans rats a daily injection of $10 \mathrm{mg} / \mathrm{kg}$ i.p. MDMA for 4 consecutive days. Four days later, rats began testing on a T-maze, and were tested once daily for 4 days and then twice on a 5th day. Rats were permitted to enter only one arm during each trial, which were separated by a 30 -second delay period. The overall percent alternation of MDMA-treated rats and saline controls did not significantly differ. These two studies suggest that pretreatment with a dose of $10 \mathrm{mg} / \mathrm{kg}$ MDMA, whether administered once or repeatedly, has no subsequent effect on spatial working memory.

Kolyaduke and Hughes (2013) performed a variation of the two-trial SA task in which all three arms of a Y-maze were open during both trials (now referred to as the acquisition and retention trials). During the acquisition trial, one arm contained a black insert and one arm contained a white insert, and during the retention trial, both arms contained a black insert (the changed arm $=$ the novel arm). Multiple choices were allowed during the 6-minute acquisition trial and the 3-minute retention trial, and there was no delay period between the two trials. Male and female PVG/c hooded rats were given a daily injection of $10 \mathrm{mg} / \mathrm{kg}$ i.p. MDMA for 10 consecutive days during early adolescence (postnatal days 35-45) or late adolescence (postnatal days 45-55). Rats were tested as adults on two separate days at least 35 days after MDMA treatment (after postnatal day 90 ). Both early and late adolescence MDMA-treated rats did not significantly differ from saline controls in percent novel entries and percent time spent in the novel arm, indicating that pretreatment with repeated doses of $10 \mathrm{mg} / \mathrm{kg}$ MDMA may have no subsequent effect on spatial working memory.

Ricaurte et al. (1993) gave adult male Long Evans rats two daily injections of $20 \mathrm{mg} / \mathrm{kg}$ s.c. MDMA at an 8-hour interval for 4 consecutive days, and this treatment was repeated again about 1 week later. About 1 month later, rats began training for a DA task on a T-maze. Seven weeks after MDMA treatment, rats began daily test sessions consisting of one forced trial followed by 10 choice trials under a constant delay of 5 seconds. The percent correct of MDMA-treated rats and saline controls increased at a similar rate over the 20 test sessions, and there were no significant differences between groups. After 5 weeks of testing under a constant delay, variable delays of $5,30,60,120$, and 180 seconds were introduced, and testing continued for an additional 3 weeks. The percent correct of MDMAtreated rats and saline controls decreased at a similar rate as the duration of the delay period increased, and again there were no significant differences between groups. Findings from this study indicate that pretreatment with repeated doses of $20 \mathrm{mg} / \mathrm{kg}$ MDMA may have no subsequent effect on spatial working memory.

Young et al. (2005) performed a two-part task on a double Y-maze: the first part was a spatial discrimination (SD) task (described in section V.C.3.a) and the second part was a DA task (summarized here). Young adult male Wistar rats were trained to criterion on the task prior to being introduced to delays of 0,15 , or 60 second and then on-drug testing. Rats were injected with $0,1.25,2.25$, or $5 \mathrm{mg} / \mathrm{kg}$ i.p. MDMA in a withinsubjects design 20 minutes before on-drug test sessions. Each test session consisted of one forced trial followed by 24 choice trials with randomly allocated delays. Overall, the percent correct of all rats significantly decreased as the duration of the delay increased. Relative to saline, doses of 1.25 and $2.25 \mathrm{mg} / \mathrm{kg}$ MDMA had no effect on percent correct at any delay, a dose of $2.25 \mathrm{mg} / \mathrm{kg}$ MDMA produced a small increase in percent correct under a 60 -second delay, and a dose of $5 \mathrm{mg} / \mathrm{kg}$ MDMA significantly decreased percent correct at all delays. Typically, this deficit would be attributed to a performance impairment, but since $5 \mathrm{mg} / \mathrm{kg}$ MDMA had no effect on accuracy in the SD component, which required the same performance abilities (see section V.C.3.a), this may be due to a working memory impairment. In all, these findings suggest that a dose of 1.25 or $2.25 \mathrm{mg} / \mathrm{kg}$ MDMA has no effect on spatial working memory, but a dose of $5 \mathrm{mg} / \mathrm{kg}$ MDMA may produce spatial working memory deficits.

Viñals et al. (2012) performed an operant/nonspatial version of the DA task in which adult male C57BL/6 mice were trained to alternate nose-poking between two nose-poking holes. Mice were trained to a criterion level on the task, and then given two daily injections of 3 or $30 \mathrm{mg} / \mathrm{kg}$ i.p. MDMA at a 4 -hour interval for 4 consecutive days. Mice were tested off-drug for 7 days after MDMA treatment and introduced to delays of $2,4,6$, or 8 seconds in a random order. Mice given $3 \mathrm{mg} / \mathrm{kg}$ MDMA injections and saline controls did not significantly differ in percent correct over all 7 days of testing. The percent correct of mice given $30 \mathrm{mg} / \mathrm{kg}$ MDMA injections was significantly higher than saline controls on the 1st day of testing but did not significantly differ from saline controls for the remaining 6 days. The increased accuracy on the 1st day of testing may be because of a slowed reaction time rather than working memory enhancements, as mice given $30 \mathrm{mg} / \mathrm{kg}$ MDMA injections also 
demonstrated a significantly longer response latency compared with saline controls. In all, these results suggest that pretreatment with repeated doses of 3 or $30 \mathrm{mg} / \mathrm{kg}$ MDMA has no subsequent effect on nonspatial working memory.

3. Radial Arm Maze. The radial arm maze (RAM) (see Dudchenko, 2004; Quillfeldt, 2016) is a useful tool to study spatial working and reference memory in rodents. The goal of this task is to learn and remember the location of food pellets using spatial cues. Performance can be separated by type of memory (working vs. reference). The effects of MDMA on working memory in the RAM task will be discussed here, while the effects on reference memory will be reviewed in section V.C.2.

The RAM consists of a central hub that provides access to eight radiating arms. All eight arms are equal in length, and a food well is attached to the end of each arm. The entire maze is typically elevated above the floor in a room with many distal spatial cues at fixed locations. Prior to training, each animal is randomly assigned a set of four baited arms and four nonbaited arms, which remains fixed for the remainder of the experiment. Training is usually conducted daily (or sometimes spaced by 1 to 2 days), with all animals completing several trials per day (2-6 trials/day for the studies reviewed). Before each trial, food pellets are placed in the food wells of the four baited arms assigned to that animal. The trial then begins by placing the animal in the central hub facing arm number one. The animal is typically allowed to enter four arms per trial before being removed from the maze. The number of working memory errors, defined as entries into a baited arm that has already been visited in that same trial, is scored for each trial. A single entry into each baited arm reflects accurate spatial working memory of the food pellet locations.

Table 2 includes the six studies that used the RAM to evaluate the effects of MDMA on spatial working memory. Five of the studies used the general methods outlined above, while Braida et al. (2002) used an alternative procedure that is described below.

Hernandez-Rabaza et al. (2010) and Ros-Simó et al. (2013) treated adolescent male rodents with two injections of MDMA on a single day. Hernandez-Rabaza et al. gave Long Evans rats two injections of $10 \mathrm{mg} / \mathrm{kg}$ i.p. MDMA at a 6-hour interval, 12 days prior to training. MDMA-treated rats and saline controls exhibited a decrease in working memory errors over the 5 days of training, and the number of working memory errors did not significantly differ between groups. Ros-Simó et al. began training CD1 mice prior to any MDMA administration. Each animal was assigned only three baited arms, and animals were not limited to a certain number of arm entries within each trial. Mice were trained for a total of 12 consecutive days and were given two injections of $20 \mathrm{mg} / \mathrm{kg}$ i.p. MDMA on the 12 th training day, one immediately after training and another
2 hours later. Three days later, mice were subject to an additional training session, during which the number of working memory errors produced by MDMA-treated mice and saline controls did not significantly differ. The findings of these two studies suggest that pretreatment with two doses of 10 or $20 \mathrm{mg} / \mathrm{kg}$ MDMA has no later effect on spatial working memory.

Figure 5 presents the findings of Kay et al. (2010), which exemplify dose-dependent effects of MDMA on working memory. Kay et al. trained adult male SpragueDawley rats off-drug until all rats reached a criterion of at least $75 \%$ correct arm entries for 7 days. After reaching criterion, rats began on-drug training. Rats were given 0 , $0.75,3$, or $4 \mathrm{mg} / \mathrm{kg}$ i.p. MDMA in a within-subjects design 15 minutes before each day of training. Relative to saline, a dose of $0.75 \mathrm{mg} / \mathrm{kg}$ MDMA had no effect on the mean overall percent correct, but doses of 3 and $4 \mathrm{mg} / \mathrm{kg}$ MDMA significantly decreased the mean overall percent correct (Fig. 5A). The deficits produced by $3 \mathrm{mg} / \mathrm{kg}$ MDMA were not due to working memory impairments, as this dose did not significantly impact the percent of working memory errors (number of errors/number of errors possible per day). A dose of $4 \mathrm{mg} / \mathrm{kg}$ MDMA did significantly increase the percent of working memory errors relative to saline; however the percent of working memory errors was still significantly smaller than the percent of reference
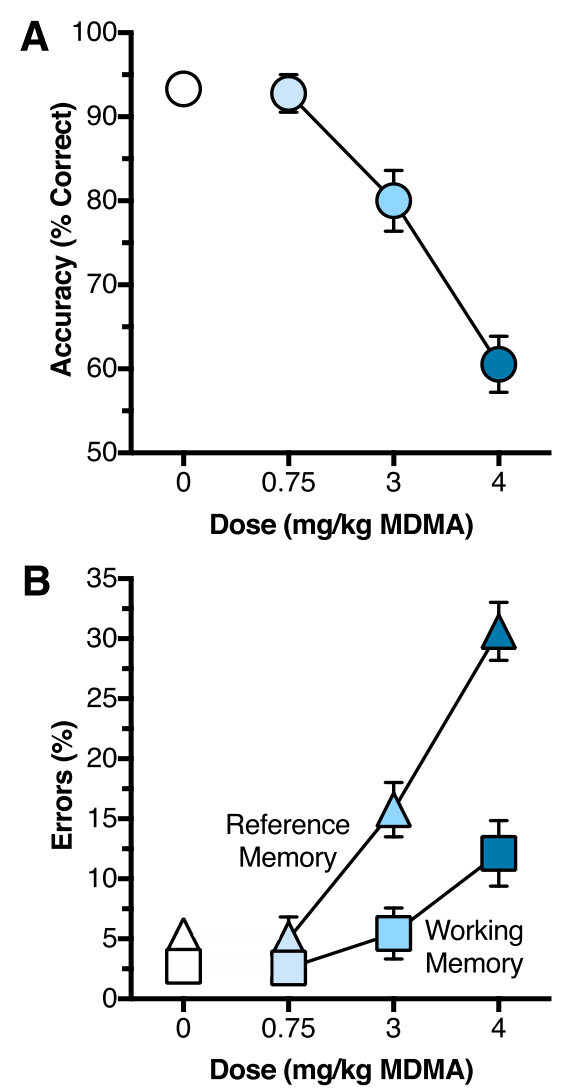

Fig. 5. Dose-dependent effects of MDMA on the radial arm maze task. $0.75 \mathrm{mg} / \mathrm{kg}$ MDMA had no effect on overall accuracy (A) or errors (B), while 3 and $4 \mathrm{mg} / \mathrm{kg}$ MDMA impaired overall accuracy (A) and increased working ( $4 \mathrm{mg} / \mathrm{kg}$ only) and reference memory errors (B). Data redrawn with permission from Figs. 1 and 3 in Kay et al. (2010). 
memory errors (Fig. 5B). These findings indicate that doses of 0.75 and $3 \mathrm{mg} / \mathrm{kg}$ MDMA have no effect on spatial working memory, but a larger dose of $4 \mathrm{mg} / \mathrm{kg}$ MDMA slightly impairs spatial working memory.

Kay et al. (2011) and Harper et al. (2013) conducted similar experiments in which adult male Sprague-Dawley rats were treated with MDMA before and/or during training. Kay et al. gave rats four injections of $10 \mathrm{mg} / \mathrm{kg}$ i.p. MDMA at 2-hour intervals, 2 days prior to training. Rats were trained off-drug until all animals reached training criterion ( 28 days later). Over the 24 off-drug training sessions, the average percent correct of MDMAtreated rats increased at a slower rate than saline controls. Two days after off-drug training, on-drug training began and continued for a total of 12 days. Rats were given 0 or $4 \mathrm{mg} / \mathrm{kg}$ i.p. MDMA in a within-subjects design 20 minutes before each on-drug training session. MDMA significantly decreased the average percent correct relative to saline, but this impairment was significantly smaller in rats treated with MDMA prior to offdrug training relative to saline controls. Nonetheless, the impairments observed during off- and on-drug training were not due to working memory deficits, as working memory error percentage was not significantly affected by any MDMA treatment.

Harper et al. also gave rats four injections of $10 \mathrm{mg} / \mathrm{kg}$ i.p. MDMA at 2-hour intervals. Training began after MDMA treatment and lasted for 47 days. Most training sessions took place off-drug, except some rats were given $4 \mathrm{mg} / \mathrm{kg}$ i.p. MDMA before training sessions on days $8,15,22,28,34$, and 41 . The average percent correct of rats pretreated with MDMA prior to all training sessions was significantly lower than saline controls on both off-drug and on-drug training days. MDMA also significantly reduced average percent correct during on-drug training days relative to saline. Again, none of these impairments were due to working memory deficits, as working memory error percentage was not significantly affected by any MDMA treatment. The findings of Kay et al. and Harper et al. suggest that pretreatment with four doses of $10 \mathrm{mg} / \mathrm{kg}$ MDMA has no subsequent effect on spatial working memory, and a dose of $4 \mathrm{mg} / \mathrm{kg}$ MDMA also has no on-drug effect on spatial working memory.

Braida et al. (2002) conducted an alternative working memory task on the RAM. In this version, all eight arms of the maze are baited, and the animal's goal is to enter all eight arms only one time during each trial. The number of errors are scored for each trial, which is synonymous with working memory errors on the typical RAM task (i.e., re-entries into a baited arm). Here, the task was conducted both without a delay and with a 2-hour delay between the fourth and fifth arm entry. Adult male Wistar rats were trained on the task to a criterion level, and then began on-drug training for 3 consecutive days. Rats were given a single injection of 1,2 , or $3 \mathrm{mg} / \mathrm{kg}$ i.p. MDMA 20 minutes before each on-drug training session. Without a delay, MDMA had no effect on the total number of errors relative to saline. With a 2-hour delay, doses of 1 and $2 \mathrm{mg} / \mathrm{kg}$ MDMA had no effect on the total number of errors during the predelay period (first 4 choices) and post-delay period (last 4 choices) relative to saline. A dose of $3 \mathrm{mg} / \mathrm{kg}$ MDMA also had no effect on the total number of errors during the pre-delay period, but significantly increased the total number of errors during the post-delay period relative to saline. These results suggest that doses of 1 and $2 \mathrm{mg} / \mathrm{kg}$ MDMA have no effect on spatial working memory, but a dose of $3 \mathrm{mg} / \mathrm{kg}$ MDMA impairs spatial working memory.

4. Other Working Memory Tasks.

a. Morris water maze. The standard Morris water maze (MWM) task (Morris, 1984) typically assesses spatial learning and spatial reference memory (see section V.C.1); however the task procedures can be manipulated to measure spatial working memory (see Vorhees and Williams, 2006). On the standard MWM task, the hidden platform remains in the same location throughout acquisition training, and therefore long-term memory is required to navigate to the platform. On the working memory version of the MWM task, the location of the hidden platform is changed each day, and therefore long-term memory of the platform location is not required and rather the task demands working memory functioning. The two studies that examined the effects of MDMA on the working memory MWM task are included in Table 2. The methods for these studies are briefly discussed here, but see section V.C.1 for a full description of the MWM apparatus/methods.

Robinson et al. (1993) conducted a spatial navigation task on the MWM that consisted of three parts: an initial learning set, a retention test (reviewed in section V.C.1.a), and a second learning set. The learning sets assessed working memory and were each 3 consecutive days in total. On each day, the platform location was chosen randomly, which remained constant for that day only. Eight trials were performed per day, with two trials from each of the four starting locations. Adult male Sprague-Dawley rats were given two daily injections of $10 \mathrm{mg} / \mathrm{kg}$ i.p. MDMA at a 12-hour interval for 4 consecutive days. The initial learning set began 2 days after MDMA treatment, and the second learning set began 8 days after MDMA treatment. On the initial learning set, the escape latency of MDMA-treated rats was significantly higher than saline controls on the first few trials of each day, but both groups demonstrated a significant decrease in escape latency across trials and showed no significant differences by the last few trials. On the second learning set, both MDMA-treated rats and saline controls demonstrated a significant decrease in escape latency across trials, and there were no significant differences between groups. These results suggest that pretreatment with repeated doses of $10 \mathrm{mg} / \mathrm{kg}$ MDMA has no subsequent effect on spatial working memory. 
Galizio et al. (2014) performed a repeated acquisition/performance procedure on the MWM. The acquisition component assessed working memory, as the platform location changed each day, while the performance component (see section V.C.1.a) assessed reference memory, as the platform location remained fixed over all days. Each day consisted of 12 trials that alternated between acquisition and performance trials. Adult male Sprague-Dawley rats were trained on the task prior to on-drug testing. Rats were given of $0,0.3$, $1.0,1.7,3.0$, or $5.6 \mathrm{mg} / \mathrm{kg}$ i.p. MDMA in a within-subjects design 15 minutes before each on-drug test session. On the acquisition component, doses of $0.3,1.0$, and $1.7 \mathrm{mg} / \mathrm{kg}$ MDMA had no effect on escape latency, while doses of 3.0 and $5.6 \mathrm{mg} / \mathrm{kg}$ MDMA significantly increased escape latency relative to saline. Doses of 3.0 and $5.6 \mathrm{mg} / \mathrm{kg}$ MDMA also produced significant increases in latency on the performance component (see section V.C.1.a), and therefore these deficits can be attributed to performance impairments rather than working memory impairments. In all, these results reveal that doses of $0.3,1.0,1.7,3.0$, and $5.6 \mathrm{mg} / \mathrm{kg}$ may have no effect on spatial working memory.

\section{Spatial Learning and Memory}

1. Morris Water Maze. The Morris water maze (MWM) (Morris, 1984) is one of the most widely used tasks for studying spatial learning and memory in rodents. The objective of this task is to learn to navigate to a hidden platform in a large circular pool of water using spatial cues. The pool is arbitrarily divided into four quadrants and is in a room with many distal visual cues at fixed locations (e.g., furniture, wall art, etc.). There are two main stages of the task: acquisition training and the probe test, which assess spatial learning and spatial reference memory, respectively.

Acquisition training takes place over a few consecutive days (3-5 days for the studies reviewed), with all animals completing several trials per day (3-8 trials/ day for the studies reviewed). On each trial, an animal is placed into the water facing the wall of the pool and is expected to swim and escape onto the hidden platform. The hidden platform remains in the same location throughout acquisition training, but the starting location of the animal is varied between trials. As a result, spatial memory of the distal visual cues is required to identify the location of the hidden platform. The escape latency (i.e., time taken to reach the platform), and often the path length (i.e., distance swam to reach the platform), is recorded for all trials. A significant decrease in escape latency/path length over days of acquisition training suggests spatial learning of the platform location.

The probe test takes place after the last acquisition training session, either the same day or the following day. The procedure is similar to acquisition training, except the hidden platform is removed from the pool and each animal performs only one trial. The total time spent swimming in each quadrant of the pool, or sometimes the average distance from the platform location, is recorded. A significantly greater amount of time spent swimming in the target quadrant (i.e., quadrant where the hidden platform used to be located) relative to the other three quadrants indicates spatial reference memory of the platform location.

Table 3 presents the 14 studies that report the effects of MDMA on the standard MWM task. Most of these studies completed both acquisition training and the probe test. Some studies do not report the change in escape latency/path length over days of acquisition training, and a few other studies do not report findings on the probe test. In these particular studies, effects on spatial learning or spatial reference memory (respectively) cannot be properly assessed. All 14 studies used high doses of 5-20 mg/kg MDMA, and none used lower, typical doses of less than $3 \mathrm{mg} / \mathrm{kg}$ MDMA.

Taghizadeh et al. (2016) were the only group to conduct on-drug acquisition training. Adult male Wistar rats were given 5,10 , or $15 \mathrm{mg} / \mathrm{kg}$ i.p. MDMA 30 minutes before the first trial of acquisition training on all 4 days. During the probe test on the following day (off-drug), MDMA-treated rats spent significantly less time in the target quadrant than saline controls. These results suggest that doses of 5,10 , and $15 \mathrm{mg} / \mathrm{kg}$ MDMA impair spatial reference memory when acquisition occurs on-drug.

The remaining studies explored the effects of administering MDMA one or more days prior to acquisition training. Mirzaei et al. (2013) gave adult male Wistar rats a single injection of $10 \mathrm{mg} / \mathrm{kg}$ i.p. MDMA, 3 days prior to acquisition training. The escape latency and path length of MDMA-treated rats were significantly higher than that of saline controls on the 1st day of training, but these values decreased significantly over the 2nd and 3rd day to a level comparable to that of the saline controls. This suggests that pretreatment with a dose of $10 \mathrm{mg} / \mathrm{kg}$ MDMA has no subsequent effect on spatial learning.

Sprague et al. (2003), Cohen et al. (2005), Able et al. (2006), Skelton et al. (2008), and Cunningham et al. (2009) all gave adult male Sprague-Dawley rats multiple injections of MDMA on a single day prior to acquisition training. Sprague et al. gave rats two injections of $20 \mathrm{mg} / \mathrm{kg}$ s.c. MDMA at a 12 -hour interval, 1 week prior to acquisition training. The escape latency and path length of MDMA-treated rats decreased significantly over 3 days of acquisition training, and there were no significant differences between MDMAtreated rats and saline controls during acquisition. During the probe test directly after the last acquisition session, MDMA-treated rats spent significantly less time in the target quadrant than saline controls, yet significantly more time in the target quadrant than two of the other three quadrants. Similarly, Cunningham 


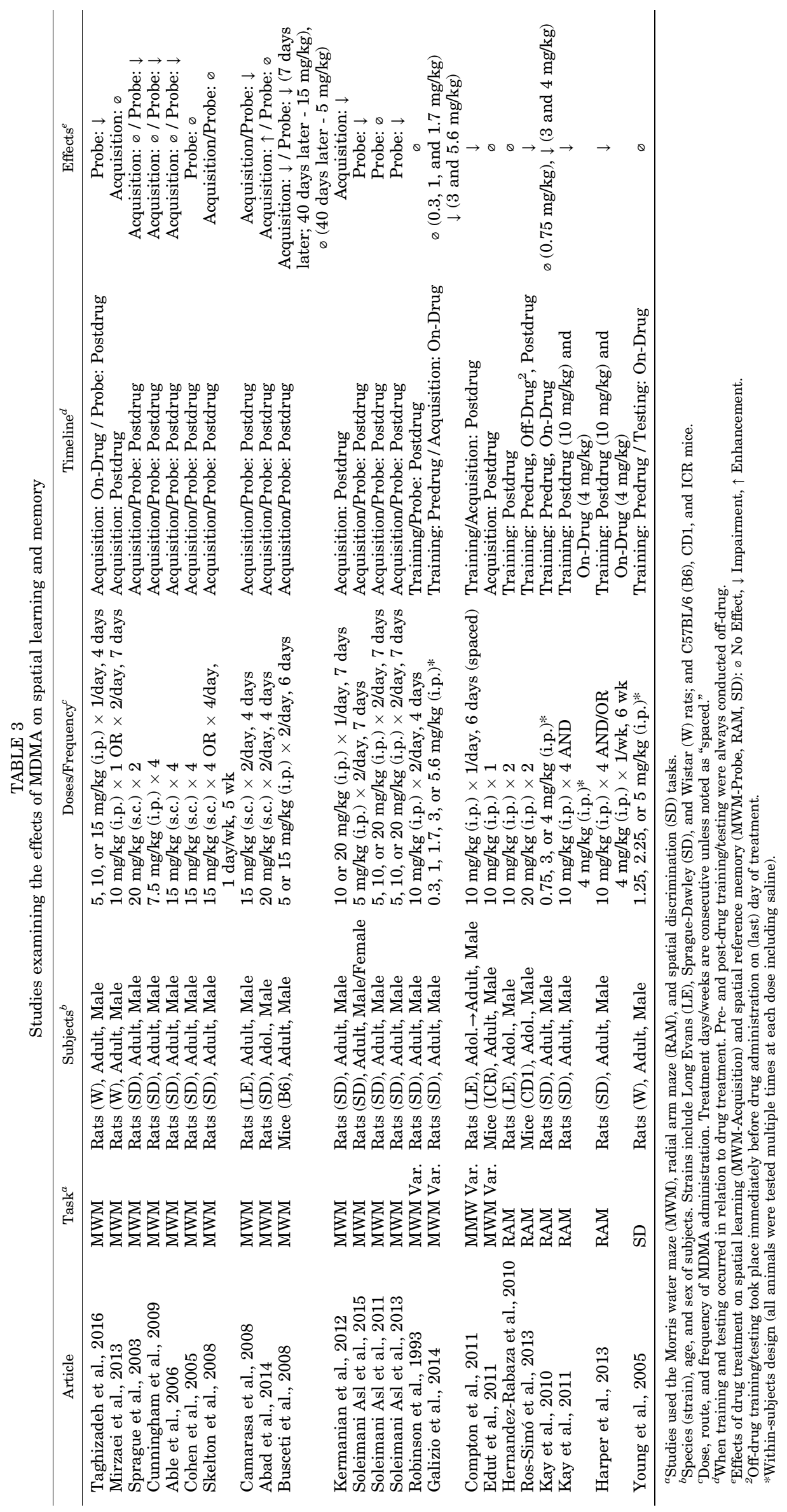


et al. gave rats four injections of $7.5 \mathrm{mg} / \mathrm{kg}$ i.p. MDMA at 2-hour intervals, 24 days prior to acquisition training. There were no significant differences between MDMAtreated rats and saline controls in the decrease in escape latency and path length over 5 days of acquisition training. During the probe test directly after the last acquisition session, MDMA-treated rats spent the same amount of time in all four quadrants, unlike the saline controls that spent significantly more time in the target quadrant than the other three quadrants. Able et al. gave rats four injections of $15 \mathrm{mg} / \mathrm{kg}$ s.c. MDMA at 2-hour intervals, 12 days prior to acquisition training. Again, there were no significant differences between MDMA-treated rats and saline controls during acquisition training, as both groups exhibited similar decreases in escape latency over all 5 days. During the probe test on the following day, the average distance from the platform location of MDMAtreated rats was significantly greater than that of saline controls. Cohen et al. also gave rats four injections of $15 \mathrm{mg} / \mathrm{kg}$ s.c. MDMA at 2-hour intervals, but at least 2 weeks prior to 5 days of acquisition training. On the probe test the day after the last acquisition session, there were no significant differences between MDMAtreated rats and saline controls in percent time spent in the target quadrant. Skelton et al. also gave rats four injections of $15 \mathrm{mg} / \mathrm{kg}$ s.c. MDMA at 2-hour intervals, 14 days prior to acquisition training. The latency of MDMA-treated rats and saline controls decreased in a similar manner over 5 days of acquisition training. During the probe test on the following day, the average distance from the platform location of MDMA-treated rats and saline controls did not significantly differ.

The findings from the five studies above suggest that pretreatment with two doses of $20 \mathrm{mg} / \mathrm{kg}$ MDMA or four doses of 7.5 or $15 \mathrm{mg} / \mathrm{kg}$ MDMA has no later effect on spatial learning. The results from the probe test of these studies suggest that pretreatment with two doses of $20 \mathrm{mg} / \mathrm{kg}$ MDMA or four doses of $7.5 \mathrm{mg} / \mathrm{kg}$ MDMA subsequently impairs spatial reference memory, while pretreatment with four doses of $15 \mathrm{mg} / \mathrm{kg}$ MDMA has no later effect on spatial reference memory (apart from Able et al.'s findings that this dose produces spatial reference memory impairments).

The remainder of the studies investigated the consequences of administering multiple daily injections of MDMA on multiple days prior to acquisition training. Camarasa et al. (2008) and Abad et al. (2014) treated rats with two daily injections of MDMA for 4 consecutive days. Camarasa et al. gave adult male Long Evans rats two daily injections of $15 \mathrm{mg} / \mathrm{kg}$ s.c. MDMA at a 7-hour interval for 4 consecutive days, 9 days prior to acquisition training. Unlike saline controls, the escape latency of MDMA-treated rats did not significantly decrease over 4 days of acquisition training. On the probe test the following day, MDMA-treated rats also did not spend significantly more time in the target quadrant than that predicted by random (1/4th of the total time). Abad et al. gave adolescent male Sprague-Dawley rats two daily injections of $20 \mathrm{mg} / \mathrm{kg}$ s.c. MDMA for 4 consecutive days, 1 week prior to acquisition training. The escape latency of MDMA-treated rats decreased at a faster rate than saline controls over 4 days of acquisition training. MDMA-treated rats and saline controls spent significantly more time in the target quadrant than the opposite quadrant on the probe test the next day. These two studies have opposing findings. The results of Camarasa et al. suggest that pretreatment with repeated doses of $15 \mathrm{mg} / \mathrm{kg}$ MDMA later impairs both spatial learning and spatial reference memory, while the results of Abad et al. suggest that pretreatment with repeated doses of $20 \mathrm{mg} / \mathrm{kg}$ MDMA later enhances spatial learning and has no effect on spatial reference memory. The use of different rat strains or ages (Camarasa et al. tested adult Long Evan rats and Abad et al. tested adolescent Sprague-Dawley rats) may account for this discrepancy in findings.

Busceti et al. (2008) used a similar MDMA regimen as Camarasa et al. and Abad et al., but instead gave adult male C57BL/6 mice two daily injections of 5 or $15 \mathrm{mg} / \mathrm{kg}$ i.p. MDMA at a 2-hour interval for 6 consecutive days. Acquisition training began 7 or 40 days after MDMA treatment, and at both time points, the escape latency of MDMA-treated mice did not significantly decrease over the 4 days. On the probe test, mice given $5 \mathrm{mg} / \mathrm{kg}$ MDMA injections spent significantly less percent time than saline controls in the target quadrant when tested 7 days later but not when tested 40 days later. Mice given $15 \mathrm{mg} / \mathrm{kg}$ MDMA injections spent significantly less percent time than saline controls in the target quadrant when tested 7 or 40 days later. These results suggest that pretreatment with repeated doses of 5 or $15 \mathrm{mg} / \mathrm{kg}$ MDMA subsequently results in spatial learning and spatial reference memory deficits, but spatial reference memory may return to normal by 40 days after treatment with repeated doses of $5 \mathrm{mg} / \mathrm{kg}$ MDMA only.

The next group of studies treated adult rats with MDMA for 7 consecutive days. Kermanian et al. (2012) gave adult male Sprague-Dawley rats a daily injection of 10 or $20 \mathrm{mg} / \mathrm{kg}$ i.p. MDMA for 1 week. Acquisition training began 1 week later, and unlike saline controls, the escape latency of MDMA-treated rats did not significantly decrease over the 4 days. Soleimani Asl et al. (2015) gave male and female adult SpragueDawley rats two daily injections of $5 \mathrm{mg} / \mathrm{kg}$ i.p. MDMA for 1 week. On the following probe test, MDMA-treated rats spent significantly less percent time in the target quadrant than saline controls. Soleimani Asl et al. (2011) and Soleimani Asl et al. (2013) gave adult male Sprague-Dawley rats two daily injections of 5,10 , or $20 \mathrm{mg} / \mathrm{kg}$ i.p. MDMA at an 8-hour interval for 1 week. Soleimani Asl et al. (2011) began 3 days of acquisition training 1 week after MDMA treatment. The probe test 
took place the day after acquisition training, during which MDMA-treated rats and saline controls spent the same percent time in the target quadrant. Soleimani Asl et al. (2013) began 3 days of acquisition training the day after MDMA treatment. The probe test also took place the day after acquisition training, but MDMAtreated rats spent significantly less percent time in the target quadrant than saline controls. In addition to testing the effects of a single dose of MDMA (described above), Mirzaei et al. (2013) gave another group of adult male Wistar rats two daily injections of $10 \mathrm{mg} / \mathrm{kg}$ i.p. MDMA for 1 week and began acquisition training the following day. The escape latency and path length of MDMA-treated rats were significantly higher than that of saline controls on the 1st day of training, but these values decreased significantly over the 2 nd and 3 rd day to a level comparable to that of saline controls.

The findings from the above studies are mixed. The results of Kermanian et al. suggest that pretreatment with repeated doses of $10 \mathrm{or} 20 \mathrm{mg} / \mathrm{kg}$ MDMA leads to spatial learning deficits, while the results of Mirzaei et al. suggest that pretreatment with repeated doses of $10 \mathrm{mg} / \mathrm{kg}$ MDMA has no effect on spatial learning. Likewise, the results of Soleimani Asl et al. (2013, 2015) suggest that pretreatment with repeated doses of 5,10 , or $20 \mathrm{mg} / \mathrm{kg}$ MDMA leads to spatial reference memory deficits. The results of Soleimani Asl et al. (2011), however, suggest that pretreatment with repeated doses of 5,10 , or $20 \mathrm{mg} / \mathrm{kg}$ MDMA has no effect on spatial reference memory. These differences in findings could be due to the timing of training/testing relative to MDMA treatment. Soleimani Asl et al. (2013) and Mirzaei et al. began acquisition training 1 day after MDMA treatment and found learning and memory deficits, while Soleimani Asl et al. (2011) and Kermanian et al. (2012) began acquisition training 1 week after MDMA treatment and found no effects. The differences between the findings of Kermanian et al. and Mirzaei et al. could also be due to the use of different rat strains (Sprague-Dawley vs. Wistar). In all, it appears that pretreatment with MDMA for 7 consecutive days may produce spatial learning and memory deficits within the week after treatment, but not after 1 week.

Skelton et al. (2008), in addition to studying the effects of multiple MDMA injections on a single day (above), gave another group of animals the same treatment weekly. Adult male Sprague-Dawley rats were given four daily injections of $15 \mathrm{mg} / \mathrm{kg}$ s.c. MDMA at 2-hour intervals once weekly for 5 weeks. Acquisition training began 14 days later, during which the latency of MDMA-treated rats and saline controls decreased in a similar manner over all 5 days. During the probe test on the following day, the average distance from the platform location of MDMA-treated rats and saline controls did not significantly differ. These results suggest that pretreatment with repeated doses of
$15 \mathrm{mg} / \mathrm{kg}$ MDMA has no subsequent effect on spatial learning or spatial reference memory.

a. Morris water maze variations. Four studies included in Table 3 used variations of the water maze to assess the effects of MDMA on spatial learning and memory. Robinson et al. (1993) conducted a spatial navigation task that is similar to the standard MWM task. Adult male Sprague-Dawley rats were given two daily injections of $10 \mathrm{mg} / \mathrm{kg}$ i.p. MDMA at a 12 -hour interval for 4 consecutive days, 2 days prior to training. The location of the hidden platform changed each day of training, and therefore this phase measured working memory rather than spatial learning (see section V.B.4.a). Training lasted for 3 days, and on the 4 th day the hidden platform was left in the same location as the previous day for a retention test of spatial reference memory of the platform location (similar to the probe test in the standard MWM task). The escape latencies of MDMA-treated rats and saline controls showed no significant differences over all four trials of the retention test, which suggests that pretreatment with repeated doses of $10 \mathrm{mg} / \mathrm{kg}$ MDMA has no subsequent effect on spatial reference memory.

Figure 6 portrays the findings of Galizio et al. (2014), which exemplify dose-dependent effects of MDMA on spatial learning and memory. Galizio et al. conducted a repeated acquisition/performance procedure on the MWM. Adult male Sprague-Dawley rats were trained on the acquisition and performance components of the task prior to any MDMA administration. Each training day consisted of 12 trials that alternated between acquisition and performance trials. The acquisition component (see section V.B.4.a) assessed working memory, as the platform location changed each training day but remained fixed for all trials on a particular day. The performance component corresponded to acquisition training on the standard MWM, as the platform location remained fixed over all days of training. Once rats reached criterion on training, the same procedure was repeated on-drug. Unlike the other MWM studies, MDMA was tested across a wide range of doses. Rats were given $0,0.3,1.0,1.7,3.0$, or $5.6 \mathrm{mg} / \mathrm{kg}$ i.p. MDMA in a within-subjects design 15 minutes before each on-drug session. On the performance component, doses of 0.3 , 1.0 , and $1.7 \mathrm{mg} / \mathrm{kg}$ MDMA had no effect on escape latency while doses of 3.0 and $5.6 \mathrm{mg} / \mathrm{kg}$ MDMA significantly increased escape latency relative to saline. These results suggest that doses of $0.3,1.0$, and $1.7 \mathrm{mg} / \mathrm{kg}$ MDMA have no effect on spatial learning but doses of 3.0 and $5.6 \mathrm{mg} / \mathrm{kg}$ MDMA impair spatial learning.

Compton et al. (2011) used a constant-start training and novel-start testing procedure on the MWM. Adolescent male Long Evans rats were given a daily injection of $10 \mathrm{mg} / \mathrm{kg}$ i.p. MDMA for 6 alternating days. Rats were trained and tested as adults about 3 months later. The experiment started with constant-start 


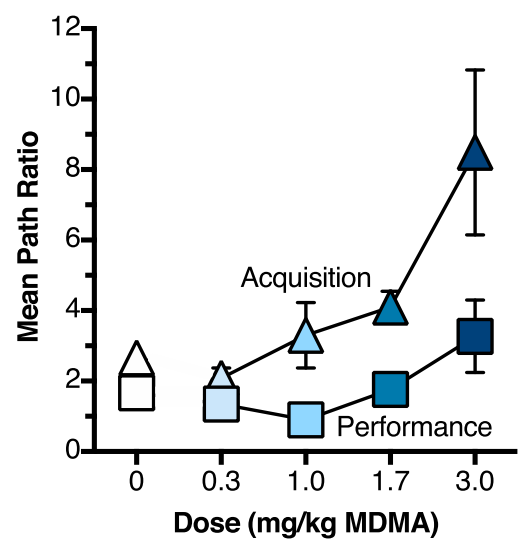

Fig. 6. Dose-dependent effects of MDMA on a variation of the Morris water maze task. $0.3,1.0,1.7 \mathrm{mg} / \mathrm{kg}$ MDMA had no effect on working memory (acquisition) or spatial learning (performance), while $3 \mathrm{mg} / \mathrm{kg}$ MDMA impaired spatial learning (performance). Data redrawn with permission from Fig. 4 (middle) in Galizio et al. (2014).

training, during which the starting location of each rat and the platform location were invariable. Novelstart testing began after rats reached training criterion, which is executed in the same manner as acquisition training on the standard MWM (variable starting locations and a fixed platform location). Rats were tested for 3 days, with each day consisting of six trials, trials one, two, four, and five were constant-start trials and trials three and six were novel-start trials. The escape latency of MDMA-treated rats on novel-start trials were significantly greater than that of saline controls, suggesting that pretreatment with repeated doses of $10 \mathrm{mg} / \mathrm{kg}$ MDMA during adolescence will impair spatial learning as adults.

Edut et al. (2011) tested the effects of MDMA treatment on the dry maze test, a variation of the MWM that does not require swimming. The dry maze consists of a circular arena with 20 tiny wells arranged in a circular manner. The goal of the task is to learn the location of the single well that is filled with water. Adult male ICR mice were first trained to drink from all 20 wells, and then introduced to a procedure identical to acquisition training on the standard MWM to learn the water well location. Mice were given a single injection of $10 \mathrm{mg} / \mathrm{kg}$ i.p. MDMA and tested 7 and 30 days later. Seven days after MDMA treatment, the latency to reach the water well of MDMA-treated mice and saline controls decreased in a similar manner over all 7 days of testing. Thirty days after MDMA treatment, the latency of MDMA-treated mice was significantly higher than saline controls on days 4 and 6 of acquisition, but both groups showed significant decreases in latency over all 7 days and by the last day of acquisition there were no significant differences. These results suggest that pretreatment with a dose of $10 \mathrm{mg} / \mathrm{kg}$ MDMA has no subsequent effect on spatial learning.

2. Radial Arm Maze. As described in section V.B.3, the radial arm maze (RAM) (see Dudchenko, 2004; Quillfeldt, 2016) is a useful tool to study spatial working and reference memory in rodents. Here, we review the five studies that examined the effects of MDMA on spatial reference memory using the RAM task, which are outlined in Table 3. The methods for these studies are as previously explained; however, now the outcome variable of interest is the number of reference memory errors per trial. Reference memory errors are defined as entries into a nonbaited arm. Entries into only baited arms reflect accurate spatial reference memory of the food pellet locations.

Hernandez-Rabaza et al. (2010) gave adolescent male Long Evans rats two injections of $10 \mathrm{mg} / \mathrm{kg}$ i.p. MDMA at a 6 -hour interval, 12 days prior to training. MDMAtreated rats and saline controls exhibited a similar decrease in reference memory errors over 5 days of training. The total reference memory errors during all 5 days also did not significantly differ between groups. Similarly, Ros-Simó et al. (2013) gave adolescent male CD1 mice two injections of $20 \mathrm{mg} / \mathrm{kg}$ i.p. MDMA, but on the 12th and last day of training (using the alternative methods described in section V.B.3). One injection was given immediately after training and the second was given 2 hours later. Three days later, mice were subject to an additional training session, during which MDMAtreated mice produced significantly more reference memory errors than saline controls. Although these two studies administered similar MDMA treatments, the findings of Hernandez-Rabaza et al. suggest that pretreatment with a two doses of $10 \mathrm{mg} / \mathrm{kg}$ MDMA has no later effect on spatial reference memory, while the findings of Ros-Simó et al. suggest that treatment with two doses of $20 \mathrm{mg} / \mathrm{kg}$ MDMA impairs consolidation of spatial reference memory.

Kay et al. (2010) gave adult male Sprague-Dawley rats (that were pretrained on the task) $0,0.75,3$, or $4 \mathrm{mg} / \mathrm{kg}$ i.p. MDMA in a within-subjects design 15 minutes before each day of training. As summarized previously, a dose of $0.75 \mathrm{mg} / \mathrm{kg}$ MDMA had no effect on the mean overall percent correct, but doses of 3 and $4 \mathrm{mg} / \mathrm{kg}$ MDMA significantly decreased the mean overall percent correct relative to saline. The deficits produced by doses of 3 and $4 \mathrm{mg} / \mathrm{kg}$ MDMA are primarily attributed to reference memory impairments, as both doses significantly increased the percent of reference memory errors relative to saline, and the percent of reference memory errors were significantly higher than the percent of working memory errors. As illustrated in Fig. 5, these findings indicate that a dose of $0.75 \mathrm{mg} / \mathrm{kg}$ MDMA has no effect on spatial reference memory but doses of 3 and $4 \mathrm{mg} / \mathrm{kg}$ MDMA impair spatial reference memory.

Kay et al. (2011) and Harper et al. (2013) gave adult male Sprague-Dawley rats MDMA before and/or during training. Kay et al. gave rats four injections of $10 \mathrm{mg} / \mathrm{kg}$ i.p. MDMA at 2-hour intervals, 2 days prior to off-drug training. After 28 days of off-drug training, on-drug training began and continued for a total of 12 days. Rats were given 0 or $4 \mathrm{mg} / \mathrm{kg}$ i.p. MDMA in a within-subjects 
design 20 minutes before each on-drug training session. The effects of MDMA on average percent correct that were previously reported in section V.B.3 can be attributed to reference memory deficits, as the effects on average percent correct and reference memory error percentage follow the same pattern. During off-drug training, the reference memory error percentage of MDMA-treated rats decreased at a slower rate than saline controls. During on-drug training, MDMA significantly decreased the reference memory error percentage relative to saline (this impairment was also significantly smaller in rats treated with MDMA prior to off-drug training vs. saline controls).

Harper et al. (2013) gave rats four injections of $10 \mathrm{mg} / \mathrm{kg}$ i.p. MDMA at 2-hour intervals and began training after MDMA treatment. Training lasted for 47 days, with a mix of on-drug sessions (days 8, 15, 22, 28,34 , and 41) and off-drug sessions (all other days). Before the on-drug training sessions, some rats were given $4 \mathrm{mg} / \mathrm{kg}$ i.p. MDMA. Again, the effects of MDMA on average percent correct that were previously reported in section V.B.3 can be attributed to reference memory deficits, as the effects on average percent correct and reference memory error percentage follow the same pattern. The reference memory error percentage of rats pretreated with MDMA prior to all training sessions was significantly higher than saline controls on both off-drug and on-drug training days. MDMA also significantly increased reference memory error percentage during on-drug training days relative to saline. The findings of Kay et al. and Harper et al. suggest that pretreatment with four doses of $10 \mathrm{mg} / \mathrm{kg}$ MDMA subsequently impairs spatial reference memory, and a dose of $4 \mathrm{mg} / \mathrm{kg}$ MDMA also impairs spatial reference memory when on-drug.

\section{Other Spatial Tasks.}

a. Spatial discrimination. Young et al. (2005) used a double Y-maze for a two-part task, spatial discrimination (SD) task, which assesses spatial reference memory and is outlined in Table 3, and a delayed alternation task, which assesses working memory and is described in section V.B.2. The double Y-maze consists of four end arms connected to a central stem ( 2 arms on each side of stem). Every arm is virtually identical from inside the maze, but the entire maze is in a room with many distal visual cues. On every trial, the animal is placed on the end of one of the arms on the left side of the maze, and the goal is to navigate to a food reward that is on one of the arms on the right side of the maze. The first part of the task is the SD task, as the animal is faced with the decision to turn left or right-one way leading to the adjacent arm and the other leading to the central stem and ultimately the food reward. Both options appear identical to the animal because there is a door placed in the central stem before the arms on the right side. The task therefore requires spatial reference memory of the location of the central stem relative to the distal visual cues.
For this study, young adult male Wistar mice were trained on the task above prior to any MDMA treatment. After reaching training criterion, mice were introduced to intertrial delays of 15 and 60 seconds and then tested on-drug with the same procedure. Mice were given $0,1.25$, 2.25 , or $5 \mathrm{mg} / \mathrm{kg}$ i.p. MDMA in a within-subjects design 20 minute before each test session. MDMA had no effect on percent correct choices at any delay relative to saline. These findings demonstrate that doses of 1.25, 2.25, and $5 \mathrm{mg} / \mathrm{kg}$ MDMA do not influence spatial reference memory retrieval.

\section{Nonspatial Learning and Memory}

1. Novel Object Recognition. The novel object recognition (NOR) task (Ennaceur and Delacour, 1988) is a relatively simple test of nonspatial memory. This method is based on the natural tendency for rodents to explore a novel object more than a familiar object. Animals are first habituated to the testing environment, a box or circular arena that is typically under dim lighting, on 1 or more days prior to testing. Testing consists of two trials, a training trial and a test trial, separated by a delay ranging from 1 minute to 24 hours. This task can measure short-term memory or long-term memory, depending on the duration of the delay. Shortterm memory does not require protein synthesis but long-term memory does require protein synthesis, and the transition from protein synthesis-independent to protein synthesis-dependent long-term potentiation begins about 2 hours after memory acquisition (Frey and Morris, 1997; Lu et al., 2008). Therefore, we can consider that delays of less than 2 hours measure short-term recognition memory, and delays of 2 hours or more measure long-term recognition memory.

During the training trial, the animal is presented with two identical objects ("A"), and the total time spent exploring the two objects is measured. During the test trial (following the delay), the animal is presented with one familiar object ("A") and one novel object ("B"), and the time spent exploring each object is measured. Object exploration is defined as touching, sniffing, or directing the nose and vibrissae toward the object at a distance of less than 1 to $2 \mathrm{~cm}$. Significantly more exploration of the novel object $B$ than of the familiar object $A$ in the test trial is an indicator of object recognition memory. A "discrimination index" or "discrimination ratio" is usually calculated to capture this data. The "discrimination index" is the difference in exploration times of the novel object $\mathrm{B}$ and the familiar object $\mathrm{A}$, divided by the total exploration time of the two objects in the test trial. The discrimination ratio is the exploration time of the novel object $\mathrm{B}$ divided by the total exploration time of the two objects in the test trial. A higher discrimination index or discrimination ratio reflects greater memory retention of the familiar object.

Table 4 outlines the 22 studies that investigated the effects of MDMA on the NOR task. Similar to the MWM 
studies, most of the NOR studies used high doses of 3$20 \mathrm{mg} / \mathrm{kg}$ MDMA, and none used lower, typical doses of less than $3 \mathrm{mg} / \mathrm{kg}$ MDMA. For most of these studies, the rodents were pretreated with MDMA and then trained and tested on the task at a later time point. Two of the 22 studies (Ros-Simó et al., 2013; Shortall et al., 2013), however, administered MDMA on the same day as the training and/or test trials, and these studies will be discussed first.

Instead of conducting only one training trial, Ros-Simó et al. (2013) trained adolescent male CD1 mice daily for 3 days. Mice were given two injections of $20 \mathrm{mg} / \mathrm{kg}$ i.p. MDMA, one directly after the third training trial and another 2 hours later. The test trial took place 72 hours later. The discrimination index of MDMA-treated mice was significantly less than that of saline controls. These results suggest that two doses of $20 \mathrm{mg} / \mathrm{kg}$ MDMA administered after memory acquisition leads to impairments in long-term recognition memory. Shortall et al. (2013) gave young adult male Lister Hooded rats a daily injection of $10 \mathrm{mg} / \mathrm{kg}$ i.p. MDMA for 2 consecutive days. The training trial began 30 minutes after the drug injection on the 2nd day, which was followed by a 2 -hour delay and then the test trial. Rats treated with MDMA did not explore the novel object more than the familiar object, and the discrimination ratio of MDMAtreated rats was significantly less than that of saline controls. This suggests that a dose of $10 \mathrm{mg} / \mathrm{kg}$ MDMA impairs long-term recognition memory when administered on the day before and the day of memory acquisition/retrieval. The findings of Ros-Simó et al. and Shortall et al. together suggest that MDMA impairs long-term recognition memory when on-drug during the memory consolidation phase.

Nawata et al. (2010) and Edut et al. (2011) gave adult male CD1 and ICR (respectively) mice a single injection of $10 \mathrm{mg} / \mathrm{kg}$ i.p. MDMA. Nawata et al. ran the training and test trials 1 or 7 days after MDMA treatment, with a 3 -hour delay between trials. The discrimination indexes of MDMA-treated mice and saline controls were comparable at both 1 and 7 days posttreatment. Edut et al. ran the training and test trials 7 or 30 days after MDMA treatment, with a 24-hour delay between trials. The discrimination indexes of MDMA-treated mice and saline controls were comparable at 7 days posttreatment, but MDMA-treated mice showed significant reductions relative to saline controls at 30 days posttreatment. Together, these findings suggest that pretreatment with a dose of $10 \mathrm{mg} / \mathrm{kg}$ MDMA has no effect on long-term recognition memory up to 1 week after treatment, but deficits may arise 30 days after treatment.

The following group of studies treated rats with multiple injections of MDMA on a single day prior to testing. Figure 7 depicts the findings of Rodsiri et al. (2011), which exemplify dose-dependent effects of MDMA on nonspatial learning and memory. Rodsiri et al. gave adult male Lister Hooded rats three injections of 3 or $6 \mathrm{mg} / \mathrm{kg}$ i.p. MDMA at 2-hour intervals. Rats were tested 2 weeks later, with a 2 -hour delay between trials. Rats given $3 \mathrm{mg} / \mathrm{kg}$ MDMA injections and saline controls did not exhibit differences in discrimination ratios, but the discrimination ratio of rats given $6 \mathrm{mg} / \mathrm{kg}$ MDMA injections was significantly less than that of saline controls (Fig. 7B). These findings indicate that there may be dose-dependent effects of MDMA on longterm recognition memory, as pretreatment with three doses of MDMA had no later effect at $3 \mathrm{mg} / \mathrm{kg}$ MDMA but led to memory impairments at $6 \mathrm{mg} / \mathrm{kg}$.

In a similar study, Piper et al. (2008) gave young adult male Sprague-Dawley rats four injections of $10 \mathrm{mg} / \mathrm{kg}$ s.c. MDMA at 1-hour intervals. Rats were tested at 15-17 and 17-19 days after MDMA treatment with shorter 15- and 60-minute delays, respectively. The discrimination ratios of MDMA-treated rats and saline controls did not significantly differ during either test. Cohen et al. (2005), Able et al. (2006), and Skelton et al. (2008) all gave adult male Sprague-Dawley rats four injections of $15 \mathrm{mg} / \mathrm{kg}$ s.c. MDMA at 2-hour intervals. Able et al. tested their rats 30 days after MDMA treatment and Cohen et al. and Skelton et al. tested their rats at least 5 weeks after MDMA treatment. All three studies used a 1-hour delay period and found that during the test trial MDMA-treated rats and saline controls explored the novel object more than the familiar object, and both groups explored the novel object for a similar amount of time. The findings from the above studies suggest that pretreatment with four doses of 10 or $15 \mathrm{mg} / \mathrm{kg}$ MDMA has no subsequent effect on short-term recognition memory.

The remaining studies treated animals with MDMA over several days prior to testing. Morley et al. (2001) and McGregor et al. (2003) treated adult male Wistar rats with MDMA for 2 consecutive days. Morley et al. gave rats one or four (at 1-hour intervals) daily injections of $5 \mathrm{mg} / \mathrm{kg}$ i.p. MDMA for 2 consecutive days. Rats were trained and tested 14 weeks later with a 15-minute delay and again 1 more week later with a 60-minute delay. The discrimination ratio of rats given one daily injection did not significantly differ from that of saline controls at either delay. The discrimination ratio of rats given four daily injections did not significantly differ from that of saline controls at the 60-minute delay, but was significantly less than saline controls at the 15-minute delay. McGregor et al. also gave rats four daily injections of $5 \mathrm{mg} / \mathrm{kg}$ i.p. MDMA at 1-hour intervals for 2 consecutive days. Approximately 10-12 weeks later, rats were tested with a 1-hour delay between trials. Two "preliminary" days of testing were conducted followed by a third identical day of testing that provided the reported data. The discrimination ratio of MDMA-treated rats was significantly less than that of saline controls. In all, the findings from these two studies suggest that treatment with one dose of $5 \mathrm{mg} / \mathrm{kg}$ 


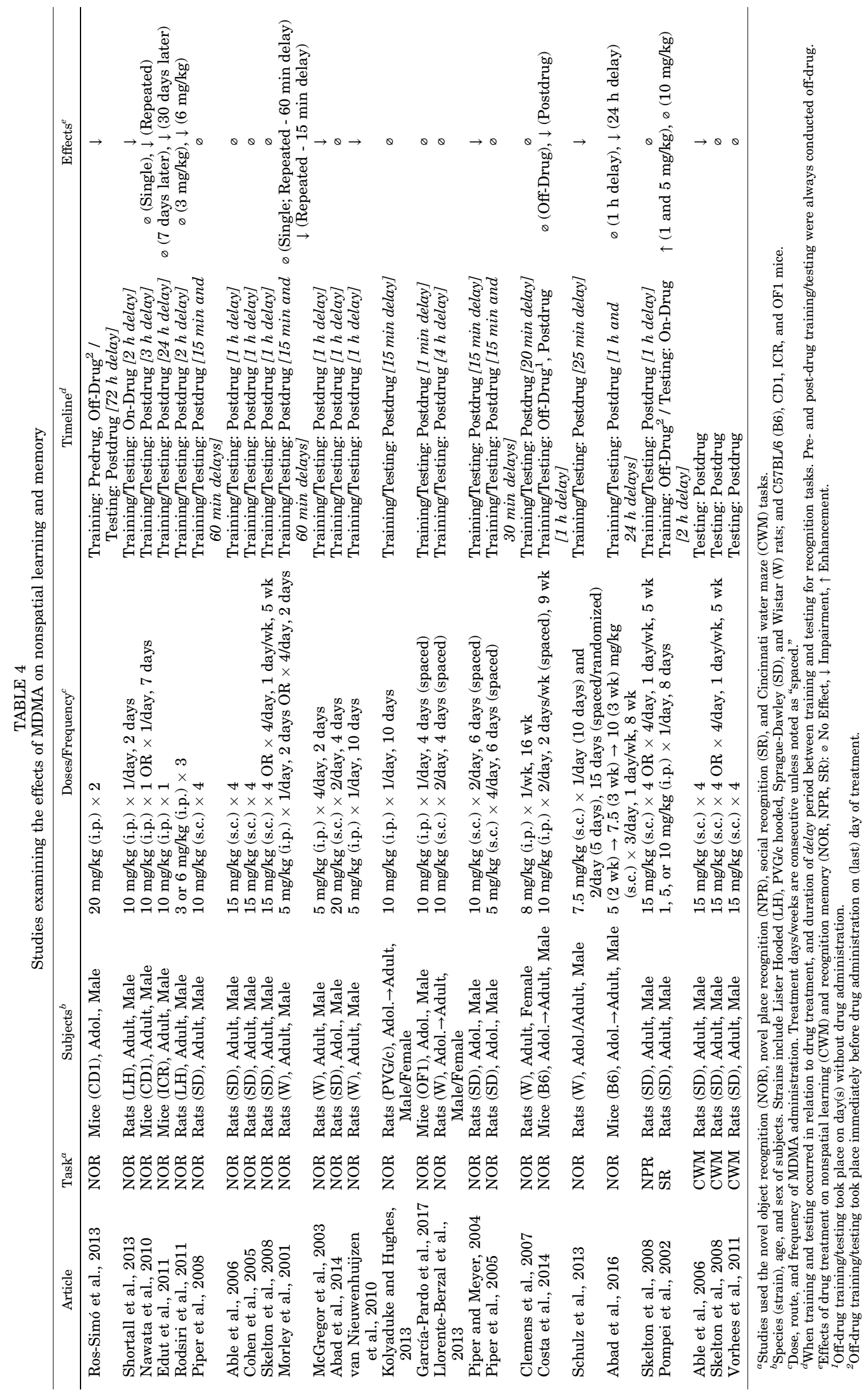



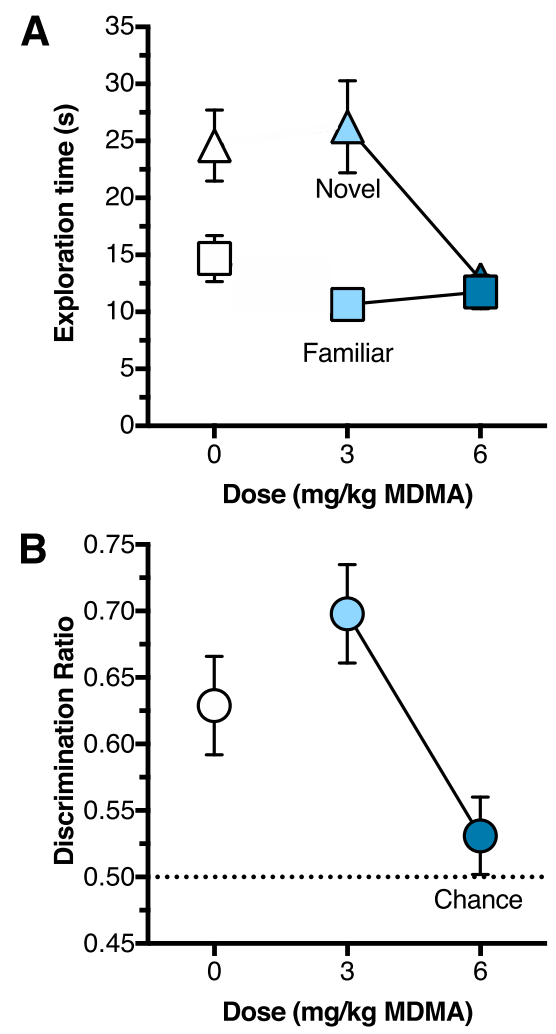

Fig. 7. Dose-dependent effects of MDMA on novel object recognition. Pretreatment with three doses of $3 \mathrm{mg} / \mathrm{kg}$ MDMA had no effect on exploration time of the novel and familiar objects during the test trial (A) or the discrimination ratio [novel/(novel+familiar)] (B), while pretreatment with three doses of $6 \mathrm{mg} / \mathrm{kg}$ MDMA significantly decreased exploration time of the novel object (A) and the discrimination ratio (B). Data redrawn with permission from Fig. 3, A and C in Rodsiri et al. (2011).

MDMA for 2 consecutive days has no subsequent effect on short-term recognition memory, while treatment with four doses of $5 \mathrm{mg} / \mathrm{kg}$ MDMA for 2 consecutive days may impair short-term recognition memory (with the exception of Morley et al.'s findings at the 60-minute delay).

Abad et al. (2014) gave adolescent male SpragueDawley rats two daily injections of $20 \mathrm{mg} / \mathrm{kg}$ s.c. MDMA for 4 consecutive days. Rats were tested 1 week later with a 1-hour delay between trials. MDMA-treated rats and saline controls explored the novel object for significantly more percent of the total exploration time than the familiar object. These findings indicate that pretreatment with repeated doses of $20 \mathrm{mg} / \mathrm{kg}$ MDMA may have no subsequent effect on short-term recognition memory.

In addition to testing a single dose of MDMA, Nawata et al. (2010) gave another group of adult male CD1 mice a daily injection of $10 \mathrm{mg} / \mathrm{kg}$ i.p. MDMA for 1 week. These mice were also tested 1 or 7 days later with a 3 -hour delay between trials. The discrimination index of MDMA-treated mice was significantly less than that of saline controls at 1 and 7 days posttreatment; however this value was significantly above chance at 1 day posttreatment. Although this study found that pretreatment with a single dose of $10 \mathrm{mg} / \mathrm{kg}$ MDMA had no effect on long-term recognition memory (see above), these additional findings suggest that pretreatment with repeated doses of $10 \mathrm{mg} / \mathrm{kg}$ MDMA may lead to long-term recognition memory deficits, with more pronounced deficits 1 week after treatment versus 1 day.

van Nieuwenhuijzen et al. (2010) and Kolyaduke and Hughes (2013) treated rats with a daily injection of MDMA for 10 consecutive days. van Nieuwenhuijzen et al. treated adult male Wistar rats with a daily dose of $5 \mathrm{mg} / \mathrm{kg}$ i.p. MDMA. Rats were tested 6 weeks after MDMA treatment with a 1-hour delay between trials. The discrimination ratio of MDMA-treated rats was significantly less than that of saline controls. Kolyaduke and Hughes treated male and female adolescent PVG/c hooded rats with a higher daily dose of $10 \mathrm{mg} / \mathrm{kg}$ i.p. MDMA during early adolescence (postnatal days 35-45) or late adolescence (postnatal days 45-55). Both groups were tested as adults at no less than 90 days old (around 5-8 weeks postdrug) with a short 15-minute delay between trials. The exploratory behavior of MDMAtreated rats and saline controls during the test trial led to similar discrimination indexes. The findings from these two studies demonstrate that pretreatment with repeated doses of MDMA may lead to short-term recognition memory impairments at doses of $5 \mathrm{mg} / \mathrm{kg}$ but surprisingly may have no effect at doses of $10 \mathrm{mg} / \mathrm{kg}$. This unexpected outcome may be because van Nieuwenhuijzen et al. and Kolyaduke and Hughes tested rats from different strains, ages, and sexes.

García-Pardo et al. (2017) gave adolescent male OF1 mice four injections of $10 \mathrm{mg} / \mathrm{kg}$ i.p. MDMA over 2 weeks, one on each of postnatal days $55,57,60$, and 62 . Testing took place on postnatal day 64, 2 days after MDMA treatment, with an ultra-short 1-minute delay between trials. The discrimination indexes of MDMA-treated mice and saline controls did not significantly differ, suggesting that pretreatment with four doses of $10 \mathrm{mg} / \mathrm{kg}$ MDMA may have no later effect on shortterm recognition memory.

The following group of studies treated adolescent rats with MDMA every 5 days (for a specific number of total days), with multiple injections given on each treatment day. Llorente-Berzal et al. (2013) gave male and female Wistar rats two injections of $10 \mathrm{mg} / \mathrm{kg}$ s.c. MDMA at a 4-hour interval every 5 days from postnatal day 30-45. Rats were tested 1 month later as adults on postnatal day 75 with a 4 -hour delay between trials. There were no significant differences between the discrimination indexes of MDMA-treated rats and saline controls. These findings demonstrate that pretreatment with repeated doses of $10 \mathrm{mg} / \mathrm{kg}$ has no subsequent effect on long-term recognition memory. Piper and Meyer (2004) gave male Sprague-Dawley rats two injections of $10 \mathrm{mg} / \mathrm{kg}$ s.c. MDMA at a 4-hour interval every 5 days from postnatal day 35 to 60 . Rats were tested 1 week later with a 15-minute delay between trials. The 
discrimination ratio of MDMA-treated rats was significantly less than that of saline controls. Piper et al. (2005) gave male Sprague-Dawley rats four injections of $5 \mathrm{mg} / \mathrm{kg}$ s.c. MDMA at 1 -hour intervals every 5 days from postnatal day 35 to 60 . Rats were tested 1 week later (postnatal day 67) with a 15-minute delay and again 1 to 2 days later (postnatal day 68 or 69 ) with a 30-minute delay. There were no significant differences between the discrimination ratios of MDMA-treated rats and saline controls under either delay condition. The findings from these two studies are mixed; the results of Piper et al. suggest that pretreatment with repeated doses of $5 \mathrm{mg} / \mathrm{kg}$ MDMA has no subsequent effect on short-term recognition memory, while the findings of Piper and Meyer suggest that pretreatment with repeated doses of $10 \mathrm{mg} / \mathrm{kg}$ produces short-term recognition memory deficits. Although the same cumulative daily doses were given, the difference in number and dose of injections (two daily injections of $10 \mathrm{mg} / \mathrm{kg}$ vs. four daily injections of $5 \mathrm{mg} / \mathrm{kg}$ ) could account for this discrepancy in findings.

The next group of studies treated animals with MDMA over several weeks. Clemens et al. (2007) gave adult female Wistar rats a single injection of $8 \mathrm{mg} / \mathrm{kg}$ i.p. MDMA once weekly for 16 weeks. Two days of testing were performed 8 weeks after MDMA treatment (with 1 day between the 2 days), and a 20 -minute delay was used for both tests. The discrimination ratio of MDMA-treated rats and saline controls did not significantly differ during either test. In addition to testing the effects of multiple MDMA injections on a single day (see above), Skelton et al. (2008) gave another group of adult male Sprague-Dawley rats the same treatment of four injections of $15 \mathrm{mg} / \mathrm{kg}$ s.c. MDMA at 2-hour intervals once weekly for 5 weeks. Again, rats were tested 5 weeks after the MDMA treatment with a 1-hour delay period. MDMA-treated rats and saline controls explored the novel object more than the familiar object, and there were no significant differences between groups. Costa et al. (2014) gave male C57BL/6 mice two injections of $10 \mathrm{mg} / \mathrm{kg}$ i.p. MDMA at a 4 - to 6-hour interval on the 2nd and 5th days of each week for 9 weeks (which started in adolescence and continued into adulthood). Mice completed a total of 5 days of testing-on the 6th day of drug treatment weeks 1,4 , and 9 and posttreatment weeks 2 and 3. A 1-hour delay was used for all five tests. The discrimination ratio of MDMA-treated mice and saline controls did not significantly differ during drug treatment weeks 1,4 , or 9 but was significantly reduced in MDMA-treated mice compared with saline controls during posttreatment weeks 2 and 3. The findings of Clemens et al. and Skelton et al. suggest that pretreatment with repeated doses of 8 or $15 \mathrm{mg} / \mathrm{kg}$ MDMA has no subsequent effect on short-term recognition memory. On the other hand, the findings of Costa et al., suggest that pretreatment with repeated doses of $10 \mathrm{mg} / \mathrm{kg}$ MDMA has no effect on short-term recognition memory 1 day posttreatment but produces impairments by 2 weeks posttreatment. This discrepancy may be because Costa et al. used mice as subjects rather than rats, or possibly because the mice were tested repeatedly throughout drug treatment.

Schulz et al. (2013) treated adolescent and adult male Wistar rats with a varying number of s.c. MDMA injections over 25 days. A single injection of $7.5 \mathrm{mg} / \mathrm{kg}$ MDMA was given on 10 of the 25 days, two injections of $7.5 \mathrm{mg} / \mathrm{kg}$ MDMA were given at a 4-hour interval on 5 of the 25 days, and no drug was given on 10 of the 25 days (treatment schedule was randomized). All rats were tested 10 days after the 25-day treatment period, and the adolescent rats were tested again as adults 6 weeks after the first test. Unlike the other NOR studies reviewed here, only one object was presented during the training trial, but the remainder of the methods were as described above. A 25-minute delay was placed between the training and test trials. The adult saline controls explored the familiar object significantly less in the test trial than the same object in the training trial, and significantly less than the novel object in the test trial. The adolescent saline controls, however, explored all three objects for a comparable amount of time during the first test. Because the adolescent saline controls did not exhibit normal recognition memory, the effects of MDMA cannot be accurately determined. During the second test, the adolescent saline controls explored the familiar object significantly less in the test trial than the same object in the training trial (but not significantly less than the novel object in the test trial). The adult and adolescent MDMAtreated rats explored all three objects for comparable amounts of time during all tests. These results suggest that pretreatment with repeated doses of $7.5 \mathrm{mg} / \mathrm{kg}$ MDMA during adulthood impairs short-term recognition memory, and the same treatment during adolescence may produce some deficits as in adults (but the effects during adolescence cannot be determined).

Abad et al. (2016) gave adolescent male C57BL/6 mice three injections of s.c. MDMA at 1-hour intervals once weekly for 8 weeks-at doses of $5 \mathrm{mg} / \mathrm{kg}$ MDMA for the first 2 weeks, $7.5 \mathrm{mg} / \mathrm{kg}$ MDMA for the next 3 weeks, and $10 \mathrm{mg} / \mathrm{kg}$ MDMA for the last 3 weeks. Mice were tested as adults, 1 week and 3 months after MDMA treatment with 1- and 24-hour delays. The discrimination indexes of MDMA-treated mice and saline controls did not significantly differ with a 1-hour delay but was significantly reduced in MDMA-treated mice compared with saline controls with a 24-hour delay at both 1 week and 3 months posttreatment. These findings suggest that pretreatment with repeated doses of MDMA (increasing from 5 to $10 \mathrm{mg} / \mathrm{kg}$ ) has no subsequent effect on short-term recognition memory but may lead to longterm recognition memory deficits.

a. Novel object recognition variations. Pompei et al. (2002) and Skelton et al. (2008) tested the effects of MDMA on a novel place recognition (NPR) test and a 
social recognition (SR) test, respectively, and these studies are outlined in Table 4 . The procedures of these tests are similar to the NOR test, but the NPR test assesses recognition memory of an object's orientation and the SR test assesses recognition memory of another animal. In the NPR test, the two objects presented in the training trial are identical to those presented in the test trial, but in the test trial one object is placed $90^{\circ}$ clockwise compared with its location in the training trial. The exploration time of each object is recorded during both trials, and recognition memory is revealed by significantly less exploration of the non-rotated object compared with the rotated object in the test trial or either object in the training trial. In the SR test, a juvenile rat is introduced into the cage of an adult male rat (the test subject) in the training trial, and the same juvenile rat is reintroduced into the cage of the adult in the test trial. The time that the adult rat spends exploring the juvenile rat (i.e., nosing, sniffing, grooming, pawing, or close following) is recorded during both trials. A decrease in exploration time from the training trial to the test trial reflects recognition memory of the juvenile rat.

Skelton et al. (2008) gave adult male Sprague-Dawley rats four injections of $15 \mathrm{mg} / \mathrm{kg}$ s.c. MDMA at 2-hour intervals on a single day or once weekly for 5 weeks. Testing took place 40 days after MDMA treatment with a 1-hour delay between trials. MDMA-treated rats did not significantly differ from saline controls on any measure of object exploration. This suggests that pretreatment with repeated doses of $15 \mathrm{mg} / \mathrm{kg}$ MDMA has no later effect on short-term recognition memory.

Pompei et al. (2002) gave adult male Sprague-Dawley rats a daily injection of 1,5 , or $10 \mathrm{mg} / \mathrm{kg}$ i.p. MDMA for 8 consecutive days. The SR test took place on the 8th day of MDMA treatment. Rats were given their final MDMA injection immediately after the training trial and tested after a 120-minute delay. All groups explored the juvenile rat less in the test trial than in the training trial. This decrease in exploration time was significantly enhanced in rats given 1 or $5 \mathrm{mg} / \mathrm{kg}$ MDMA injections compared with saline controls and did not significantly differ between rats given $10 \mathrm{mg} / \mathrm{kg}$ MDMA injections and saline controls. These findings reveal that pretreatment with repeated doses MDMA may enhance short-term recognition memory at doses of 1 or $5 \mathrm{mg} / \mathrm{kg}$ MDMA (although the authors' conclusions are inconsistent with their graphical data) and may have no effect on short-term recognition memory at a dose of $10 \mathrm{mg} / \mathrm{kg}$ MDMA when memory consolidation and retrieval occur on-drug.

2. Other Nonspatial Tasks.

a. Cincinnati water maze. The Cincinnati water maze (CWM) task (Vorhees, 1987) is a nonspatial variation of the MWM task. The CWM is a 9-unit multiple T-maze that is filled with water. Animals are required to swim through the maze to escape onto a hidden platform. The maze is configured so that the path to the goal runs along only the long arms of each T. Testing is performed under red light or complete darkness to limit or eliminate the use of distal visual cues, and therefore animals must rely on egocentric cues to navigate to the hidden platform. Typically, each animal completes two trials per day for several days. The starting location of the animal and the platform location remain constant over all trials and days. The escape latency (i.e., time taken to reach the hidden platform) and number of errors (i.e., entries into one of the short arms of a T) are recorded during all trials. A decrease in escape latency/number of errors over the days of testing reflects nonspatial learning of the platform location.

Three studies assessed the effects of MDMA on the CWM task, which are listed in Table 4. Prior to testing, Able et al. (2006), Skelton et al. (2008), and Vorhees et al. (2011) all gave adult male Sprague-Dawley rats four injections of $15 \mathrm{mg} / \mathrm{kg}$ s.c. MDMA at 2-hour intervals on a single day, and Skelton et al. gave another group of rats this same treatment once weekly for 5 weeks. Able et al. began testing 4 days after MDMA treatment and tested rats for a total of 6 days. The rate at which the number of errors and escape latency of MDMA-treated rats decreased over the 6 testing days was slower than that of saline controls. Specifically, MDMA-treated rats made significantly more errors than saline controls on days 4 and 5 , and a trend toward significantly more errors on day 6 . Skelton et al. began testing 1 week after MDMA treatment and tested rats for a total of 6 days. While the average number of errors and the average escape latency of MDMA-treated rats (both single day and weekly) were significantly higher than saline controls, these measures decreased at a similar rate over the 6 testing days in all three groups. Both groups of MDMA-treated rats therefore exhibited performance impairments but not learning impairments. Vorhees et al. began testing 2 weeks after MDMA treatment and tested rats for a total of 21 days. The number of errors and escape latency of MDMAtreated rats and saline controls decreased at a similar rate over the 21 testing days, and the overall average number of errors and average escape latency also did not significantly differ between groups. The findings from these three studies reveal pretreatment with repeated doses of $15 \mathrm{mg} / \mathrm{kg}$ MDMA has no effect on nonspatial learning when tested 1 week or more after treatment but produces nonspatial learning impairments when testing begins less than 1 week after treatment.

\section{E. Fear-Motivated Learning and Memory}

1. Passive Avoidance. The passive avoidance (PA) task is a fear-motivated task that is used to evaluate learning and memory in rodents. A common version of this task is the step-through PA task (Jarvik and Kopp, 1967), which takes place in a two-compartment chamber consisting of one bright (e.g., illuminated, white 
walls) compartment and one dark (e.g., nonilluminated, black walls) compartment connected by a guillotine door. The task requires animals to inhibit their natural tendency to prefer dark areas/avoid bright areas to avoid an aversive stimulus. Each animal is first habituated to both compartments of the chamber as well as crossing through the guillotine door prior to training. Training is usually completed in a single trial, which begins by placing the animal in the bright compartment with the guillotine door closed. After a brief period, the guillotine door is opened, and once the animal enters the dark component, the guillotine door is closed, and the animal receives an inescapable foot shock. Testing typically takes place 24 hours after training, during which the animal is returned to the bright compartment, and again the guillotine door is opened after a brief period. If the animal remembers that entering the dark compartment lead to a foot shock during training, then the animal will inhibit its natural tendency to enter the dark compartment.

The step-through latency (i.e., time taken to enter the dark compartment once the guillotine door is opened) is measured during both the training and test trials, and the cutoff time/maximum latency recorded is usually 300 seconds. A significant increase in step-through latency from training to testing reflects normal memory retention, whereas the lack of this increase reflects memory deficits. A significantly lower step-through latency relative to normal during testing is also an indicator of memory deficits. The type of memory measured here involves both explicit memory (i.e., association with the context) and implicit memory (i.e., operant conditioning to the shock).

Table 5 lists the 12 studies that explored the effects of MDMA on the PA task. Eleven of these studies conducted the step-through PA task, whereas only one study (McNamara et al., 1995) performed another version, the step-down PA task (methods described below). The animals from most of these studies were treated with MDMA 1 or more days prior training, 30 minutes before training, and/or immediately after training. All of the studies evaluated long-term memory as delays of 24 hours or more were placed between the training and test trials.

Moyano et al. $(2004,2005)$ and Barrionuevo et al. (2000) all tested the effects of on-drug training. Adult male Wistar rats were given a single injection of MDMA 30 minutes before training and then tested 24 hours later. Moyano et al. $(2004,2005)$ found that rats injected with $10 \mathrm{mg} / \mathrm{kg}$ i.p. MDMA before training exhibited a significantly lower step-through latency than saline controls during testing, and Barrionuevo et al. (2000) found the same results with a dose of $20 \mathrm{mg} / \mathrm{kg}$ i.p. MDMA. These findings suggest that doses of 10 and $20 \mathrm{mg} / \mathrm{kg}$ MDMA produce long-term memory deficits when memory acquisition occurs on-drug.

Shariati et al. (2014) and Budzynska et al. (2017) explored the effects of administering the drug immediately after training. Figure 8 exhibits the findings of Budzynska et al., which exemplify the dosedependent effects of MDMA on fear-motivated learning and memory. Budzynska et al. gave adult male Swiss Webster mice a single injection of $1,2.5,5$, or $10 \mathrm{mg} / \mathrm{kg}$ i.p. MDMA immediately after training and tested the mice 24 hours later. The step-through latency of mice treated with 1 or $10 \mathrm{mg} / \mathrm{kg}$ MDMA did not significantly differ from that of saline controls, while mice treated with 2.5 or $5 \mathrm{mg} / \mathrm{kg}$ MDMA showed a significantly higher step-through latency than saline controls. Shariati et al. tested two groups of adult male Wistar rats-one group received a single injection of $10 \mathrm{mg} / \mathrm{kg}$ i.p. MDMA following two training trials, and another group received a daily injection of $10 \mathrm{mg} / \mathrm{kg}$ i.p. MDMA on 2 consecutive days per week for 3 weeks, with the last injection administered immediately following training. All rats were tested 24 hours after MDMA treatment, and both groups of MDMA-treated rats demonstrated a significantly shorter step-through latency than saline controls. Together, the above results indicate that administering MDMA immediately after memory acquisition has no effect on long-term memory retention at a dose of $1 \mathrm{mg} / \mathrm{kg}$ but enhances long-term memory retention at doses of 2.5 or $5 \mathrm{mg} / \mathrm{kg}$. The findings regarding a dose of $10 \mathrm{mg} / \mathrm{kg}$ MDMA are mixed, as Budzynska et al. found that this dose has no effect on long-term memory retention, while Shariati et al. found that single or repeated administration of this dose impairs long-term memory retention. This discrepancy could be due to the use of different species (mice vs. rats) or the number of training trials (one vs. two).

Jahanshahi et al. (2013) also treated young adult male Wistar rats with MDMA between training and testing, but the MDMA treatment began 24 hours after two training trials and lasted for 4 weeks. Rats were given three injections of $2.5,5$, or $10 \mathrm{mg} / \mathrm{kg}$ i.p) MDMA at 3 -hour intervals once weekly for 4 weeks. Testing took place following drug treatment, and all three groups of MDMA-treated rats exhibited a significantly longer step-through latency than saline controls. These results reveal that treatment with doses of $2.5,5$, and $10 \mathrm{mg} / \mathrm{kg}$ MDMA after acquisition may enhance longterm memory retention.

The next group of studies treated animals with a specific MDMA regimen prior to training and testing. Timár et al. (2003) and Murnane et al. (2012) gave animals four injections of MDMA at 2-hour intervals. Timár et al. gave adolescent male Wistar rats doses of $10 \mathrm{mg} / \mathrm{kg}$ s.c. MDMA and tested them 3 days and 4 weeks after MDMA treatment, with 48 hours separating training and testing. During both tests, MDMA-treated rats and saline controls did not significantly differ in stepthrough latency. Murnane et al. gave adolescent male Swiss Webster mice doses of 10 or $20 \mathrm{mg} / \mathrm{kg}$ i.p. MDMA. Rats were trained 2 days after MDMA treatment and tested 2 days after training. Again, MDMA-treated rats 
TABLE 5

Studies examining the effects of MDMA on fear-motivated learning and memory

\begin{tabular}{|c|c|c|c|c|c|}
\hline Article & Task $^{a}$ & Subjects $^{b}$ & Doses/Frequency $^{c}$ & Timeline $^{d}$ & Effects $^{e}$ \\
\hline Moyano et al., 2004 & $\mathrm{PA}$ & Rats (W), Adult, Male & $10 \mathrm{mg} / \mathrm{kg}$ (i.p.) $\times 1$ & $\begin{array}{l}\text { Training: On-Drug } \\
\text { Testing: Postdrug }\end{array}$ & $\downarrow$ \\
\hline Moyano et al., 2005 & PA & Rats (W), Adult, Male & $\begin{array}{l}10 \mathrm{mg} / \mathrm{kg} \text { (i.p.) } \times 1 \mathrm{AND} / \mathrm{OR} \\
\quad \times 2 / \text { day, } 4 \text { days }\end{array}$ & $\begin{array}{l}\text { Training: On-Drug (Single), } \\
\text { Postdrug (Repeated) } \\
\text { Testing: Postdrug }\end{array}$ & $\begin{array}{c}\downarrow(\text { Single }) \\
\varnothing \text { (Repeated) }\end{array}$ \\
\hline Barrionuevo et al., 2000 & PA & Rats (W), Adult, Male & $20 \mathrm{mg} / \mathrm{kg}$ (i.p.) $\times 1$ & $\begin{array}{l}\text { Training: On-Drug } \\
\text { Testing: Postdrug }\end{array}$ & $\downarrow$ \\
\hline Budzynska et al., 2017 & PA & Mice (SW), Adult, Male & $1,2.5,5$, or $10 \mathrm{mg} / \mathrm{kg}$ (i.p.) $\times 1$ & $\begin{array}{l}\text { Training: Off-Drug } \\
\text { Testing: Postdrug }\end{array}$ & $\begin{array}{l}\uparrow(2.5 \text { and } 5 \mathrm{mg} / \mathrm{kg}) \\
\varnothing(1 \text { and } 10 \mathrm{mg} / \mathrm{kg})\end{array}$ \\
\hline Shariati et al., 2014 & PA & Rats (W), Adult, Male & $\begin{array}{l}10 \mathrm{mg} / \mathrm{kg} \text { (i.p. }) \times 1 \mathrm{OR} \times 1 / \text { day } \\
2 \mathrm{day} / \mathrm{wk}, 3 \mathrm{wk}\end{array}$ & $\begin{array}{l}\text { Training: Off-Drug } \\
\text { Testing: Postdrug }\end{array}$ & $\downarrow$ \\
\hline Jahanshahi et al., 2013 & PA & Rats (W), Adult, Male & $\begin{array}{l}2.5,5 \text {, or } 10 \mathrm{mg} / \mathrm{kg}(\text { i.p. }) \times 3 / \text { day, } \\
1 \text { day } / \mathrm{wk}, 4 \mathrm{wk}\end{array}$ & $\begin{array}{l}\text { Training: Predrug } \\
\text { Testing: Postdrug }\end{array}$ & $\uparrow$ \\
\hline Timár et al., 2003 & PA & Rats (W), Adol., Male & $10 \mathrm{mg} / \mathrm{kg}$ (s.c.) $\times 4$ & Training/Testing: Postdrug & $\varnothing$ \\
\hline Murnane et al., 2012 & PA & Mice (SW), Adol., Male & 10 or $20 \mathrm{mg} / \mathrm{kg}$ (i.p.) $\times 4$ & Training/Testing: Postdrug & $\varnothing$ \\
\hline García-Pardo et al., 2015 & PA & Mice (OF1), Adol., Male & $\begin{array}{l}10 \mathrm{mg} / \mathrm{kg}(\text { i.p. }) \\
\text { (spaced) }\end{array}$ & Training/Testing: Postdrug & $\downarrow$ \\
\hline García-Pardo et al., 2017 & PA & Mice (OF1), Adol., Male & $\begin{array}{l}10 \mathrm{mg} / \mathrm{kg}(\text { i.p. }) \\
\text { (spaced) }\end{array}$ & Training/Testing: Postdrug & $\downarrow$ \\
\hline $\begin{array}{l}\text { Rodríguez-Arias et al., } \\
2011\end{array}$ & PA & Mice (OF1), Adol., Male & $\begin{array}{l}10 \text { or } 20 \mathrm{mg} / \mathrm{kg}(\text { i.p. }) \times 2 / \text { day, } \\
2 \text { days/wk, } 2 \text { wk }\end{array}$ & Training/Testing: Postdrug & $\varnothing$ \\
\hline McNamara et al., 1995 & PA & Rats (SD), Adult, Male & $\begin{array}{l}5,10 \text {, or } 20 \mathrm{mg} / \mathrm{kg} \text { (i.p.) } \times 2 / \text { day, } \\
4 \text { days }\end{array}$ & Testing: Postdrug & $\varnothing$ \\
\hline Shortall et al., 2013 & $\mathrm{FC}$ & Rats (LH), Adult, Male & $\begin{array}{l}10 \mathrm{mg} / \mathrm{kg} \text { (i.p.) } \times \text { (spaced) } \\
\text { 1/day, } 3 \text { days }\end{array}$ & $\begin{array}{l}\text { Training: Off-Drug }{ }^{2} \\
\text { Testing: Postdrug }\end{array}$ & $\varnothing$ \\
\hline Johansson et al., 2015 & $\mathrm{FC}$ & Mice (ICR), Adult, Male & $20 \mathrm{mg} / \mathrm{kg}$ (i.p.) $\times 2$ & Training/Testing: Postdrug & $\downarrow$ \\
\hline
\end{tabular}

${ }^{a}$ Studies used the passive avoidance (PA) and contextual fear conditioning (FC) tasks.

${ }^{b}$ Species (strain), age, and sex of subjects. Strains include Lister Hooded (LH), Sprague-Dawley (SD), and Wistar (W) rats; and ICR, OF1, and Swiss Webster (SW) mice. ${ }^{c}$ Dose, route, and frequency of MDMA administration. Treatment days/weeks are consecutive unless noted as "spaced."

${ }^{d}$ When training and testing occurred in relation to drug treatment. Pre- and post-drug training/testing were always conducted off-drug.

${ }^{e}$ Effects of drug treatment on learning and memory: $\varnothing$ No Effect, $\downarrow$ Impairment, $\uparrow$ Enhancement.

${ }^{2}$ Off-drug training/testing took place immediately before drug administration on (last) day of treatment.

and saline controls did not significantly differ in stepthrough latency. In all, these studies reveal that pretreatment with four doses of 10 or $20 \mathrm{mg} / \mathrm{kg}$ MDMA has no subsequent effect on long-term memory retention.

In addition to testing the effects of on-drug training (see above), Moyano et al. (2005) gave another group of adult male Wistar rats two daily injections of $10 \mathrm{mg} / \mathrm{kg}$ i.p. MDMA for 4 consecutive days. Rats were trained 1 week after MDMA treatment and tested 24 hours after training. The step-through latency of MDMAtreated rats and saline controls did not significantly differ. Moyano et al. tested an additional group, which received both of the previously described treatments,

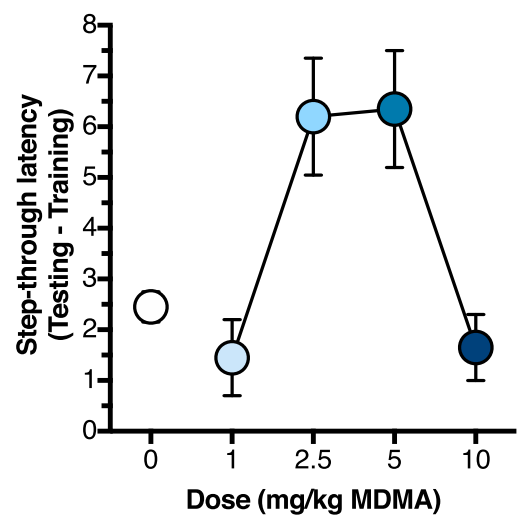

Fig. 8. Dose-dependent effects of MDMA on passive avoidance. Posttraining doses of 2.5 and $5 \mathrm{mg} / \mathrm{kg}$ MDMA enhanced long-term memory, while posttraining doses of 1 and $10 \mathrm{mg} / \mathrm{kg}$ MDMA had no effect on long-term memory. Data redrawn with permission from Fig. 5 in Budzynska et al. (2017). two daily injections of $10 \mathrm{mg} / \mathrm{kg}$ i.p. MDMA for 4 consecutive days, 1 week prior to training, and a single injection of $10 \mathrm{mg} / \mathrm{kg}$ i.p. MDMA, 30 minutes before training. This group of MDMA-treated rats exhibited a significantly slower step-through latency than saline controls. Together these findings suggest that pretreatment with repeated doses of $10 \mathrm{mg} / \mathrm{kg}$ MDMA has no subsequent effect on long-term memory retention, while a single dose of $10 \mathrm{mg} / \mathrm{kg}$ MDMA impairs long-term memory retention when memory acquisition occurs on-drug.

García-Pardo et al. (2015, 2017) gave adolescent male OF 1 mice a single injection of $10 \mathrm{mg} / \mathrm{kg}$ i.p. MDMA on four alternating days ( 2 to 3 days between each injection). García-Pardo et al. (2015) trained their mice 4 days after MDMA treatment and García-Pardo et al. (2017) trained their mice 5 days after MDMA treatment, and all mice were tested at 24 hours and 1 week after training. Both studies had identical findings-the step-through latency of MDMA-treated mice did not change significantly from training to testing (24 hours and 1 week later), and the step-through latency of MDMA-treated mice was significantly shorter than that of saline controls at 1 week after training (but not at 24 hours). These findings suggest that pretreatment with four doses of $10 \mathrm{mg} / \mathrm{kg}$ MDMA leads to long-term memory impairments that are more significant at 1 week versus 24 hours after acquisition.

Rodríguez-Arias et al. (2011) gave adolescent male OF1 mice two daily injections of 10 or $20 \mathrm{mg} / \mathrm{kg}$ i.p. MDMA at a 4-hour interval on 2 consecutive days per 
week for 2 weeks. Mice were trained 22 days after MDMA treatment and tested 24 hours later. The stepthrough latency of MDMA-treated mice and saline controls did not significantly differ, revealing that pretreatment with repeated doses of 10 or $20 \mathrm{mg} / \mathrm{kg}$ MDMA may have no subsequent effect on long-term memory.

Unique to the other studies reviewed here, McNamara et al. (1995) tested adult male Sprague-Dawley rats on the step-down version of the PA task. Rats were given two daily injections of 5,10 , or $20 \mathrm{mg} / \mathrm{kg}$ i.p. MDMA at a 12-hour interval for 4 consecutive days and tested 6 days later. On each trial, a rat was placed on a triangular platform that was mounted above a grid floor. When the rat stepped off the platform, it received a foot shock. Repeated trials were conducted until the rat remained on the platform for at least 2 minutes. MDMA-treated rats and saline controls did not significantly differ in the number of trials it took for them to reach this threshold, suggesting that pretreatment with repeated doses of 5, 10 , or $20 \mathrm{mg} / \mathrm{kg}$ MDMA has no effect on memory function.

2. Contextual Fear Conditioning. The contextual fear conditioning (FC) paradigm (Fanselow, 1986; Anagnostaras et al., 1999, 2010, 2015) is an efficient model to measure hippocampal-dependent learning and memory in rodents. In contextual FC, an animal learns to associate an aversive stimulus (typically a foot shock) with a specific context. As a result, the initially neutral context elicits a fear response in the animal. In rodents, this fear response arises as freezing behavior, which is a measure of contextual fear memory. Thus a significant decrease in freezing is indicative of memory deficits. Two studies explored the effects of MDMA on contextual FC and are outlined in Table 5. These studies used two different variations of the typical FC procedure, which are described below.

Shortall et al. (2013) conducted a "conditioned emotional response" task, which is a variation of the contextual FC task. The task took place in a two-compartment box that consisted of a dark side and a light side separated by a computer-operated door. For training, each animal was placed on the light side of the box, and after 30 seconds the door was opened. When the animal entered the dark side of the box, the door was closed, and the animal was subject to two light/tone and footshock pairings (a 5 -second light and tone cue that coterminated with a 1-second foot shock) with a 1-minute interval between pairings. For testing, each animal was returned to the dark side of the box, and freezing was measured for 5-minute without any light/tone or foot shock presentation. In this study, young adult male Lister Hooded rats were given a single injection of $10 \mathrm{mg} / \mathrm{kg}$ i.p. MDMA on experiment days 1,2 , and 8 . Rats were trained on experiment day 8 immediately prior to MDMA treatment and tested 24 hours later. MDMAtreated rats and saline controls did not significantly differ in freezing time during the test. These results suggest that treatment with repeated doses of $10 \mathrm{mg} / \mathrm{kg}$ MDMA prior to and following memory acquisition has no effect on longterm context memory.

Johansson et al. (2015) performed another variation of the contextual FC task, contextual fear discrimination. This task took place in two contexts, Context A and Context B, which differed by a variety of sensory modalities (different floor/walls, noise, illumination, and scent). Training took place in Context A, and each animal completed one training trial per day for 3 days. For each trial, the animal was introduced to Context A, and after a 3-minute baseline period they received a 2 -second foot shock and then remained in the context for an additional 15 seconds. Testing began 3 days later, and each animal was exposed to both Context A and Context B on all 12 days of testing (random order of exposure with a 1.5- to 2-hour interval between each exposure). The trials in Context A were identical to training (3-minute baseline +2 -second foot shock + 15-second postshock period), and the trials in Context $B$ were 3 minutes in duration with no foot shock. In this study, adult male ICR mice were given two injections of $20 \mathrm{mg} / \mathrm{kg}$ i.p. MDMA at a 2-hour interval, 4 days prior to training. The freezing behavior of saline controls increased significantly in Context $\mathrm{A}$ and decreased significantly in Context B over the 12 days of testing and overall was significantly greater in Context A than in Context $\mathrm{B}$ on the last 8 days of testing. Conversely, the freezing behavior of MDMA-treated rats remained constant over the 12 days of testing and did not significantly differ between Context A and Context B. These results suggest that pretreatment with two doses of $20 \mathrm{mg} / \mathrm{kg}$ MDMA leads to later deficits in learning to discriminate between two contexts.

\section{Analysis of Findings}

This review includes a total of 90 experiments on the cognitive effects of MDMA in animals. Clearly, findings are mixed on whether MDMA impairs, enhances, or has no effect on cognition. Figure 9 depicts the breakdown of findings from all experiments reviewed here. Of the 90 total experiments, MDMA produced cognitive enhancements in one experiment, mixed parameterdependent cognitive enhancements/no effects in three experiments, no cognitive effects in 46 experiments, mixed parameter-dependent impairments/no effects in 17 experiments, and cognitive impairments in 23 experiments. $^{2}$ MDMA produced cognitive impairments in

\footnotetext{
${ }^{2}$ All experiments in the current review were categorized by whether MDMA treatment produced: 1) impairments, 2) a mix of impairments and no effects, 3) no effects, 4) a mix of no effects and enhancements, 5) enhancements. The "mixed" categories (2 and 4) include experiments with findings that are inconsistent across different treatment and/or task parameters (e.g., MDMA dose, frequency of drug administration, experimental timeline, etc.). See Tables 1-5 ("Effects" columns) for examples of experiments with mixed findings.
} 


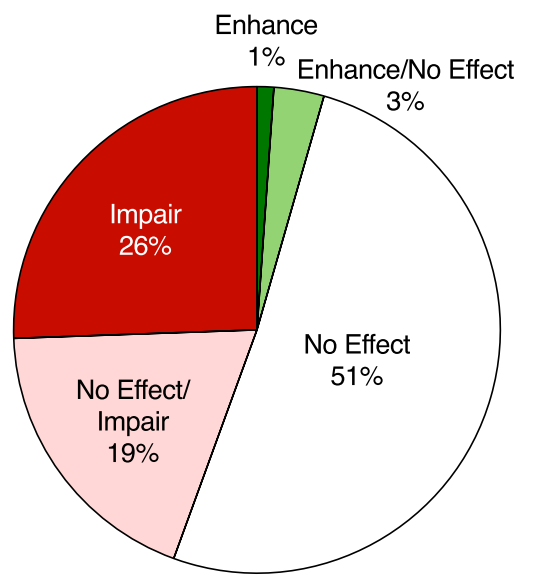

All Experiments

Fig. 9. Breakdown of findings from all 90 experiments. Most experiments (46 out of 90) found no effects of MDMA on cognition.

only 40 of the 90 experiments (44.4\%), and in 17 of these experiments only certain parameters led to impairments. Thus MDMA did not influence cognition in the majority of these experiments, even when dose is ignored. MDMA did not produce any cognitive impairments in 50 of the 90 experiments (55.6\%), and an additional 17 experiments showed negligible effects under certain parameters. Therefore, some negligible effects were found in $74.4 \%$ of all experiments. To better understand these findings, we further analyze the factors that may modulate the cognitive effects of MDMA.

\section{A. Findings by Cognitive Domain}

We first analyze the findings within each major section -attention (2 studies), working memory (23 studies), spatial learning and memory (24 studies), nonspatial learning and memory (27 studies), and fear-motivated learning and memory (14 studies). Figure 10 illustrates the breakdown of findings by cognitive domain.

The effects of MDMA on attention were examined in two studies on the 5-CSRT task (Table 1). Taffe et al. (2001) found that MDMA produced attention deficits on-drug but no effects postdrug, and Taffe et al. (2002) found that MDMA produced no effects postdrug. Therefore, it appears that MDMA produces attention deficits when on-drug but not following drug treatment. However, there are not enough studies to reach a definitive conclusion of these findings.

The effects of MDMA on working memory were examined in 23 studies using the DMS/DNMS, OST, SA/DA, RAM, or MWM tasks (Table 2). Of these 23 studies, 19 found no effects on working memory, three found no effects at doses of $1.25-3 \mathrm{mg} / \mathrm{kg}$ and working memory impairments at doses of $3-5 \mathrm{mg} / \mathrm{kg}$, and one found working memory impairments only (Fig. 10A). Thus the majority of these studies found that MDMA treatment does not alter working memory.
While Braida et al. (2002), Young et al. (2005), and Kay et al. (2010) found that doses of $3-5 \mathrm{mg} / \mathrm{kg}$ impair spatial working memory while on-drug, most of the studies with similar testing parameters found no effects on spatial working memory. In Wistar rats, the on-drug effects appear to be dose-dependent, as doses of 1$2.25 \mathrm{mg} / \mathrm{kg}$ had no effects but doses of $3-5 \mathrm{mg} / \mathrm{kg}$ impaired spatial working memory (Braida et al., 2002; Young et al., 2005). Marston et al. (1999) found that treatment with doses of $10-20 \mathrm{mg} / \mathrm{kg}$ leads to postdrug working memory impairments, but several other studies concluded that similar treatments lead to no postdrug effects. In all, it appears that MDMA generally has no on-drug or postdrug impact on working memory.

The effects of MDMA on spatial learning and memory were explored in 24 studies using the MWM, RAM, and SD tasks (Table 3). Of these 24 studies, one found spatial learning enhancements and no effect on spatial reference memory, eight found no effects on spatial learning and memory, six found a mix of no effects and spatial learning and memory impairments (impairments found with doses of $3-5.6 \mathrm{mg} / \mathrm{kg}$ but not $0.3-$ $1.7 \mathrm{mg} / \mathrm{kg}$, spatial reference memory but not spatial learning, or later postdrug testing), and nine found spatial learning and memory impairments only (Fig. 10B). Here, the slight majority of studies found impairments, but the true effect of MDMA on spatial learning and memory remains unclear. The effects of on-drug training and/or testing appear to be dose-dependent yet differ by strain. In Wistar rats, doses of $1.25-5 \mathrm{mg} / \mathrm{kg}$ had no effects (Young et al., 2005) and doses of 5-15 produced impairments (Taghizadeh et al., 2016). In Sprague-Dawley rats, doses of $0.3-1.7 \mathrm{mg} / \mathrm{kg}$ had no effects (Kay et al., 2010; Galizio et al., 2014) and doses of $3-5.6 \mathrm{mg} / \mathrm{kg}$ produced impairments (Kay et al., 2010, 2011; Harper et al., 2013; Galizio et al., 2014). The postdrug findings remain mixed, as there is evidence that highly similar/identical experimental designs produced dissimilar effects. In the MWM studies, spatial reference memory during the probe test appears to be more sensitive to impairment than spatial learning during acquisition. Overall, these findings reveal that the effects of MDMA on spatial learning and memory while on-drug may be dose-dependent but the postdrug effects are still unclear.

The effects of MDMA on nonspatial learning and memory were explored in 27 studies using the NOR, NPR, SR, and CWM tasks (Table 4). Of these 27 studies, one found nonspatial learning and memory enhancements at doses of 1 and $5 \mathrm{mg} / \mathrm{kg}$ and no effects at a dose of $10 \mathrm{mg} / \mathrm{kg}, 13$ found no effects, 6 found a mix of no effects and nonspatial learning and memory impairments (impairments found with a dose of $6 \mathrm{mg} / \mathrm{kg}$ but not $3 \mathrm{mg} / \mathrm{kg}$, more drug administrations, longer delay periods, or later postdrug testing), and 7 found nonspatial learning and memory impairments only 

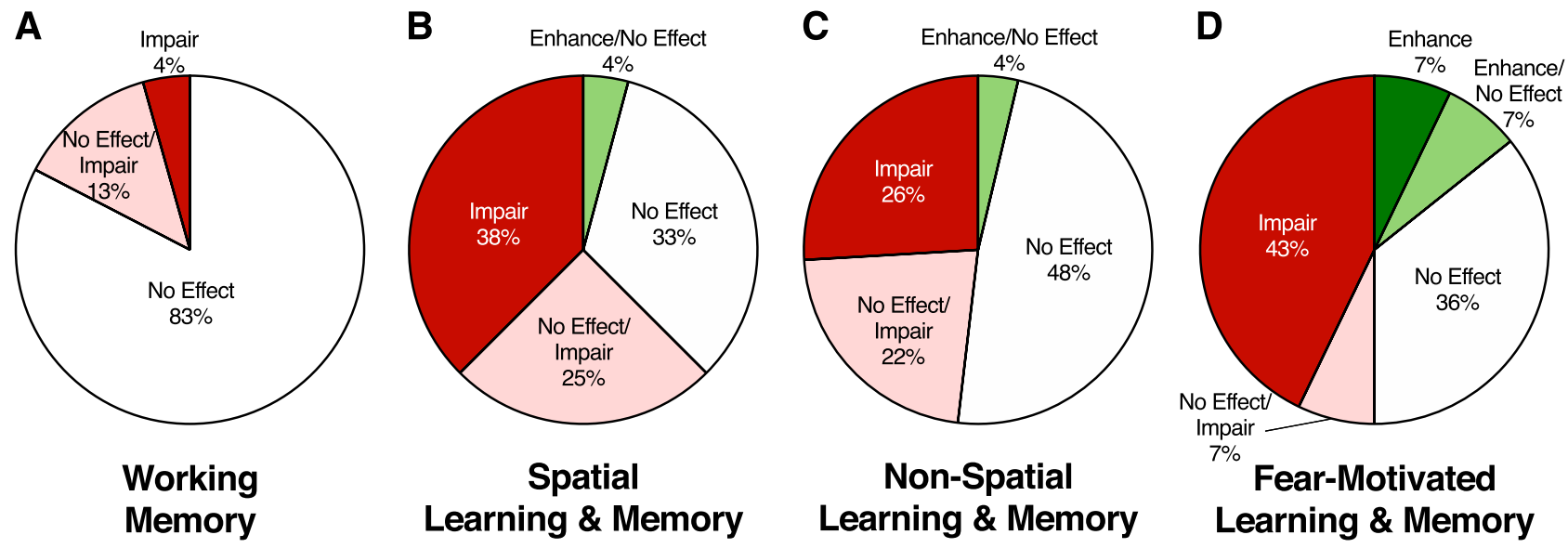

Fig. 10. Breakdown of findings from 23 working memory (A), 24 spatial learning and memory (B), 27 nonspatial learning and memory (C), and 14 fearmotivated learning and memory (D) experiments.

(Fig. 10C). Thus the majority of studies found no effects on nonspatial learning and memory. There appears to be no precise reason for the observed impairments, as studies with almost identical methods produced no effects in other cases. There does appear to be a lesser rate of impairments in Sprague-Dawley rats than in the other strain/species. In all, the evidence suggests that MDMA likely has no effect on nonspatial learning and memory, but the reasons for occasional impairments are ambiguous.

The effects of MDMA on fear-motivated learning and memory were examined in 14 studies using the PA and FC tasks (Table 5). Of these 14 studies, one found memory enhancements, one found memory enhancements at doses of 2.5 and $5 \mathrm{mg} / \mathrm{kg}$ and no effects at doses of 1 and $10 \mathrm{mg} / \mathrm{kg}, 5$ found no effects, 1 found no effects with postdrug training and memory impairments with on-drug training, and 6 found memory impairments only (Fig. 10D). Here, on-drug training always impaired memory acquisition, but only high doses of $10-20 \mathrm{mg} / \mathrm{kg}$ were tested. Administration of MDMA between training and testing enhanced or had no effect on memory consolidation at doses of $2.5-10 \mathrm{mg} / \mathrm{kg}$ and impaired or had no effect on memory consolidation at doses of $10-20 \mathrm{mg} / \mathrm{kg}$. Postdrug training and testing most often resulted in no effects. In all, the effects of MDMA on fear-motivated learning and memory are mixed but appear to be highly dependent on dose and when the drug is administered.

Overall, this review reveals that MDMA likely has no effect on working memory and nonspatial learning and memory and may or may not impair spatial learning and memory and fear-motivated learning and memory. The reasons for these ambiguous findings may be revealed through further analyses.

\section{B. Findings by Dose}

With respect to typical, occasional users of MDMA and its potential for therapeutic use, an examination of the impact of low, clinically and community-relevant dosing is essential. To examine the role of dose in the cognitive effects of MDMA, we divided all experiments into four groups by dose of MDMA administered-less than $3,3-6,7.5-10$, and $15-30 \mathrm{mg} / \mathrm{kg}$. Given the average human weight of $70 \mathrm{~kg}$, these levels correspond to less than 210, 210-420, 525-700, and 1050-2100 mg. Of the studies reviewed here, 15 experiments administered doses of less than $3 \mathrm{mg} / \mathrm{kg}, 31$ experiments administered doses of $3-6 \mathrm{mg} / \mathrm{kg}, 50$ experiments administered doses of $7.5-10 \mathrm{mg} / \mathrm{kg}$, and 31 experiments administered doses of $15-30 \mathrm{mg} / \mathrm{kg}$ (note: some experiments used a range of doses, and the totals above account for experiments that administered doses from multiple levels). Figure 11 illustrates the breakdown of findings by these dose categories. Of these it is important to note that only the lowest dose range $(<3 \mathrm{mg} / \mathrm{kg})$ seems to reflect the doses taken by most recreational MDMA users (i.e., 1 to $2 \mathrm{mg} / \mathrm{kg}$ ), and it is likely that any potential therapeutic dosing would be even lower. Although there are several studies in this dose range, there are very few that examine microdosing (e.g., $<1 \mathrm{mg} / \mathrm{kg}$ ). At these doses, MDMA may have high therapeutic value and will almost certainly pose even less risk. Therefore, we suggest more studies, both human and animal, to examine MDMA at microdose ranges (e.g., $<1 \mathrm{mg} / \mathrm{kg}$ ).

Perhaps the most important finding from this review is that there is no evidence that doses below $3 \mathrm{mg} / \mathrm{kg}$ MDMA, the doses that people ordinarily take, produce cognitive impairments in animals, even when the animals are on-drug (Fig. 11A). Doses of 0.1, 0.3, 0.32, $0.75,1.0,1.25,1.7,1.75,1.8,2.0$, and $2.25 \mathrm{mg} / \mathrm{kg}$ produced no effects on working memory when animals were tested on-drug on the DMS (LeSage et al., 1993; Frederick et al., 1995a,b; Harper et al., 2005), OST (Hawkey et al., 2014), DA (Young et al., 2005), RAM (Braida et al., 2002; Kay et al., 2010), or MWM (Galizio et al., 2014) tasks. Doses of 0.3, 0.75, 1.0, 1.25, 1.7, and $2.25 \mathrm{mg} / \mathrm{kg}$ produced no effects on spatial learning and memory when animals were tested on-drug on the 
A

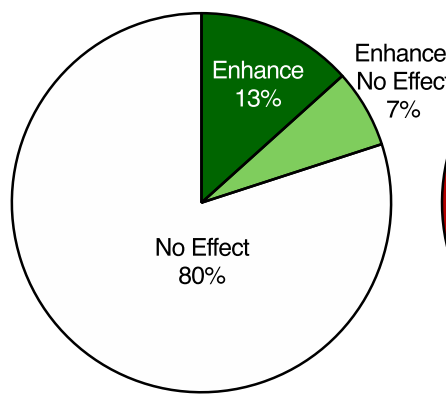

$<3 \mathrm{mg} / \mathrm{kg}$ MDMA
B

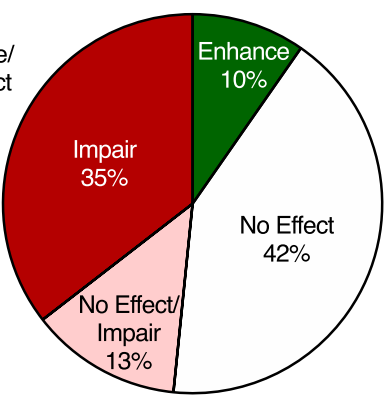

3-6 mg/kg MDMA

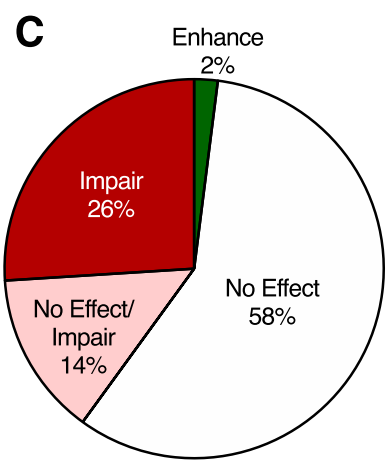

7.5-10 mg/kg MDMA

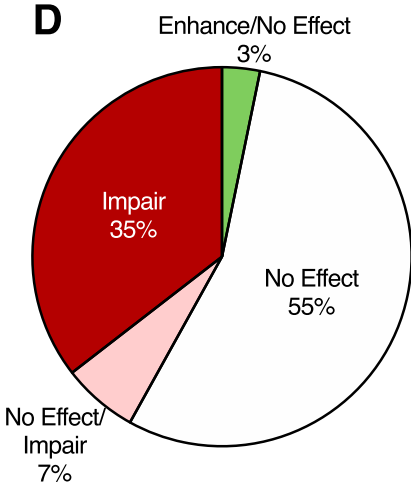

15-30 $\mathrm{mg} / \mathrm{kg}$ MDMA

Fig. 11. Breakdown of findings from experiments that administered MDMA at doses of less than $3 \mathrm{mg} / \mathrm{kg}$ [(A); $n=15], 3-6 \mathrm{mg} / \mathrm{kg}$ [(B); $n=31], 7.5-$ $10 \mathrm{mg} / \mathrm{kg}[(\mathrm{C}) ; n=50]$, and $15-30 \mathrm{mg} / \mathrm{kg}[(\mathrm{D}) ; n=31]$. There is no evidence that MDMA produces cognitive impairments at doses below $3 \mathrm{mg} / \mathrm{kg}$ (A), and the evidence regarding doses of $3-30 \mathrm{mg} / \mathrm{kg}$ is mixed (B-D).

MWM (Galizio et al., 2014), RAM (Kay et al., 2010), or SD (Young et al., 2005) tasks. A dose of $1 \mathrm{mg} / \mathrm{kg}$ produced recognition memory enhancements when administered immediately after training / before ondrug testing on the SR task (Pompei et al., 2002). A dose of $1 \mathrm{mg} / \mathrm{kg}$ had no effect on memory and a dose of $2.5 \mathrm{mg} / \mathrm{kg}$ produced memory enhancements when administered between training and testing on the PA task (Jahanshahi et al., 2013; Budzynska et al., 2017). Evidently, doses of less than $3 \mathrm{mg} / \mathrm{kg}$ MDMA only led to no effects or memory enhancements in the studies reviewed here.

The majority of the studies reviewed here used unrealistically high MDMA doses of $3 \mathrm{mg} / \mathrm{kg}$ or greater. Doses of 10,15 , and $20 \mathrm{mg} / \mathrm{kg}$ were very common, as 69 of the 90 experiments studied the effects of one of these three doses. In an average human of $70 \mathrm{~kg}$, $10 \mathrm{mg} / \mathrm{kg}$ is equivalent to $700 \mathrm{mg}, 15 \mathrm{mg} / \mathrm{kg}$ is equivalent to $1050 \mathrm{mg}$, and $20 \mathrm{mg} / \mathrm{kg}$ is equivalent to $1400 \mathrm{mg}$. Given that the average human MDMA dose is about 1 to $2 \mathrm{mg} / \mathrm{kg}$, these animal doses are 5-20 times greater than the doses taken by typical human users. Alternatively, this can be regarded as taking up to 20 MDMA tablets (each tablet $=$ about $1 \mathrm{mg} / \mathrm{kg}$ ) at one time, overdoses that would likely cause shock and alarm even among heavy users. In 48 of the 69 high-dose ( $\geq 3 \mathrm{mg} / \mathrm{kg}$ ) experiments, doses of 10,15 , or $20 \mathrm{mg} / \mathrm{kg}$ were administered multiple (2-4) times per day. Twice daily administration of these doses is comparable to taking 20,30, or 40 MDMA tablets in 1 day. Cohen et al. (2005), Able et al. (2006), Skelton et al. (2008), Vorhees et al. (2011), and Viñals et al. (2012), gave rodents extreme treatments of $60 \mathrm{mg} / \mathrm{kg}$ per day, which is equivalent to a human taking $4200 \mathrm{mg}$ of MDMA or 60 MDMA tablets per day. The most extreme MDMA treatment was delivered by Murnane et al. (2012), who gave rodents a total of $80 \mathrm{mg} / \mathrm{kg}$ per day, which is equivalent to a human taking $5600 \mathrm{mg}$ of MDMA or 80 MDMA tablets per day. These doses clearly do not reflect typical MDMA use in humans, and the validity of high-dose findings, outside of understanding very heavy users, should be of concern. It is somewhat misleading to portray the "typical" toxic effects of a drug based on what is essentially a $5-20 \times$ overdose. If those criteria were applied to other drugs, many existing therapeutics would be regarded as very unsafe, even lethal, including all of the statins, most antihypertensives, selective serotonin reuptake inhibitors, and even acetaminophen (paracetamol) (see Larson et al. (2005) for more about the high incidence and seriousness of acetaminophen overdose).

Regardless of the extreme MDMA treatments given to animal subjects, the findings on the cognitive effects of high-dose MDMA remains somewhat unconvincing. Of the 31 experiments that gave doses of $3-6 \mathrm{mg} / \mathrm{kg}$, 11 found impairments, 4 found a mix of impairments and no effects depending on task parameters, 13 found no effects, and 3 found enhancements (Fig. 11B). Of the 50 experiments that gave doses of $7.5-10 \mathrm{mg} / \mathrm{kg}$, 13 found impairments, seven found a mix of impairments and no effects depending on task parameters, 29 found no effects, and one found enhancements (Fig. $11 \mathrm{C})$. Of the 31 experiments that gave doses of 15 $30 \mathrm{mg} / \mathrm{kg}, 11$ found impairments, 2 found a mix of impairments and no effects depending on task parameters, 17 found no effects, and 1 found a mix of no effects and enhancements depending on task parameters (Fig. 11D). Thus the administration of $3-30 \mathrm{mg} / \mathrm{kg}$ MDMA led to cognitive impairments in only less than half of experiments. Overall, the most compelling evidence of high-dose ( $\geq 3 \mathrm{mg} / \mathrm{kg}$ ) MDMA-induced impairments is in spatial reference memory (assessed via the MWM probe and the RAM) and fear-motivated memory acquisition (assessed via on-drug PA training); high doses did not consistently lead to impairments in any other cognitive domain (e.g., nonspatial learning and memory).

In all, we found no evidence that low, clinically and community-relevant doses of MDMA ( $<3 \mathrm{mg} / \mathrm{kg}$ ) produce cognitive impairments in animals. The findings 
regarding higher doses ( $\geq 3 \mathrm{mg} / \mathrm{kg}$ ) are mixed yet led to cognitive impairments in less than half of experiments, which were primarily in the cognitive domains of spatial and fear-motivated learning and memory. Across all experiments, we did not find differences in effects based on route or frequency of administration. While heavy MDMA users, which account for only a small fraction of users, may use potentially memory-impairing doses ( $\geq 3 \mathrm{mg} / \mathrm{kg}$ ), typical recreational and therapeutic doses lie below this range and did not produce cognitive deficits in any animal study.

\section{Findings by When the Drug Was Administered}

Here, we consider the effects of MDMA on learning and memory (all experiments except those on attention or working memory) with respect to when the drug was administered. Findings are categorized by whether MDMA was administered during training, between training and testing, during testing, or entirely prior to training and testing.

The effects of MDMA on memory acquisition are determined by on-drug training. Findings from the five experiments that conducted on-drug training (and then off-drug testing) reveal a clear dose-dependent effect of MDMA on memory acquisition. Doses of 0.3 , 1 , and $1.7 \mathrm{mg} / \mathrm{kg}$ had no effect on memory acquisition (Galizio et al., 2014), while doses of $3-20 \mathrm{mg} / \mathrm{kg}$ impaired memory acquisition (Barrionuevo et al., 2000; Moyano et al., 2004, 2005; Galizio et al., 2014; Taghizadeh et al., 2016).

The effects of MDMA on memory consolidation are determined by administering the drug between training and testing (typically immediately after training). Findings from the six experiments that administered MDMA after training yet before off-drug testing again present a dose-dependent effect on memory consolidation. Doses of $2.5,5$, and $10 \mathrm{mg} / \mathrm{kg}$ enhanced memory consolidation (Jahanshahi et al., 2013; Budzynska et al., 2017), while doses of 1 and $10 \mathrm{mg} / \mathrm{kg}$ also had no effect on memory consolidation (Shortall et al., 2013; Budzynska et al., 2017). Higher doses of 10 and $20 \mathrm{mg} / \mathrm{kg}$ impaired memory consolidation (Ros-Simó et al., 2013; Shariati et al., 2014).

The effects of MDMA on memory retrieval are determined by on-drug testing. Findings from the four experiments that conducted on-drug testing (but offdrug training) again exhibit a dose-dependent effect of MDMA on memory retrieval. Doses of $0.75,1.25,2.25$, and $5 \mathrm{mg} / \mathrm{kg}$ had no effect on memory retrieval (Young et al., 2005; Kay et al., 2010), while doses of 3 and $4 \mathrm{mg} / \mathrm{kg}$ impaired memory retrieval (Kay et al., 2010; Kay et al., 2011; Harper et al., 2013). Different rat strains (Sprague-Dawley vs. Wistar) may account for the contradictory effects of doses in the $3-5 \mathrm{mg} / \mathrm{kg}$ range (specifically, the $5 \mathrm{mg} / \mathrm{kg}$ outlier).

Pompei et al. (2002) administered MDMA immediately after training, and testing took place 2 hours later on-drug. In this design, both memory consolidation and retrieval could be influenced by MDMA. Doses of 1 and $5 \mathrm{mg} / \mathrm{kg}$ enhanced memory consolidation/retrieval, while a dose of $10 \mathrm{mg} / \mathrm{kg}$ had no effect on memory consolidation/retrieval. Additionally, Shortall et al. (2013) administered MDMA before training and conducted testing 2 hours later so both training and testing occurred on-drug. In this case, MDMA could influence memory acquisition, consolidation, and retrieval. A dose of $10 \mathrm{mg} / \mathrm{kg}$ impaired memory acquisition/ consolidation/retrieval.

Experiments in which memory acquisition and testing are performed completely postdrug treatment measure the persistent, long-term effects of exposure to MDMA. Most of the learning and memory studies reviewed here were performed in this manner, a total of 51 experiments, and all tested doses of $3 \mathrm{mg} / \mathrm{kg}$ or greater. Only 15 experiments found that MDMA consistently produced postdrug impairments in learning and memory, and another 10 experiments found impairments under specific task parameters only. Most of the experiments, a total of 36, found that MDMA produced no postdrug impairments in learning and memory under all/some task parameters. The reasons for occasional impairments, however, are ambiguous; there appears to be no clear pattern in terms of experimental methods.

Overall, the on-drug effects of MDMA on learning and memory appear to be dose-dependent, with lower doses producing no effects or enhancements and higher doses producing impairments. The threshold for impaired acquisition and retrieval appears to be approximately $3 \mathrm{mg} / \mathrm{kg}$ or more, which corresponds to the doses that are considered atypically high in human users. The dose threshold for impaired consolidation appears to be higher, at about 10 or more $\mathrm{mg} / \mathrm{kg}$, and there is even evidence that doses of $2.5-10 \mathrm{mg} / \mathrm{kg}$ can enhance consolidation. The postdrug effects of MDMA on learning and memory were negligible in most experiments, even given that these effects were assessed only at doses of $3 \mathrm{mg} / \mathrm{kg}$ or greater.

\section{Findings by Species, Strain, Age, and Sex}

To analyze findings by the species tested in each experiment, we focus on the five experiments in monkeys, the 19 experiments in mice, and the 65 experiments in rats [pigeons were only used in one study (LeSage et al., 1993), and no cognitive effects were found]. Of the five experiments in monkeys, four found no effects and one found impairments while on-drug but no post-drug effects. Of the 19 experiments in mice, one found a mix of enhancements and no effects (depending on dose), eight found no effects, five found a mix of no effects and impairments (depending on treatment/task parameters), and five found impairments only. Of the 65 experiments in rats, 3 found a mix of enhancements and no effects (depending on treatment/task parameters), 
33 found no effects, 11 found a mix of no effects and impairments (depending on treatment/task parameters), and 18 found impairments only. In all three species, the majority of experiments found that MDMA has no cognitive effects. About $74 \%$ of the experiments in mice, about $72 \%$ of the experiments in rats, and all experiments in monkeys found negligible effects at some/all parameters.

The studies reviewed here tested a wide variety of rat and mouse strains. Except for the slight trends mentioned previously (in sections VI.A and VI.C), there appears to be no notable systematic differences in findings between the strains used in the present studies. Animal age (adolescents and/or adults) also did not appear to impact the findings. Of the 23 experiments that trained and/or tested adolescent rodents, one found a mix of enhancements and no effects, 13 found no effects, 2 found a mix of no effects and impairments, and 7 found impairments. This pattern of findings regarding adolescent animals generally mirrors that of all experiments (see Fig. 9). The majority of experiments tested male animals, but of the five experiments that included female animals, four found no effects and one found impairments. Although this suggests that MDMA may have less cognitive risk in females than males, there are not enough mixed-sex studies to have any confidence in this conclusion.

In all, there appears to be no differences in the cognitive effects of MDMA between rats and mice, and if anything, a less pronounced effect in monkeys. We also did not find any major differences in effects based on strain, age, or sex.

\section{High Doses and Neurotoxicology of Drugs of Abuse}

An abundance of studies have reported neurotoxicity of MDMA and amphetamines, and as has been reviewed elsewhere, many of these studies exclusively used high doses (McCann and Ricaurte, 2004). Fundamentally, toxicology depends on the proper selection of doses relevant to those used by people, as even commonly consumed vitamins are readily toxic at high doses. For example, high doses of vitamin A are readily neurotoxic and cause birth defects, but we rarely hear calls that it be controlled or outlawed. Likewise, botulinum toxin is the most lethal substance known, but is used readily and safely at appropriate doses (Rietjens and Alink, 2006). In neurotoxicological research on drugs of abuse, there is an incentive to find neurotoxicological effects; these kinds of findings lead to more grants and more publications, while a lack of effects often leads to neither (Edwards and Roy, 2017). It is therefore natural to use high doses that are more likely to yield toxic effects. With a drug like MDMA that has no established medical use and is arguably a public health menace, there may seem to be little cost to arguing it causes brain damage rather than arguing it does not. However, when a previously maligned drug is argued to have new medical value, a proper assessment of its true toxicology is essential. Even with these factors, we found that a majority of experiments did not find evidence of MDMAinduced cognitive deficits in animals, even at high doses of $3 \mathrm{mg} / \mathrm{kg}$ or greater (Fig. 11). A careful consideration of the overall findings suggests that the preclinical literature on MDMA behavioral toxicity may only be relevant to certain, atypical, habitual users of high doses, rather than the typical recreational user; those findings are probably even less relevant to proposed therapeutic uses, where the drug may be given at low doses and only a few times.

\section{Conclusions}

This systematic review highlights that doses of less than $3 \mathrm{mg} / \mathrm{kg}$ MDMA, which we believe are appropriate to model typical human MDMA consumption, do not seem to impair cognition in animals. At doses of $3 \mathrm{mg} / \mathrm{kg}$ or greater, which model atypical, heavy MDMA use, the cognitive effects are unclear, as some findings suggest that these doses produce cognitive impairments while the slight majority suggest that they still do not influence cognition. The on-drug effects of MDMA on cognition have been assessed across a wide range of doses and appear to be dose-dependent. The postdrug effects of doses below $3 \mathrm{mg} / \mathrm{kg}$ have not yet been studied, but studies on doses of $3 \mathrm{mg} / \mathrm{kg}$ or greater reveal mixed findings that trend toward insignificance. After analyzing almost 25 years of findings with respect to methodology, we believe that the preclinical evidence of MDMA-induced cognitive deficits is relatively weak.

Previous neurotoxicity evidence suggests that rats, mice, and non-human primates exhibit vast differences in sensitivity to MDMA, with non-human primates showing the highest sensitivity and mice showing the lowest sensitivity to MDMA-induced serotonergic deficits. These differences are believed to arise from species differences in MDMA metabolism (Green et al., 2003, 2009, 2012a). Conversely, the present review suggests that rats and mice do not exhibit differences in sensitivity to MDMA-induced cognitive impairments, and that non-human primates are possibly less sensitive than rodents to these impairments. There is also some evidence of MDMA-induced cognitive impairments in rats and mice at doses lower than those necessary to produce neurotoxicity $(20 \mathrm{mg} / \mathrm{kg}$ in rats, $50 \mathrm{mg} / \mathrm{kg}$ in mice). Together, this evidence suggests that MDMAinduced neurotoxicity and cognitive impairments may be unrelated, and active metabolites may not be responsible for the cognitive effects of MDMA.

Our analyses reveal that MDMA may have no effect on working memory or nonspatial learning and memory, but the potential to impair spatial learning and memory and/or fear-motivated learning and memory. 
The most convincing impairments were those induced by high doses $(3-20 \mathrm{mg} / \mathrm{kg})$ in spatial reference memory and passive avoidance memory acquisition; however, visuospatial short-term and long-term memory deficits have not been consistently found in heavy MDMA users (Laws and Kokkalis, 2007). Our review also suggests that MDMA has no effect on working memory in animals across a range of doses, but retrospective studies have regularly found working memory deficits in MDMA users (Murphy et al., 2009, 2012; Nulsen et al., 2010). Human studies use nonrandom assignment and often test extremely heavy users; these deficits could have been present prior to MDMA use or may have been the result of very heavy atypical use. Since low doses (i.e., 1 to $2 \mathrm{mg} / \mathrm{kg}$ ) of pure MDMA produce similar pharmacokinetic, pharmacological, and psychoactive effects in animals and humans (Baumann et al., 2007, 2009; Green et al., 2009, 2012a) and do not produce cognitive impairments in animals, we suspect that low doses of pure MDMA also do not impair cognition in humans.

To date, most evidence of MDMA-induced neurotoxicity and cognitive dysfunction has resulted from extreme animal dosing or heavy recreational use. While we agree that atypical heavy MDMA use may lead to some neural and behavioral toxicity, there is insufficient evidence that typical (i.e., low to moderate) MDMA use is detrimental to brain structure/function. Factors such as polydrug use, adulterants, hyperthermia, and hyponatremia can still increase the potential for adverse effects and are often involved in recreational MDMA use (Green et al., 2003; Baumann et al., 2007). Nevertheless, it is unlikely that less than $3 \mathrm{mg} / \mathrm{kg}$ of pure MDMA poses significant danger to neurological health if administered infrequently and in a controlled setting. Given that MDMA is administered in this manner during clinical investigations (Mithoefer et al., 2016), the therapeutic value of MDMA should not be dismissed due to potential neurological risks. However, it is critical to note that the margin between current therapeutic doses ( 1 to $2 \mathrm{mg} / \mathrm{kg}$ ) and potentially memory-impairing doses ( $\geq 3 \mathrm{mg} / \mathrm{kg}$ ) is narrow. Therefore, $3 \mathrm{mg} / \mathrm{kg}$ should be considered the absolute limit for therapeutic dosing, and we recommend exploring even lower doses $(<1 \mathrm{mg} / \mathrm{kg})$.

We strongly suggest that preclinical MDMA researchers become more concerned with the critical aspect of proper animal dosing. There is considerable pessimism regarding the validity of allometric scaling in MDMA research (Baumann et al., 2007, 2009; Green et al., 2009, 2012a). Accordingly, the administration of excessively high doses of MDMA to animal subjects is not appropriate for determining potential toxic effects in typical MDMA users. Even at high doses, evidence of MDMA-induced cognitive deficits is relatively inconsistent. Future studies should aim to examine the effects of low-dose MDMA to reliably model typical human consumption and to evaluate any potential therapeutic value.

\section{Acknowledgments}

The authors thank Christina Gremel, Michael Gorman, and two anonymous reviewers for their thoughtful comments on an earlier version of this manuscript.

\section{Authorship Contributions}

Performed data analysis: Pantoni.

Wrote or contributed to the writing of the manuscript: Pantoni, Anagnostaras.

\section{References}

Abad S, Camarasa J, Pubill D, Camins A, and Escubedo E (2016) Adaptive plasticity in the hippocampus of young mice intermittently exposed to MDMA could be the origin of memory deficits. Mol Neurobiol 53:7271-7283.

Abad S, Fole A, del Olmo N, Pubill D, Pallàs M, Junyent F, Camarasa J, Camins A and Escubedo E (2014) MDMA enhances hippocampal-dependent learning and memory under restrictive conditions, and modifies hippocampal spine density. Psychopharmacology (Berl) 231:863-874.

Able JA, Gudelsky GA, Vorhees CV, and Williams MT (2006) 3,4Methylenedioxymethamphetamine in adult rats produces deficits in path integration and spatial reference memory. Biol Psychiatry 59:1219-1226.

Aguirre N, Ballaz S, Lasheras B, and Del Río J (1998) MDMA ('Ecstasy') enhances 5-HT1A receptor density and 8-OH-DPAT-induced hypothermia: blockade by drugs preventing 5-hydroxytryptamine depletion. Eur J Pharmacol 346:181-188.

Anagnostaras SG, Maren S, and Fanselow MS (1999) Temporally graded retrograde amnesia of contextual fear after hippocampal damage in rats: within-subjects examination. J Neurosci 19:1106-1114.

Anagnostaras SG, Sage JR, and Carmack SA (2015) Pavlovian fear conditioning, in Encyclopedia of Psychopharmacology (Stolerman IP and Price LH eds) pp 12371240, Springer, Berlin, Heidelberg.

Anagnostaras SG, Wood SC, Shuman T, Cai DJ, Leduc AD, Zurn KR, Zurn JB, Sage JR, and Herrera GM (2010) Automated assessment of pavlovian conditioned freezing and shock reactivity in mice using the video freeze system. Front Behav Neurosci 4:158

Barrionuevo M, Aguirre N, Del Río JD, and Lasheras B (2000) Serotonergic deficits and impaired passive-avoidance learning in rats by MDEA: a comparison with MDMA. Pharmacol Biochem Behav 65:233-240.

Battaglia G, Brooks BP, Kulsakdinun C, and De Souza EB (1988) Pharmacologic profile of MDMA (3,4-methylenedioxymethamphetamine) at various brain recognition sites. Eur J Pharmacol 149:159-163.

Baumann MH, Wang X, and Rothman RB (2007) 3,4-Methylenedioxymethamphetamine (MDMA) neurotoxicity in rats: a reappraisal of past and present findings. Psychopharmacology (Berl) 189:407-424.

Baumann MH, Zolkowska D, Kim I, Scheidweiler KB, Rothman RB, and Huestis MA (2009) Effects of dose and route of administration on pharmacokinetics of (+ or -)-3,4-methylenedioxymethamphetamine in the rat. Drug Metab Dispos 37:2163-2170.

Baylen CA and Rosenberg H (2006) A review of the acute subjective effects of MDMA/ecstasy. Addiction 101:933-947.

Betzler F, Viohl L, and Romanczuk-Seiferth N (2017) Decision-making in chronic ecstasy users: a systematic review. Eur J Neurosci 45:34-44.

Bouso JC, Doblin R, Farré M, Alcázar MÁ, and Gómez-Jarabo G (2008) MDMAassisted psychotherapy using low doses in a small sample of women with chronic posttraumatic stress disorder. J Psychoactive Drugs 40:225-236.

Braida D, Pozzi M, Cavallini R, and Sala M (2002) 3,4 methylenedioxymethamphetamine (ecstasy) impairs eight-arm radial maze performance and arm entry pattern in rats. Behav Neurosci 116:298-304.

Brunt TM, Koeter MW, Niesink RJ, and van den Brink W (2012) Linking the pharmacological content of ecstasy tablets to the subjective experiences of drug users. Psychopharmacology (Berl) 220:751-762.

Budzynska B, Michalak A, Frankowska M, Kaszubska K, and Biała G (2017) Acute behavioral effects of co-administration of mephedrone and MDMA in mice. Pharmacol Rep 69:199-205.

Busceti CL, Biagioni F, Riozzi B, Battaglia G, Storto M, Cinque C, Molinaro G, Gradini R, Caricasole A, Canudas AM, et al. (2008) Enhanced tau phosphorylation in the hippocampus of mice treated with 3,4-methylenedioxymethamphetamine ("Ecstasy"). J Neurosci 28:3234-3245.

Camarasa J, Marimón JM, Rodrigo T, Escubedo E, and Pubill D (2008) Memantine prevents the cognitive impairment induced by 3,4-methylenedioxymethamphetamine in rats. Eur J Pharmacol 589:132-139.

Carmack SA, Howell KK, Rasaei K, Reas ET, and Anagnostaras SG (2014) Animal model of methylphenidate's long-term memory-enhancing effects. Learn Mem 21 82-89.

Cassel JC, Riegert C, Rutz S, Koenig J, Rothmaier K, Cosquer B, Lazarus C, Birthelmer A, Jeltsch H, Jones BC, et al. (2005) Ethanol, 3,4methylenedioxymethamphetamine (ecstasy) and their combination: long-term behavioral, neurochemical and neuropharmacological effects in the rat. Neuropsychopharmacology 30:1870-1882.

Center for Behavioral Health Statistics and Quality (2016) 2015 National Survey on Drug Use and Health: Detailed Tables, Substance Abuse and Mental Health Services Administration, Rockville, MD. 
Clemens KJ, Cornish JL, Hunt GE, and McGregor IS (2007) Repeated weekly exposure to MDMA, methamphetamine or their combination: long-term behavioural and neurochemical effects in rats. Drug Alcohol Depend 86:183-190.

Cohen MA, Skelton MR, Schaefer TL, Gudelsky GA, Vorhees CV, and Williams MT (2005) Learning and memory after neonatal exposure to 3,4methylenedioxymethamphetamine (ecstasy) in rats: interaction with exposure in adulthood. Synapse 57:148-159.

Colado MI, Murray TK, and Green AR (1993) 5-HT loss in rat brain following 3,4-methylenedioxymethamphetamine (MDMA), p-chloroamphetamine and fenfluramine administration and effects of chlormethiazole and dizocilpine. Br J Pharmacol 108:583-589.

Compton DM, Selinger MC, Westman E, and Otero P (2011) Differentiation of MDMA or 5-MeO-DIPT induced cognitive deficits in rat following adolescent exposure. Psychol Neurosci 4:157-169.

Costa G, Simola N, and Morelli M (2014) MDMA administration during adolescence exacerbates MPTP-induced cognitive impairment and neuroinflammation in the hippocampus and prefrontal cortex. Psychopharmacology (Berl) 231:4007-4018.

Cowan RL (2007) Neuroimaging research in human MDMA users: a review. Psychopharmacology (Berl) 189:539-556.

Cunningham JI, Raudensky J, Tonkiss J, and Yamamoto BK (2009) MDMA pretreatment leads to mild chronic unpredictable stress-induced impairments in spatial learning. Behav Neurosci 123:1076-1084.

Curran HV (2000) Is MDMA ('Ecstasy') neurotoxic in humans? An overview of evidence and of methodological problems in research. Neuropsychobiology 42:34-41.

Dudchenko PA (2004) An overview of the tasks used to test working memory in rodents. Neurosci Biobehav Rev 28:699-709.

Edut S, Rubovitch V, Schreiber S, and Pick CG (2011) The intriguing effects of ecstasy (MDMA) on cognitive function in mice subjected to a minimal traumatic brain injury (mTBI). Psychopharmacology (Berl) 214:877-889.

Edwards MA and Roy S (2017) Academic research in the $21^{\text {st }}$ century: maintaining scientific integrity in a climate of perverse incentives and hypercompetition. Environ Eng Sci 34:51-61.

Eisner B (1989) Ecstasy: The MDMA Story, Ronin Publishing, Berkeley, CA

EMCDDA (2016) European Drug Report: Trends and Developments, 2016, Publications Office of the European Union, Luxembourg.

Ennaceur A and Delacour J (1988) A new one-trial test for neurobiological studies of memory in rats. 1: behavioral data. Behav Brain Res 31:47-59.

Fanselow MS (1986) Associative vs topographical accounts of the immediate shockfreezing deficit in rats: implications for the response selection rules governing species-specific defensive reactions. Learn Motiv 17:16-39.

Fantegrossi WE (2008) In vivo pharmacology of MDMA and its enantiomers in rhesus monkeys. Exp Clin Psychopharmacol 16:1-12.

Fraser A (2012) The spaces, politics, and cultural economies of electronic dance music. Geogr Compass 6:500-511.

Frederick DL, Ali SF, Slikker W Jr, Gillam MP, Allen RR, and Paule MG (1995b) Behavioral and neurochemical effects of chronic methylenedioxymethamphetamine (MDMA) treatment in rhesus monkeys. Neurotoxicol Teratol 17:531-543.

Frederick DL, Gillam MP, Allen RR, and Paule MG (1995a) Acute effects of methylenedioxymethamphetamine (MDMA) on several complex brain functions in monkeys. Pharmacol Biochem Behav 51:301-307.

Freudenmann RW, Öxler F, and Bernschneider-Reif S (2006) The origin of MDMA (ecstasy) revisited: the true story reconstructed from the original documents. Addiction 101:1241-1245.

Frey U and Morris RG (1997) Synaptic tagging and long-term potentiation. Nature 385:533-536.

Galizio M, Byrd BD, Robinson AM, Hawkey A, Rayburn-Reeves R, and April LB (2014) Repeated acquisition in the Morris swim task: effects of MDMA, methamphetamine and methylphenidate. Psychol Rec 64:143-150.

García-Pardo MP, Escobar-Valero C, Rodríguez-Arias M, Miñarro J, and Aguilar MA (2015) Involvement of NMDA glutamate receptors in the acquisition and reinstatement of the conditioned place preference induced by MDMA. Behav Pharmacol 26:411-417.

García-Pardo MP, Roger-Sánchez C, Rodríguez-Arias M, Miñarro J, and Aguilar MA (2017) Cognitive and behavioural effects induced by social stress plus MDMA administration in mice. Behav Brain Res 319:63-72.

Giraudon I and Bello PY (2007) Monitoring ecstasy content in France: results from the National Surveillance System 1999-2004. Subst Use Misuse 42:1567-1578.

Gouzoulis-Mayfrank E and Daumann J (2006) Neurotoxicity of methylenedioxyamphetamines (MDMA; ecstasy) in humans: how strong is the evidence for persistent brain damage? Addiction 101:348-361.

Green AR, Gabrielsson J, Marsden CA, and Fone KC (2009) MDMA: on the translation from rodent to human dosing. Psychopharmacology (Berl) 204:375-378.

Green AR, King MV, Shortall SE, and Fone KCF (2012a) Lost in translation: preclinical studies on 3,4-methylenedioxymethamphetamine provide information on mechanisms of action, but do not allow accurate prediction of adverse events in humans. Br J Pharmacol 166:1523-1536.

Green AR, King MV, Shortall SE, and Fone KCF (2012b) Ecstasy cannot be assumed to be 3,4-methylenedioxyamphetamine (MDMA). Br J Pharmacol 166:1521-1522.

Green AR, Mechan AO, Elliott JM, O'Shea E, and Colado MI (2003) The pharmacology and clinical pharmacology of 3,4-methylenedioxymethamphetamine (MDMA, "ecstasy"). Pharmacol Rev 55:463-508.

Harper DN (2011) Attenuation of the disruptive effects of (+/-)3,4methylenedioxymethamphetamine and cocaine on delayed matching-to-sample performance with D1 versus D2 antagonists. Addict Biol 18:912-920.

Harper DN, Wisnewski R, Hunt M, and Schenk S (2005) (+/-)3,4methylenedioxymethamphetamine, d-amphetamine, and cocaine impair delayed matching-to-sample performance by an increase in susceptibility to proactive interference. Behav Neurosci 119:455-463.

Harper DN, Kay C, and Hunt M (2013) Prior MDMA exposure inhibits learning and produces both tolerance and sensitization in the radial-arm maze. Pharmacol Biochem Behav 105:34-40.
Hawkey A, April LB, and Galizio M (2014) Effects of MDMA on olfactory memory and reversal learning in rats. Neurobiol Learn Mem 114:209-216.

Hayner GN and McKinney H (1986) MDMA. The dark side of ecstasy. J Psychoactive Drugs 18:341-347.

Hernandez-Rabaza V, Navarro-Mora G, Velazquez-Sanchez C, Ferragud A, Marin MP, Garcia-Verdugo JM, Renau-Piqueras J, and Canales JJ (2010) Neurotoxicity and persistent cognitive deficits induced by combined MDMA and alcohol exposure in adolescent rats. Addict Biol 15:413-423.

Hughes RN (2004) The value of spontaneous alternation behavior (SAB) as a test of retention in pharmacological investigations of memory. Neurosci Biobehav Rev 28:497-505

Jahanshahi M, Haidari K, Mahaki-Zadeh S, Nikmahzar E, and Babakordi F (2013) Effects of repeated administration of 3,4-methylenedioxymethamphetamine (MDMA) on avoidance memory and cell density in rats' hippocampus. Basic Clin Neurosci 4:57-63.

Jarvik ME and Kopp R (1967) An improved one-trial passive avoidance learning situation. Psychol Rep 21:221-224

Johansson EM, García-Gutiérrez MS, Moscoso-Castro M, Manzanares J, and Valverde O (2015) Reduced contextual discrimination following alcohol consumption or MDMA administration in mice. PLoS One 10:e0142978

Kay C, Harper DN, and Hunt M (2010) Differential effects of MDMA and scopolamine on working versus reference memory in the radial arm maze task. Neurobiol Learn Mem 93:151-156.

Kay C, Harper DN, and Hunt M (2011) The effects of binge MDMA on acquisition and reversal learning in a radial-arm maze task. Neurobiol Learn Mem 95:473-483.

Kermanian F, Mehdizadeh M, Soleimani M, Ebrahimzadeh Bideskan AR, AsadiShekaari M, Kheradmand H, and Haghir H (2012) The role of adenosine receptor agonist and antagonist on hippocampal MDMA detrimental effects; a structural and behavioral study. Metab Brain Dis 27:459-469.

Kolbrich EA, Goodwin RS, Gorelick DA, Hayes RJ, Stein EA, and Huestis MA (2008) Plasma pharmacokinetics of 3,4-methylenedioxymethamphetamine after controlled oral administration to young adults. Ther Drug Monit 30:320-332.

Kolyaduke OV and Hughes RN (2013) Increased anxiety-related behavior in male and female adult rats following early and late adolescent exposure to 3,4methylenedioxymethamphetamine (MDMA). Pharmacol Biochem Behav 103:742-749.

Kuypers KP, Theunissen EL, van Wel JH, de Sousa Fernandes Perna EB, Linssen A Sambeth A, Schultz BG, and Ramaekers JG (2016) Verbal memory impairment in polydrug ecstasy users: a clinical perspective. PLoS One 11:e149438.

Larson AM, Polson J, Fontana RJ, Davern TJ, Lalani E, Hynan LS, Reisch JS, Schiødt FV, Ostapowicz G, Shakil AO, et al.; Acute Liver Failure Study Group (2005) Acetaminophen-induced acute liver failure: results of a United States multicenter, prospective study. Hepatology 42:1364-1372.

Lawn JC (1985) Schedules of controlled substances: temporary placement of 3,4methylenedioxymethamphetamine (MDMA) into schedule 1. Fed Regist 50 $23118-23120$

Lawn JC (1988) Schedules of controlled substances: scheduling of 3,4-methylenedioxymethamphetamine (MDMA) into schedule 1 of the controlled substances act. Fed Regist 51:36552-36560.

Laws KR and Kokkalis J (2007) Ecstasy (MDMA) and memory function: a metaanalytic update. Hum Psychopharmacol 22:381-388.

LeSage M, Clark R, and Poling A (1993) MDMA and memory: the acute and chronic effects of MDMA in pigeons performing under a delayed-matching-to-sample procedure. Psychopharmacology (Berl) 110:327-332.

Lin JH (1998) Applications and limitations of interspecies scaling and in vitro extrapolation in pharmacokinetics. Drug Metab Dispos 26:1202-1212.

Llorente-Berzal A, Puighermanal E, Burokas A, Ozaita A, Maldonado R, Marco EM, and Viveros MP (2013) Sex-dependent psychoneuroendocrine effects of THC and MDMA in an animal model of adolescent drug consumption. PLoS One 8:e78386.

Logan BJ, Laverty R, Sanderson WD, and Yee YB (1988) Differences between rats and mice in MDMA (methylenedioxymethylamphetamine) neurotoxicity. Eur $J$ Pharmacol 152:227-234.

Lu Y, Christian K, and Lu B (2008) BDNF: a key regulator for protein synthesisdependent LTP and long-term memory? Neurobiol Learn Mem 89:312-323.

Lyles J and Cadet JL (2003) Methylenedioxymethamphetamine (MDMA, ecstasy) neurotoxicity: cellular and molecular mechanisms. Brain Res Brain Res Rev 42:155-168.

Marston HM, Reid ME, Lawrence JA, Olverman HJ, and Butcher SP (1999) Behavioural analysis of the acute and chronic effects of MDMA treatment in the rat. Psychopharmacology (Berl) 144:67-76.

McCann UD and Ricaurte GA (2001) Caveat emptor: editors beware. Neuropsychopharmacology 24:333-336.

McCann UD and Ricaurte GA (2004) Amphetamine neurotoxicity: accomplishments and remaining challenges. Neurosci Biobehav Rev 27:821-826.

McGregor IS, Gurtman CG, Morley KC, Clemens KJ, Blokland A, Li KM, Cornish JL, and Hunt GE (2003) Increased anxiety and "depressive" symptoms months after MDMA ("ecstasy") in rats: drug-induced hyperthermia does not predict long-term outcomes. Psychopharmacology (Berl) 168:465-474.

McNamara MG, Kelly JP, and Leonard BE (1995) Some behavioural and neurochemical aspects of subacute (+/-)3,4-methylenedioxymethamphetamine administration in rats. Pharmacol Biochem Behav 52:479-484.

Mirzaei F, Soleimani Asl S, Shahidi S, Shariati H, Bakhtiar M, Mehdizadeh M, and Sohrabi M (2013) Chronic and sub-acute effects of 3, 4-methylenedioxy methamphetamine (MDMA) on spatial memory and passive avoidance learning in Wistar rats. Anat Sci J 10:24-28.

Mithoefer MC, Grob CS, and Brewerton TD (2016) Novel psychopharmacological therapies for psychiatric disorders: psilocybin and MDMA. Lancet Psychiatry 3: 481-488.

Mithoefer MC, Wagner MT, Mithoefer AT, Jerome L, and Doblin R (2011) The safety and efficacy of +/-3,4-methylenedioxymethamphetamine-assisted psychotherapy in subjects with chronic, treatment-resistant posttraumatic stress disorder: the first randomized controlled pilot study. J Psychopharmacol 25:439-452. 
Mithoefer MC, Wagner MT, Mithoefer AT, Jerome L, Martin SF, Yazar-Klosinski B, Michel Y, Brewerton TD, and Doblin R (2013) Durability of improvement in post-traumatic stress disorder symptoms and absence of harmful effects or drug dependency after 3,4-methylenedioxymethamphetamine-assisted psychotherapy: a prospective long-term follow-up study. J Psychopharmacol 27:28-39.

Mordenti J and Chappell W (1989) The use of interspecies scaling in toxicokinetics, in Toxicokinetics and New Drug Development (Yacogi A, Kelly J, and Batra V eds) pp 42-96, Pergamon Press, New York.

Morgan MJ (2000) Ecstasy (MDMA): a review of its possible persistent psychological effects. Psychopharmacology (Berl) 152:230-248.

Morley KC, Gallate JE, Hunt GE, Mallet PE, and McGregor IS (2001) Increased anxiety and impaired memory in rats 3 months after administration of 3,4methylenedioxymethamphetamine ("ecstasy"). Eur J Pharmacol 433:91-99.

Morris R (1984) Developments of a water-maze procedure for studying spatial learning in the rat. $J$ Neurosci Methods 11:47-60.

Moyano S, Del Río J, and Frechilla D (2005) Acute and chronic effects of MDMA on molecular mechanisms implicated in memory formation in rat hippocampus: surface expression of CaMKII and NMDA receptor subunits. Pharmacol Biochem Behav 82:190-199.

Moyano S, Frechilla D, and Del Río J (2004) NMDA receptor subunit and CaMKII changes in rat hippocampus induced by acute MDMA treatment: a mechanism for learning impairment. Psychopharmacology (Berl) 173:337-345.

Mueller F, Lenz C, Steiner M, Dolder PC, Walter M, Lang UE, Liechti ME, and Borgwardt S (2016) Neuroimaging in moderate MDMA use: a systematic review. Neurosci Biobehav Rev 62:21-34.

Murnane KS, Perrine SA, Finton BJ, Galloway MP, Howell LL, and Fantegrossi WE (2012) Effects of exposure to amphetamine derivatives on passive avoidance performance and the central levels of monoamines and their metabolites in mice: correlations between behavior and neurochemistry. Psychopharmacology (Berl) 220:495-508.

Murphy PN, Bruno R, Ryland I, Wareing M, Fisk JE, Montgomery C, and Hilton J (2012) The effects of 'ecstasy' (MDMA) on visuospatial memory performance: findings from a systematic review with meta-analyses. Hum Psychopharmacol 27:113-138.

Murphy PN, Wareing M, Fisk JE, and Montgomery C (2009) Executive working memory deficits in abstinent ecstasy/MDMA users: a critical review. Neuropsychobiology 60: $159-175$.

Nawata Y, Hiranita T, and Yamamoto T (2010) A cannabinoid CB(1) receptor antagonist ameliorates impairment of recognition memory on withdrawal from MDMA (Ecstasy). Neuropsychopharmacology 35:515-520.

Nichols DE (1986) Differences between the mechanism of action of MDMA, MBDB, and the classic hallucinogens. Identification of a new therapeutic class: entactogens. J Psychoactive Drugs 18:305-313.

Nulsen CE, Fox AM, and Hammond GR (2010) Differential effects of ecstasy on shortterm and working memory: a meta-analysis. Neuropsychol Rev 20:21-32.

Oehen P, Traber R, Widmer V, and Schnyder U (2013) A randomized, controlled pilot study of MDMA ( \pm 3,4-Methylenedioxymethamphetamine)-assisted psychotherapy for treatment of resistant, chronic Post-Traumatic Stress Disorder (PTSD). $J$ Psychopharmacol 27:40-52.

Palamar JJ (2017) There's something about Molly: the underresearched yet popular powder form of ecstasy in the United States. Subst Abus 38:15-17.

Parrott AC (2004) Is ecstasy MDMA? A review of the proportion of ecstasy tablets containing MDMA, their dosage levels, and the changing perceptions of purity. Psychopharmacology (Berl) 173:234-241.

Parrott AC, Rodgers J, Buchanan T, Ling J, Heffernan T, and Scholey AB (2006) Dancing hot on ecstasy: physical activity and thermal comfort ratings are associated with the memory and other psychobiological problems reported by recreational MDMA users. Hum Psychopharmacol 21:285-298.

Piper BJ, Fraiman JB, and Meyer JS (2005) Repeated MDMA ("ecstasy") exposure in adolescent male rats alters temperature regulation, spontaneous motor activity, attention, and serotonin transporter binding. Dev Psychobiol 47:145-157.

Piper BJ, Fraiman JB, Owens CB, Ali SF, and Meyer JS (2008) Dissociation of the neurochemical and behavioral toxicology of MDMA ('Ecstasy') by citalopram. Neuropsychopharmacology 33:1192-1205

Piper BJ and Meyer JS (2004) Memory deficit and reduced anxiety in young adult rats given repeated intermittent MDMA treatment during the periadolescent period. Pharmacol Biochem Behav 79:723-731.

Pitts EG, Curry DW, Hampshire KN, Young MB, and Howell LL (2018) ( \pm )-MDMA and its enantiomers: potential therapeutic advantages of R(-)-MDMA. Psychopharmacology (Berl) 235:377-392.

Pompei P, Cavazzuti E, Martarelli D, Pediconi D, Arletti R, Lucas L, and Massi M (2002) Preprotachykinin A gene expression after administration of 3,4-methylene dioxymethamphetamine (Ecstasy). Eur J Pharmacol 450:245-251.

Quillfeldt JA (2016) Behavioral methods to study learning and memory in rats, in Rodent Model as Tools in Ethical Biomedical Research (Andersen ML and Tufik S eds) pp 271-311, Springer International Publishing, Cham, Switzerland.

Reneman L, de Win MM, van den Brink W, Booij J, and den Heeten GJ (2006) Neuroimaging findings with MDMA/ecstasy: technical aspects, conceptual issues and future prospects. J Psychopharmacol 20:164-175.

Ricaurte GA, Forno LS, Wilson MA, DeLanney LE, Irwin I, Molliver ME, and Langston JW (1988) (+/-)3,4-Methylenedioxymethamphetamine selectively damages central serotonergic neurons in nonhuman primates. JAMA 260:51-55.

Ricaurte GA, Markowska AL, Wenk GL, Hatzidimitriou G, Wlos J, and Olton DS (1993) 3,4-Methylenedioxymethamphetamine, serotonin and memory. J Pharmacol Exp Ther 266:1097-1105.

Ricaurte GA and McCann UD (1992) Neurotoxic amphetamine analogues: effects in monkeys and implications for humans. Ann N Y Acad Sci 648:371-382.

Ricaurte GA, Yuan J, and McCann UD (2000) (+/-)3,4-Methylenedioxymethamphetamine ('ecstasy')-induced serotonin neurotoxicity: studies in animals. Neuropsychobiology 42:5-10.
Rietjens IM and Alink GM (2006) Future of toxicology--low-dose toxicology and riskbenefit analysis. Chem Res Toxicol 19:977-981.

Riley SC, James C, Gregory D, Dingle H, and Cadger M (2001) Patterns of recreational drug use at dance events in Edinburgh, Scotland. Addiction 96:1035-1047. Robbins TW (2002) The 5-choice serial reaction time task: behavioural pharmacology and functional neurochemistry. Psychopharmacology (Berl) 163:362-380.

Roberts CA, Jones A, and Montgomery C (2016) Meta-analysis of executive functioning in ecstasy/polydrug users. Psychol Med 46:1581-1596.

Robinson TE, Castañeda E, and Whishaw IQ (1993) Effects of cortical serotonin depletion induced by 3,4-methylenedioxymethamphetamine (MDMA) on behavior, before and after additional cholinergic blockade. Neuropsychopharmacology 8:77-85.

Rodríguez-Arias M, Maldonado C, Vidal-Infer A, Guerri C, Aguilar MA, and Miñarro $J$ (2011) Intermittent ethanol exposure increases long-lasting behavioral and neurochemical effects of MDMA in adolescent mice. Psychopharmacology (Berl) 218:429-442.

Rodsiri R, Spicer C, Green AR, Marsden CA, and Fone KC (2011) Acute concomitant effects of MDMA binge dosing on extracellular 5-HT, locomotion and body temperature and the long-term effect on novel object discrimination in rats. Psychopharmacology (Berl) 213:365-376.

Ros-Simó C, Moscoso-Castro M, Ruiz-Medina J, Ros J, and Valverde O (2013) Memory impairment and hippocampus specific protein oxidation induced by ethanol intake and 3, 4-methylenedioxymethamphetamine (MDMA) in mice. $J$ Neurochem 125:736-746.

Rudnick G and Wall SC (1992) The molecular mechanism of "ecstasy" [3,4methylenedioxy-methamphetamine (MDMA)]: serotonin transporters are targets for MDMA-induced serotonin release. Proc Natl Acad Sci USA 89:1817-1821.

Scholey AB, Parrott AC, Buchanan T, Heffernan TM, Ling J, and Rodgers J (2004) Increased intensity of ecstasy and polydrug usage in the more experienced recreational ecstasy/MDMA users: a WWW study. Addict Behav 29:743-752.

Schulenberg JE, Johnston LD, O'Malley PM, Bachman JG, Miech RA, and Patrick ME (2018) Monitoring the Future National Survey Results on Drug Use 1975-2017: Volume II, College Students and Adults Ages 19-55, National Institute on Drug Abuse, Bethesda, MD.

Schulz S, Becker T, Nagel U, von Ameln-Mayerhofer A, and Koch M (2013) Chronic co-administration of the cannabinoid receptor agonist WIN55,212-2 during puberty or adulthood reverses 3,4 methylenedioxymetamphetamine (MDMA)-induced deficits in recognition memory but not in effort-based decision making. Pharmacol Biochem Behav 106:91-100.

Schwartz RH and Miller NS (1997) MDMA (ecstasy) and the rave: a review. Pediatrics 100:705-708.

Shankaran M and Gudelsky GA (1999) A neurotoxic regimen of MDMA suppresses behavioral, thermal and neurochemical responses to subsequent MDMA administration. Psychopharmacology (Berl) 147:66-72.

Shariati MBH, Sohrabi M, Shahidi S, Nikkhah A, Mirzaei F, Medizadeh M, and Asl SS (2014) Acute effects of ecstasy on memory are more extensive than chronic effects. Basic Clin Neurosci 5:225-230.

Shortall SE, Macerola AE, Swaby RT, Jayson R, Korsah C, Pillidge KE, Wigmore PM Ebling FJ, Richard Green A, Fone KC, et al. (2013) Behavioural and neurochemical comparison of chronic intermittent cathinone, mephedrone and MDMA administration to the rat. Eur Neuropsychopharmacol 23:1085-1095.

Shulgin AT (1986) The background and chemistry of MDMA. J Psychoactive Drugs 18:291-304.

Shulgin AT and Nichols DE (1978) Characterization of three new psychomimetics, in The Psychopharmacology of Hallucinogens (Stillman RC and Willette RE eds), Pergamon Press, Oxford, UK.

Shuman T, Wood SC, and Anagnostaras SG (2009) Modafinil and memory: effects of modafinil on Morris water maze learning and Pavlovian fear conditioning. Behav Neurosci 123:257-266.

Skelton MR, Able JA, Grace CE, Herring NR, Schaefer TL, Gudelsky GA, Vorhees CV, and Williams MT (2008) (+/-)-3,4-Methylenedioxymethamphetamine treatment in adult rats impairs path integration learning: a comparison of single vs once per week treatment for 5 weeks. Neuropharmacology 55:1121-1130.

Soleimani Asl S, Farhadi H, Naghdi N, Choopani S, Samzadeh-Kermani A, and Mehdizadeh M (2011) Non-acute effects of different doses of 3, 4-methylenedioxymethamphetamine on spatial memory in the Morris water maze in Sprague-Dawley male rats. Neural Regen Res 6:1715-1719.

Soleimani Asl S, Mehdizadeh M, Hamedi Shahraki S, Artimani T, and Joghataei MT (2015) Sex differences in MDMA-induced toxicity in Sprague-Dawley rats. Funct Neurol 30:131-137.

Soleimani Asl S, Mousavizadeh K, Pourheydar B, Soleimani M, Rahbar E, and Mehdizadeh M (2013) Protective effects of N-acetylcysteine on 3 , 4-methylenedioxymethamphetamine-induced neurotoxicity in male SpragueDawley rats [published correction appears in Metab Brain Dis 29:887, 2014]. Metab Brain Dis 28:677-686.

Sprague JE, Preston AS, Leifheit M, and Woodside B (2003) Hippocampal serotonergic damage induced by MDMA (ecstasy): effects on spatial learning. Physiol Behav 79:281-287.

Stone DM, Hanson GR, and Gibb JW (1987) Differences in the central serotonergic effects of methylenedioxymethamphetamine (MDMA) in mice and rats. Neuropharmacology 26:1657-1661.

Taffe MA, Davis SA, Yuan J, Schroeder R, Hatzidimitriou G, Parsons LH, Ricaurte GA, and Gold LH (2002) Cognitive performance of MDMA-treated rhesus monkeys: sensitivity to serotonergic challenge. Neuropsychopharmacology 27:993-1005.

Taffe MA, Weed MR, Davis S, Huitrón-Resendiz S, Schroeder R, Parsons LH, Henriksen SJ, and Gold LH (2001) Functional consequences of repeated (+/-)3,4-methylenedioxymethamphetamine (MDMA) treatment in rhesus monkeys. Neuropsychopharmacology 24:230-239.

Taghizadeh G, Pourahmad J, Mehdizadeh H, Foroumadi A, Torkaman-Boutorabi A, Hassani S, Naserzadeh P, Shariatmadari R, Gholami M, Rouini MR, et al. (2016) 
Protective effects of physical exercise on MDMA-induced cognitive and mitochondrial impairment. Free Radic Biol Med 99:11-19.

ter Bogt TF, Engels RC, and Dubas JS (2006) Party people: personality and MDMA use of house party visitors. Addict Behav 31:1240-1244.

Timár J, Gyarmati S, Szabó A, and Fürst S (2003) Behavioural changes in rats treated with a neurotoxic dose regimen of dextrorotatory amphetamine derivatives. Behav Pharmacol 14:199-206.

Topp L, Hando J, Dillon P, Roche A, and Solowij N (1999) Ecstasy use in Australia: patterns of use and associated harm. Drug Alcohol Depend 55:105-115.

van Nieuwenhuijzen PS, Long LE, Hunt GE, Arnold JC, and McGregor IS (2010) Residual social, memory and oxytocin-related changes in rats following repeated exposure to $\gamma$-hydroxybutyrate (GHB), 3,4-methylenedioxymethamphetamine (MDMA) or their combination. Psychopharmacology (Berl) 212:663-674.

Verbaten MN (2003) Specific memory deficits in ecstasy users? The results of a metaanalysis. Hum Psychopharmacol 18:281-290.

Vidal Giné C, Ventura Vilamala M, Fornís Espinosa I, Gil Lladanosa C, Calzada Álvarez N, Fitó Fruitós A, Rodríguez Rodríguez J, Domíngo Salvany A, and de la Torre Fornell R (2016) Crystals and tablets in the Spanish ecstasy market 2000-2014: are they the same or different in terms of purity and adulteration? Forensic Sci Int 263:164-168.

Viñals X, Maldonado R, and Robledo P (2012) Effects of repeated treatment with MDMA on working memory and behavioural flexibility in mice. Addict Biol 18:263-273.

Vogels N, Brunt TM, Rigter S, van Dijk P, Vervaeke H, and Niesink RJ (2009) Content of ecstasy in the Netherlands: 1993-2008. Addiction 104:2057-2066.

Vorhees CV (1987) Maze learning in rats: a comparison of performance in two water mazes in progeny prenatally exposed to different doses of phenytoin. Neurotoxicol Teratol 9:235-241.
Vorhees CV, He E, Skelton MR, Graham DL, Schaefer TL, Grace CE, Braun AA, Amos-Kroohs R, and Williams MT (2011) Comparison of (+)-methamphetamine, \pm -methylenedioxymethamphetamine, (+)-amphetamine and \pm -fenfluramine in rats on egocentric learning in the Cincinnati water maze. Synapse 65 : $368-378$.

Vorhees CV and Williams MT (2006) Morris water maze: procedures for assessing spatial and related forms of learning and memory. Nat Protoc 1:848-858.

Weir E (2000) Raves: a review of the culture, the drugs and the prevention of harm. CMAJ 162:1843-1848.

Wichems CH, Hollingsworth CK, and Bennett BA (1995) Release of serotonin induced by 3,4-methylenedioxymethamphetamine (MDMA) and other substituted amphetamines in cultured fetal raphe neurons: further evidence for calciumindependent mechanisms of release. Brain Res 695:10-18.

Winstock AR, Griffiths P, and Stewart D (2001) Drugs and the dance music scene: a survey of current drug use patterns among a sample of dance music enthusiasts in the UK. Drug Alcohol Depend 64:9-17.

Wood S, Sage JR, Shuman T, and Anagnostaras SG (2014) Psychostimulants and cognition: a continuum of behavioral and cognitive activation. Pharmacol Rev 66: 193-221.

Young JM, McGregor IS, and Mallet PE (2005) Co-administration of THC and MDMA ('ecstasy') synergistically disrupts memory in rats. Neuropsychopharmacology 30: 1475-1482.

Zakzanis KK, Campbell Z, and Jovanovski D (2007) The neuropsychology of ecstasy (MDMA) use: a quantitative review. Hum Psychopharmacol 22:427-435. 


\section{Correction to "Cognitive Effects of MDMA in Laboratory Animals: A Systematic Review Focusing on Dose"}

In the above article [Pantoni MM and Anagnostaras SG (2019) Pharmacol Rev, 71: 413-449; DOI: https://doi.org/10.1124/pr.118.017087], the evidence of MDMAinduced cognitive enhancements at doses of less than $3 \mathrm{mg} / \mathrm{kg}$ was accidentally omitted from Fig. 11A. The corrected Fig. 11 is provided below. The PDF and HTML versions of the article have been corrected.

A

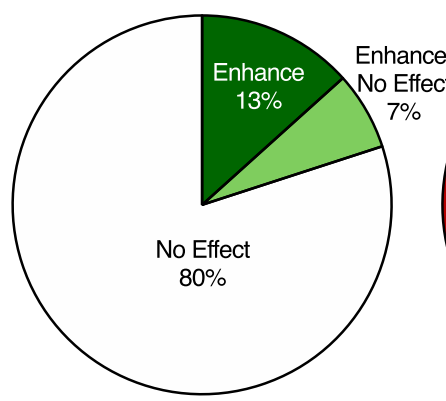

$<3 \mathrm{mg} / \mathrm{kg}$ MDMA
B

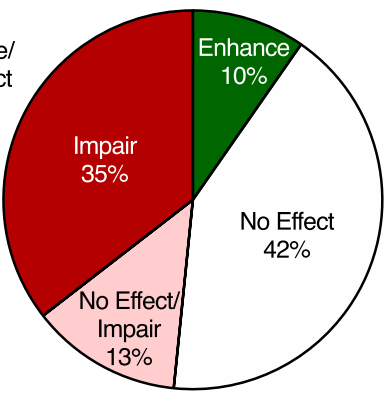

3-6 mg/kg MDMA

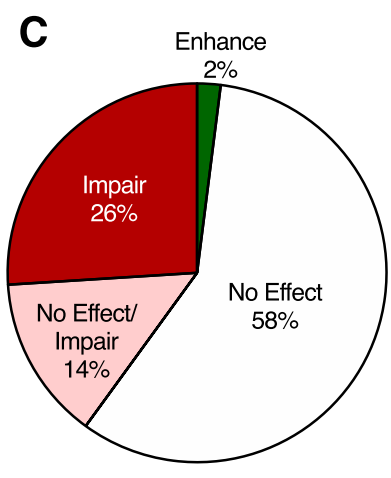

7.5-10 mg/kg MDMA

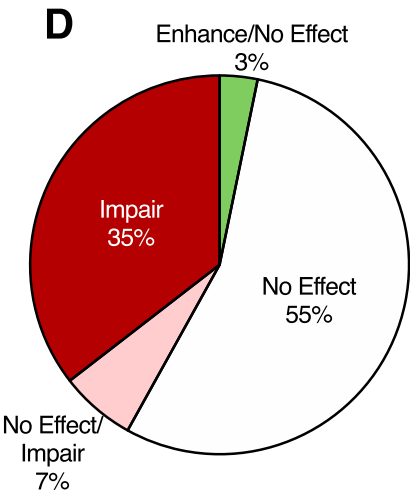

$15-30 \mathrm{mg} / \mathrm{kg}$ MDMA

The authors apologize for any inconvenience caused by this error. 